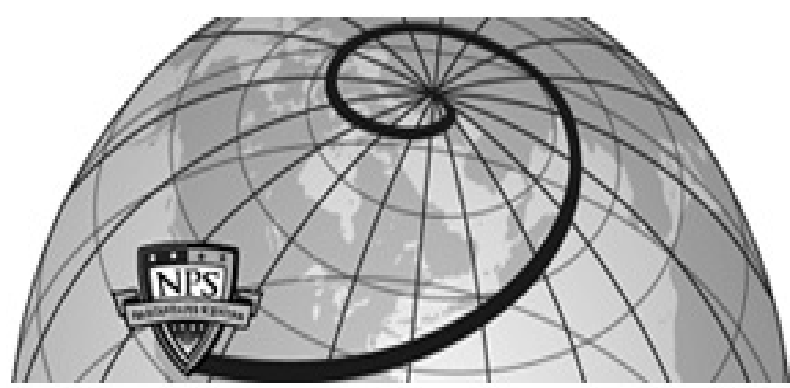

Calhoun: The NPS Institutional Archive DSpace Repository

\title{
Impact of quality of life on the reenlistment
} intentions of junior enlisted United States marines

Edwards, Douglas W.

Monterey, California. Naval Postgraduate School

https://hdl.handle.net/10945/6069

This publication is a work of the U.S. Government as defined in Title 17, United States Code, Section 101. Copyright protection is not available for this work in the United States.

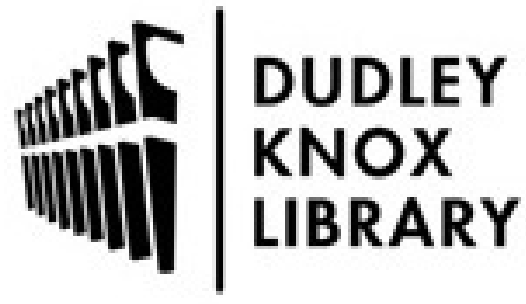

http://www.nps.edu/library
Calhoun is the Naval Postgraduate School's public access digital repository for research materials and institutional publications created by the NPS community. Calhoun is named for Professor of Mathematics Guy K. Calhoun, NPS's first appointed -- and published -- scholarly author.

Dudley Knox Library / Naval Postgraduate School 411 Dyer Road / 1 University Circle Monterey, California USA 93943 


\section{NAVAL POSTGRADUATE SCHOOL Monterey, California}

\section{THESIS}

IMPACT OF QUALITY OF LIFE ON THE
REENLISTMENT INTENTIONS OF JUNIOR ENLISTED
UNITED STATES MARINES
by
Douglas W. Edwards
March 2002
Thesis Co-Advisors:

Approved for public release; distribution is unlimited. 


\section{REPORT DOCUMENTATION PAGE}

Form Approved OMB No. 0704-0188

Public reporting burden for this collection of information is estimated to average 1 hour per response, including the time for reviewing instruction, searching existing data sources, gathering and maintaining the data needed, and completing and reviewing the collection of information. Send comments regarding this burden estimate or any other aspect of this collection of information, including suggestions for reducing this burden, to Washington headquarters Services, Directorate for Information Operations and Reports, 1215 Jefferson Davis Highway, Suite 1204, Arlington, VA 22202-4302, and to the Office of Management and Budget, Paperwork Reduction Project (0704-0188) Washington DC 20503.

\begin{tabular}{|c|c|c|c|}
\hline 1. AGENCY USE ONLY (Leave blank) & $\begin{array}{l}\text { 2. REPORT DATE } \\
\text { March } 2002\end{array}$ & \multicolumn{2}{|c|}{$\begin{array}{l}\text { 3. REPORT TYPE AND DATES COVERED } \\
\text { Master's Thesis }\end{array}$} \\
\hline \multicolumn{3}{|c|}{$\begin{array}{l}\text { 4. TITLE AND SUBTITLE: Impact of Quality of Life on the Reenlistment } \\
\text { Intentions of Junior Enlisted United States Marines }\end{array}$} & \multirow[t]{2}{*}{ 5. FUNDING NUMBERS } \\
\hline \multicolumn{3}{|l|}{ 6. AUTHOR(S) Douglas W. Edwards } & \\
\hline \multicolumn{3}{|c|}{$\begin{array}{l}\text { 7. PERFORMING ORGANIZATION NAME(S) AND ADDRESS(ES) } \\
\text { Naval Postgraduate School } \\
\text { Monterey, CA } 93943-5000\end{array}$} & $\begin{array}{l}\text { 8. PERFORMING } \\
\text { ORGANIZATION REPORT } \\
\text { NUMBER }\end{array}$ \\
\hline \multicolumn{3}{|c|}{$\begin{array}{l}\text { 9. SPONSORING / MONITORING AGENCY NAME(S) AND ADDRESS(ES) } \\
\text { N/A }\end{array}$} & $\begin{array}{l}\text { 10. SPONSORING / MONITORING } \\
\text { AGENCY REPORT NUMBER }\end{array}$ \\
\hline
\end{tabular}

11. SUPPLEMENTARY NOTES The views expressed in this thesis are those of the author and do not reflect the official policy or position of the Department of Defense or the U.S. Government.

\begin{tabular}{l|l} 
12a. DISTRIBUTION / AVAILABILITY STATEMENT & 12b. DISTRIBUTION CODE \\
Approved for public release; distribution is unlimited. &
\end{tabular}

\section{ABSTRACT (maximum 200 words)}

The purpose of this thesis was to investigate the impact of Quality of Life (QOL) programs and QOL domains on the reenlistment intentions of junior enlisted United States Marines. Data were extracted from the FY 2001 USMC Retention Survey. The data set was restricted to junior enlisted Marines in paygrades E2 through E4 with Active Duty Base Dates of calendar year 1998 and 1999 and was further stratified by gender. A complete conceptual model for reenlistment was developed which incorporated demographic characteristics, QOL programs, QOL domains, and civilian employment opportunities. Cross-tabulations of survey responses were performed by gender, race, marital status, and geographic location. Logit maximum likelihood estimation techniques were used to determine the marginal and percentage effects of QOL programs and QOL domains. The results confirm previous research in this area.

14. SUBJECT TERMS Retention and Quality of Life (QOL)

15. NUMBER OF

PAGES

155

16. PRICE CODE

17. SECURITY

CLASSIFICATION OF REPORT

18. SECURITY
CLASSIFICATION OF THIS
PAGE

Unclassified

Unclassified
19. SECURITY CLASSIFICATION OF ABSTRACT

Unclassified
20. LIMITATION

OF ABSTRACT

UL 
THIS PAGE INTENTIONALLY LEFT BLANK 
Approved for public release; distribution is unlimited

IMPACT OF QUALITY OF LIFE ON THE REENLISTMENT INTENTIONS OF JUNIOR ENLISTED UNITED STATES MARINES

\author{
Douglas W. Edwards \\ Major, United States Marine Corps \\ B.B.A., University of Georgia, 1984 \\ Submitted in partial fulfillment of the \\ requirements for the degree of \\ MASTER OF SCIENCE IN MANAGEMENT
}

from the

NAVAL POSTGRADUATE SCHOOL

March 2002

Author:

Douglas W. Edwards

Approved by:

Alice Crawford, Thesis Co-Advisor

Stephen Mehay, Thesis Co-Advisor

Douglas A. Brook, Ph.D.

Dean

Graduate School of Business and Public Policy 
THIS PAGE INTENTIONALLY LEFT BLANK 


\begin{abstract}
The purpose of this thesis was to investigate the impact of Quality of Life (QOL) programs and QOL domains on the reenlistment intentions of junior enlisted United States Marines. Data were extracted from the FY 2001 USMC Retention Survey. The data set was restricted to junior enlisted Marines in paygrades E2 through E4 with Active Duty Base Dates of calendar year 1998 and 1999 and was further stratified by gender. A complete conceptual model for reenlistment was developed which incorporated demographic characteristics, QOL programs, QOL domains, and civilian employment opportunities. Cross-tabulations of survey responses were performed by gender, race, marital status, and geographic location. Logit maximum likelihood estimation techniques were used to determine the marginal and percentage effects of QOL programs and QOL domains. The results confirm previous research in this area.
\end{abstract}


THIS PAGE INTENTIONALLY LEFT BLANK 
I. INTRODUCTION

A. BACKGROUND .

B. PURPOSE .. 4

C. METHODOLOGY .........................................................

D. ORGANIZATION OF STUDY .................................................

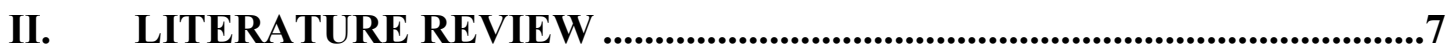

A. WHAT IS “QUALITY OF LIFE"?................................................7

1. USMC QOL Programs ................................................................9

2. QOL Related Domains ..............................................................11

a. Work Life …………………......................................11

b. $\quad$ The Marine Corps and the Family...............................13

c. Sense of Community .........................................................14

B. THE RETENTION DECISION _................................................16

III. MODEL DEVELOPMENT ….......................................................21

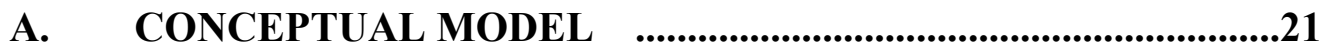

B. DATA SOURCE, RESTRICTIONS, AND SURVEY SCALE

RELIABILITY …………………………….......................21

1. Data Source ...........................................................21

2. $\quad$ Restrictions Imposed .................................................................24

3. Survey Scale Reliability .............................................................24

C. CANDIDATE EXPLANATORY VARIABLES .............................26

1. Categorical Variables .................................................................27

2. Continuous Variables ................................................................29

D. EXPLORATORY ANALYSIS OF PRELIMINARY

EXPLANATORY VARIABLES ..........................................................35

1. Retention Intentions ..........................................................37

2. QOL Programs ………....................................................40

a. MWR Program Availability ..........................................40

b. Availability of Day Care..................................................42

c. Availability of Family Support Services.......................44

d. Your Family's Medical Care ..........................................46

e. Family Dental Care ......................................................48

f. Voluntary Education ....................................................49

1. Quality of Education Benefits............................50

2. Availability of Education Benefits....................52

g. Military Housing ...................................................53

1. Quality of Military Housing ............................54

2. Availability of Military Housing ....................55

3. QOL Domains

a. Leadership ……….........................................57

1. Commitment to Subordinates..........................57

2. Trust in Marine Leadership............................60

b. USMC Career ………........................................61 
1. Job Security

2. Time Away From Home ...................................63

c. Current Military Job/Working Conditions .................66

1. Job Responsibility .............................................66

2. Workload Distribution ......................................67

d. Personal/Family Life ...................................................69

1. Family Influence on Career ............................69

2. Work/Personal Time Balance .........................71

e. USMC Culture .................................................73

1. Interaction Between Races................................74

2. Administration of Regulations.........................75

f. USMC Values ……………………….................76

1. What the Marine Corps Stands for for is important to me ..........................................77

2. I would be happy to spend the rest of my career in the Marine Corps ..................79

g. USMC Sense of Community.........................................80

1. I do not feel emotionally attached the Marine Corps ..................................................80

2. I do not feel a strong sense of belonging to the Marine Corps .......................82

h. Education/Training ....................................................84

1. I want more education/training so that $I$ can get out and get a job .......................85

2. More education opportunities would encourage me to reenlist ......................86

i. $\quad$ Satisfaction with USMC ...............................................87

1. Primary MOS Assignment.............................87

2. Your Family Life While in the Marine Corps ........................................................89

IV. MODEL SPECIFICATION AND RESULTS.............................................93

A. FINAL RETENTION MODEL …….........................................93

1. Dependent Variable: Junior Enlisted Males .........................93

2. Dependent Variable: Junior Enlisted Females......................94

B. MODEL SPECIFICATION …….........................................95

C. EXPLANATORY VARIABLE SELECTION ..................................96

1. Demographic ……….........................................97

a. Paygrade …………………………..............97

b. Race/Ethnic Group ….................................................97

c. Marital Status $\quad$......................................................97

d. Dependent Children .................................................98

2. QOL Programs ………………..............................98

a. QOL Programs …….........................................98

b. Military Housing ………………………….................99

c. Medical Benefits .....................................................99

d. Educational Benefits .....................................................99 
3. QOL Domains

a. Leadership $\quad$......................................................100

b. Marine Corps Career ...................................................100

c. Primary MOS Assignment............................................100

d. Current Duty Station .....................................................101

e. $\quad$ Working Conditions ....................................................101

f. Personal Life $\quad$...................................................101

g. Family Life $\quad$.....................................................102

h. USMC Culture …….....................................102

i. $\quad$ Sense of Community ...................................................102

4. Civilian Employment Opportunities .....................................102

E. RESULTS .................................................103

1. Junior Enlisted Male Data Set................................................104

2. Junior Enlisted Female Data Set ..........................................105

F. MARGINAL EFFECTS AND PERCENTAGE EFFECTS

OF RETENTION FACTORS ….............................................108

1. Interaction of NO BELONG and BLACK ..........................109

2. Interaction of MARRIED and Satisfaction with Education Benefits

3. Interaction of MARRIED and QOL Programs ..................113

4. Interaction of MARRIED and Family Service Center

5. Interaction of MARRIED and MWR ..................................114

6. Interaction of CHILDREN and DAYCARE ......................114

7. INFANTRY ...........................................114

V. SUMMARY, CONCLUSIONS, AND RECOMMENDATIONS .............117

A. SUMMARY ..............................................118

B. CONCLUSIONS

C. RECOMMENDATIONS ………..........................................122

1. Increase participation of Junior Enlisted

Marines and Family Members in the Marine

Corps Family Team Building and Single Marine Programs.

2. Continue to improve the Quality and Availability

of Military Housing for Junior Enlisted Marines

3. Use Probability Samples for future Surveys ......................123

4. Results of this thesis should be used by the 2002 USMC QOL Study Team

5. Use Conceptual Model with Actual Retention Data ..........124

APPENDIX A. FY 2001 USMC RETENTION SURVEY ............................125

APPENDIX B. PRELIMINARY VARIABLES IN DESCENDING ORDER 

APPENDIX C. BASIC RETENTION MODEL WITH
INTERACTIONS
....................................................141
LIST OF REFERENCES
....................................................149
INITIAL DISTRIBUTION LIST
155 


\section{LIST OF TABLES}

Table 2.1 Summary of Work Life Research .......................................................12

Table 2.2 Community Factors with USMC Related Example................................15

Table 2.3 Reasons to Stay in the USMC, Males .................................................18

Table 2.4 Reasons to Stay in the USMC, Females ..............................................18

Table 2.5 Reasons to Leave the USMC, Males ...............................................18

Table 2.6 Reasons to Leave the USMC, Females..............................................19

Table 3.1 Comparison of FY 2001 USMC Retention Survey and USMC

Demographic Characteristics (By Percentage) .....................................22

Table 3.2 Coefficient Alpha Reliability Estimates for FY 2001 USMC

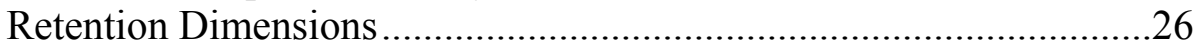

Table 3.3 Frequency Distributions of Categorical Variables, Junior Enlisted Males27

Table 3.4 Frequency Distribution of Categorical Variables, Junior

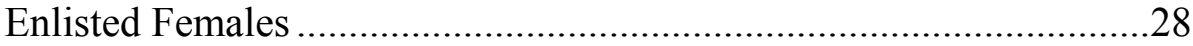

Table 3.5 Variable Means in Descending Order, Likert Scale 1-7, Males ........................................................................30

Table 3.6 Variable Means in Descending Order, Likert Scale 1-7, Females ...................................................................32

Table 3.7 Variable Means in Descending Order, Likert Scale 1-5,Males ............33

Table 3.8 Variable Means in Descending Order, Likert Scale 1-5, Females........34

Table 3.9 Variable Means in Descending Order, Likert Scale 1-5, Males ............34

Table 3.10 Variable Means in Descending Order, Likert Scale 1-5,Females.........35

Table 3.11 Reenlistment Intentions by Gender......................................................37

Table 3.12 Reenlistment Intentions Cross-Tabulation Percentage, Race ................38

Table 3.13 Reenlistment Intentions Cross-Tabulation Percentage, Marital Status

Table 3.14 Reenlistment Intentions Cross-Tabulation Percentage, Geographic

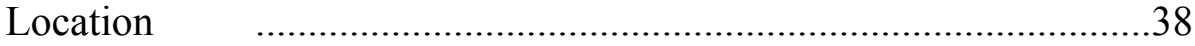

Table 3.15 FY 1999 DoD Active Duty Survey of Members Likelihood of Choosing to Stay on Active Duty .........................................................39

Table 3.16 MWR Program Availability: Gender...............................................41

Table 3.17 MWR Program Availability: Race.....................................................41

Table 3.18 MWR Program Availability: Marital Status ..........................................41

Table 3.19 MWR Program Availability: Geographic Location..............................42

Table 3.20 Availability of Day Care: Gender ......................................................43

Table 3.21 Availability of Day Care: Race.......................................................43

Table 3.22 Availability of Day Care: Marital Status ..............................................43

Table 3.23 Availability of Day Care: Geographic Location.....................................44

Table 3.24 Availability of Family Support Services: Gender..................................45

Table 3.25 Availability of Family Support Services: Race …………………….....45

Table 3.26 Availability of Family Support Services: Marital Status .......................45

Table 3.27 Availability of Family Support Services:

Geographic Location 
Table 3.28

Table 3.29

Table 3.30

Table 3.31

Table 3.32

Table 3.33

Table 3.34

Table 3.35

Table 3.36

Table 3.37

Table 3.38

Table 3.39

Table 3.40

Table 3.41

Table 3.42

Table 3.43

Table 3.44

Table 3.45

Table 3.46

Table 3.47

Table 3.48

Table 3.49

Table 3.50

Table 3.51

Table 3.52

Table 3.53

Table 3.54

Table 3.55

Table 3.56

Table 3.57

Table 3.58

Table 3.59

Table 3.60

Table 3.61

Table 3.62

Table 3.63

Table 3.64

Table 3.65

Table 3.66

Table 3.67

Table 3.68

Table 3.69

Table 3.70

Table 3.71

Table 3.72

Table 3.73

Family Medical Care: Gender

Family Medical Care: Race .........................................................47

Family Medical Care: Marital Status ................................................47

Family Medical Care: Geographic Location......................................48

Family Dental Care: Gender ........................................................48

Family Dental Care: Race ..............................................................49

Family Dental Care: Marital Status ..............................................49

Family Dental Care: Geographic Location ........................................44

Quality of Education Benefits: Gender.............................................50

Quality of Education Benefits: Race...............................................51

Quality of Education Benefits: Marital Status ..................................51

Quality of Education Benefits: Geographic Location........................51

Availability of Education Benefits: Gender......................................52

Availability of Education Benefits: Race .......................................53

Availability of Education Benefits: Marital Status ............................53

Availability of Education Benefits: Geographic Location..................53

Availability of Military Housing: Gender.........................................54

Availability of Military Housing: Race ..........................................54

Availability of Military Housing: Marital Status................................55

Availability of Military Housing: Geographic Location .....................55

Quality of Military Housing: Gender...............................................56

Quality of Military Housing: Race ...................................................56

Quality of Military Housing: Marital Status ......................................57

Quality of Military Housing: Geographic Location............................57

Commitment to Subordinates: Gender.............................................58

Commitment to Subordinates: Race ..............................................59

Commitment to Subordinates: Marital Status....................................59

Commitment to Subordinates: Geographic Location .........................59

Trust in Leadership: Gender ......................................................60

Trust in Leadership: Race .........................................................61

Trust in Leadership: Marital Status...............................................61

Trust in Leadership: Geographic Location ....................................61

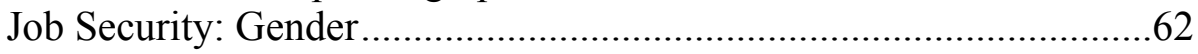

Job Security: Race..............................................................63

Job Security: Marital Status ......................................................63

Job Security: Geographic Location...............................................63

Time Away from Home: Gender ....................................................64

Time Away from Home: Race ........................................................65

Time Away from Home: Marital Status .........................................65

Time Away from Home: Geographic Location .................................65

Job Responsibility: Gender ......................................................66

Job Responsibility: Race.........................................................66

Job Responsibility: Marital Status ..............................................67

Job Responsibility: Geographic Location .......................................67

Workload Distribution: Gender ...............................................68

Workload Distribution: Race ......................................................68 
Table 3.74 Workload Distribution: Marital Status...................................................69

Table 3.75 Workload Distribution: Geographic Location ......................................69

Table 3.76 Family Influence on Career: Gender................................................70

Table 3.77 Family Influence on Career: Race …………………………................70

Table 3.78 Family Influence on Career: Marital Status...........................................71

Table 3.79 Family Influence on Career: Geographic Location ..............................71

Table 3.80 Work/Personal Time Balance: Gender ..............................................72

Table $3.81 \quad$ Work/Personal Time Balance: Race ................................................72

Table 3.82 Work/Personal Time Balance: Marital Status.......................................73

Table 3.83 Work/Personal Time Balance: Geographic Location ............................73

Table 3.84 Interaction between Races: Gender …………....................................74

Table 3.85 Interaction between Races: Race .....................................................74

Table 3.86 Interaction between Races: Marital Status..........................................74

Table 3.87 Interaction between Races: Geographic Location ................................75

Table 3.88 Administration of Regulations: Gender ..............................................75

Table 3.89 Administration of Regulations: Race..................................................76

Table 3.90 Administration of Regulations: Marital Status …………………….......76

Table 3.91 Administration of Regulations: Geographic Location..........................76

Table 3.92 What the Marine Corps Stands for is Important to me:

Gender

Table 3.93 What the Marine Corps Stands for is Important to me:

Race

Table 3.94 What the Marine Corps Stands for is Important to me:

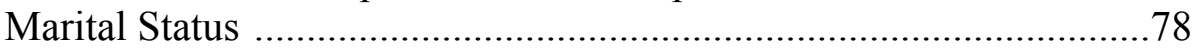

Table 3.95 What the Marine Corps Stands for is Important to me:

Geographic Location......................................................................78

Table 3.96 I would be happy to Spend the Rest of my career in the

Marine Corps: Gender........................................................................

Table 3.97 I would be happy to Spend the Rest of my career in the

Marine Corps: Race .........................................................................

Table 3.98 I would be happy to Spend the Rest of my career in the

Marine Corps: Marital Status................................................................ 80

Table 3.99 I would be happy to Spend the Rest of my career in the

Marine Corps: Geographic Location ...................................................8

Table 3.100 I do not feel emotionally attached to the Marine Corps:

Gender

Table 3.101 I do not feel emotionally attached to the Marine Corps:

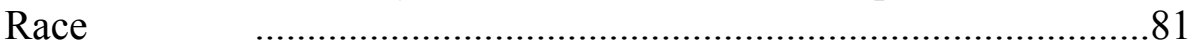

Table 3.102 I do not feel emotionally attached to the Marine Corps:

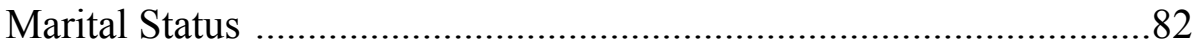

Table 3.103 I do not feel emotionally attached to the Marine Corps:

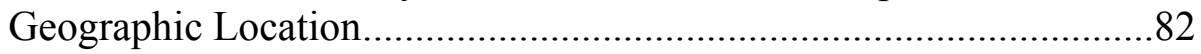

Table 3.104 I do not feel a strong sense of belonging to the Marine

Corps: Gender.

Table 3.105 I do not feel a strong sense of belonging to the Marine

Corps: Race 
Table 3.106 I do not feel a strong sense of belonging to the Marine

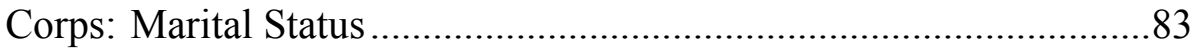

Table 3.107 I do not feel a strong sense of belonging to the Marine

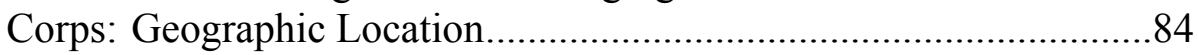

Table 3.108 I want more education/training so that I can get out and

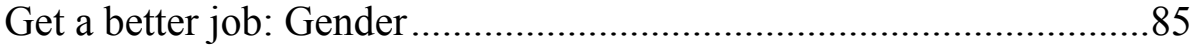

Table 3.109 I want more education/training so that I can get out and

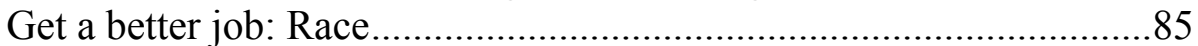

Table 3.110 I want more education/training so that I can get out and

Get a better job: Marital Status ............................................................... 85

Table 3.111 I want more education/training so that I can get out and

Get a better job: Geographic Location.................................................86

Table 3.112 More education opportunities would encourage me to reenlist

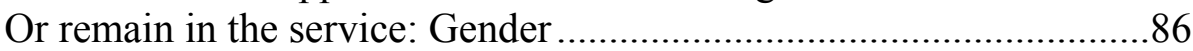

Table 3.113 More education opportunities would encourage me to reenlist

Or remain in the service: Race............................................................. 86

Table 3.114 More education opportunities would encourage me to reenlist

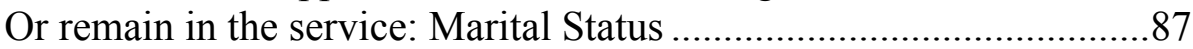

Table 3.115 More education opportunities would encourage me to reenlist

Or remain in the service: Geographic Location....................................87

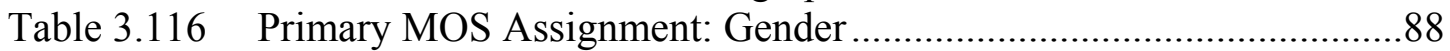

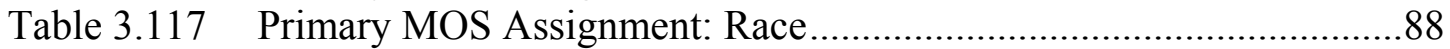

Table 3.118 Primary MOS Assignment: Marital Status ………………………........8

Table 3.119 Primary MOS Assignment: Geographic Location................................89

Table 3.120 Family Life While in the Marine Corps: Gender..................................90

Table 3.121 Family Life While in the Marine Corps: Race.....................................90

Table 3.122 Family Life While in the Marine Corps: Marital Status ........................90

Table 3.123 Family Life While in the Marine Corps:

Geographic Location.......................................................................91

Table 4.1 Final Explanatory Variables ...........................................................93

Table 4.2 Explanatory Variables and Expected Signs .......................................103

Table 4.3 Reenlistment Intention Logit Model, Male......................................104

Table 4.4 Reenlistment Intention Logit Model, Female ……………………......105

Table 4.5 Marginal Effects and Percentage Effects of Statistically

Significant Variables;Male Reenlistment Intentions ..........................106

Table 4.6 Marginal Effects and Percentage Effects of Statistically

Significant Variables; Female Reenlistment Intentions......................107

Table 4.7 Additional Logit Model Specifications...............................................108

Table 4.8 Reenlistment Intention Logit Model, NO_BELBLACK .....................110

Table 4.9 Reenlistment Intention Logit Model with NO_BELBLACK

Marginal \& Percentage Effects for Statistically Significant

Variables,Female

Table 4.10 Reenlistment Intention Logit Model with MARRIEDED, Male

Table 4.11 Reenlistment Intention Logit Model with Marginal Effects

And Percentage Effects MARRIEDED, Male. 
Table B.1. Mean Distribution of Continuous Variables, Junior Enlisted Males ............................................................................. 135

Table B.2. Mean Distribution of Continuous Variables,

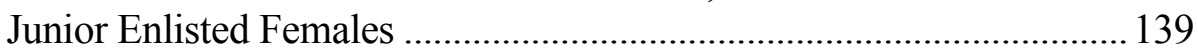

Table C.1. Basic Retention Model with NO_BELBLACK, Male ........................... 143

Table C.2. Basic Retention Model with MARRIED*SATISFACTION WITH EDUCATION, Female ......................................................................... 143

Table C.3. Basic Retention Model with MARRIED*QOL_PRGM, Male 144

Table C.4. Basic Retention Model with MARRIED*QOL_PRGM, Female 145

Table C.5. Basic Retention Model with MARRIED*FAMSVC, Male................... 145

Table C.6. Basic Retention Model with MARRIED*FAMSVC, Female................ 146

Table C.7. Basic Retention Model with MARRIED*MWR, Male .......................... 147

Table C.8. Basic Retention Model with MARRIED*MWR, Female....................... 147

Table C.9 Basic Retention Model with CHILDREN*DAYCARE, Male

Table C.10 Basic Retention Model with CHILDREN*DAYCARE, Female

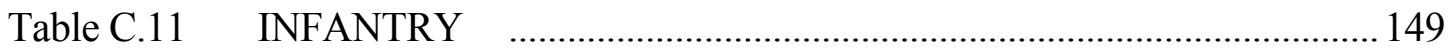


THIS PAGE INTENTIONALLY LEFT BLANK 


\section{ACKNOWLEDGEMENTS}

I would like to thank my beautiful wife, Cindy, for her love and support. Thanks also go to our boys, Matt and David, for their persistent daily encouragement to leave the computer for awhile to throw the baseball and enjoy the magnificent Monterey Peninsula. Thanks to Dr. Michael White of NPRST for providing the survey data used in this thesis. I am grateful for the support of my co-advisors, Professors Alice Crawford and Steve Mehay. Finally, thank God-from Whom all Blessings flow! 


\section{INTRODUCTION}

\section{A. BACKGROUND}

The Marine Corps has consistently placed great attention on recruiting and retaining high quality enlisted Marines. "Quality of Life" (QOL) programs, such as post exchanges, military housing, libraries, voluntary education programs, physical fitness facilities, and family readiness (e.g., Marine Corps Family Team Building) exist primarily because of their perceived value in improving recruiting, retention, readiness, and performance efforts. In addition to QOL programs, there are numerous QOL-related domains, such as work, family, and community that also impact upon retention.

At all levels of government and within DoD, QOL issues have been a 'top priority'. President George W. Bush has made "improving the quality of life for our Service men and women a top priority of his Administration, as has the Secretary of Defense." (DoD Morale and QOL Study, 2001) According to Congressman Dave Hobson, Chairman of the House Military Construction (MILCON) Appropriations Subcommittee, " a soldier, sailor, airman, or Marine will not maintain a high level of morale if working conditions are antiquated and in poor repair. Likewise, a military family who must live in housing that was poorly built, is poorly maintained, and does not meet their needs will undoubtedly factor that in when the time comes for the service member to consider reenlistment." (Hobson, 2001)

Kerce (1999) finds that perceptions of QOL have a causal relationship to recruiting, retention, and readiness. Additionally, Kerce (1998) cites the following assumptions that reflect the rationale underlying QOL programs:

- Organizations that demonstrate concern for their members encourage commitment to the organization.

- Positive perceptions of quality of life are associated with increased readiness and retention.

- Spouse and family satisfaction with military life is a factor in retention.

- Educational achievements of individuals improve performance and maintain required expertise in the Marine Corps.

- Support services facilitate concentration on military duties. 
Accordingly, the Marine Corps annually allocates millions of dollars to support QOL programs and related QOL domains.

Until recently, the Marine Corps has been unable to measure the impact that specific QOL programs have upon desired military outcomes such as recruiting, readiness, and retention. Kerce (1999) conducted a pilot test of an integrated system for assessing the impact of Marine Corps QOL programs. This groundbreaking research provides bivariate (descriptive) data from surveys of actual program participants, and provides a baseline from which to gauge the relative value of specific QOL programs to program users.

Survey instruments used by the military, such as the FY 2001 USMC Retention Survey, focus upon "satisfaction" with various domains, like personal/family life and working conditions. Recent QOL research supports the notion that QOL is a 'composite' of numerous domains (Baker and White, 1998) instead of a single, unitary construct. For this research, QOL is considered to be a composite of multiple domains. This thesis uses data from the FY 2001 USMC Retention Survey to explore the impact that QOL programs and QOL-related domains, such as work, family, and community have upon the reenlistment intentions of junior enlisted Marines.

The retention of junior enlisted Marines is essential for the Marine Corps to meet its career force manpower requirements. Junior enlisted Marines, grade E-2 through E-4, represent approximately 55 percent of USMC manpower (Bicknell, 2001). Most members of this group are still within the initial (first term) enlistment period, and will be making (or have made) the 'dichotomous' (stay or leave) reenlistment decision.

The role of commanding officers and senior leaders in recruiting junior enlisted Marines into the career force is likely to grow in importance. The First Term Alignment Plan (FTAP) was initiated FY 1998 to provide first term reenlistment goals (quotas) to operating and supporting force commanders. Thus, the retention of quality junior enlisted Marines is a mission assigned to all commanders and career Marines.

The role of Marine leaders within the officer and staff non-commissioned officer (SNCO) ranks is also an important QOL factor. The perceived quality of leadership is likely to influence QOL and the reenlistment decision of junior Marines. Commanders and subordinate leaders are also responsible for finding the proper balance between the 
often competing requirements of combat-related training and time to maintain family/personal relationships, leisure, and similar non-work pursuits. The ability of Marine leaders to reconcile these competing demands effectively is likely to be a key input to the Marine when making the decision to reenlist.

Changing demographic conditions may also have an impact upon QOL and the reenlistment decision. As of FY 2001 (Marines Magazine, 2001), enlisted Marine family members $(133,314)$ nearly outnumbered active duty enlisted Marines $(155,383)$. Without careful coordination, the competing interests of the military and the family as 'Greedy Institutions' (Segal, 1988) can create friction between the Marine and the Marine Corps, decreasing the probability of retaining an otherwise qualified Marine.

The Marine Corps Family Team Building (MCTFB) program was created to provide resources to the Marine and family members to enhance family readiness by reducing the amount of friction created by this relationship. Every Marine Commanding Officer at the battalion/squadron level and above is required to organize a Key Volunteer organization to coordinate organizational family readiness activities within the command. Additionally, an officer or SNCO is assigned additional duties as the Family Readiness Officer to coordinate and assist the unit's Key Volunteer organization and serve as the unit point of contact for routine family readiness matters.

The Marine Corps, like all of the services, would like to provide consistency and equity of QOL programs. According to Phillip Short, Director, USMC Personal and Readiness Division in 1999, "my goal is that a Marine on Okinawa who goes to Cherry Point has the same quality of services. We have one Marine Corps, one standard." (Fuentes, 1999) Thus, one focus of this thesis will be to explore the FY 2001 USMC Retention Survey data to determine if there are perceived differences in QOL between Marines stationed in the continental United States (CONUS) and outside the continental United States (OCONUS).

Finally, insight into the QOL programs and the QOL-related domains that impact upon the reenlistment decision of junior enlisted Marines will provide additional 'firepower' as we fight to retain these future leaders. Understanding which QOL programs and related domains are important to junior enlisted Marines and the effect these areas have on the reenlistment decision will enable Marine leaders to target 
resources on the programs and domains that promise the greatest return on investment in terms of increased retention.

\section{B. PURPOSE}

Recently, the Marine Corps homepage ( question: "How Can We leverage our substantial investment in "Quality of Life" programs--housing, fitness, family programs, and the like to support Marine Corps retention?" One objective of this thesis is to explore possible answers to the question.

This research also evaluates the impact United States Marine Corps QOL programs and related QOL domains have on the retention decision of Marine Corps junior enlisted Marines. The objective is to determine the importance of QOL programs and related QOL domains (work conditions, job satisfaction) to junior enlisted Marines (paygrade E-2 through E-4) and the impact these variables have upon reenlistment intentions.

Research questions addressed in this thesis are:

1. What impact do specific QOL programs and QOL domains have on the reenlistment intentions of junior Marines?

2. What QOL programs and QOL-related domains (e.g., work conditions, job satisfaction) are important to junior enlisted Marines?

3. Are there differences in QOL programs and related QOL domains between different geographic locations?

\section{METHODOLOGY}

A review of literature dealing with QOL, USMC QOL programs, QOL-related domains, and retention is conducted to offer insight into how QOL programs and domains may affect the reenlistment intentions of junior enlisted Marines. A conceptual model for reenlistment intentions of junior enlisted Marines is developed. The data set from the 2001 USMC Retention Survey is used to further explore the issues. A multivariate analysis of 7,570 observations from the survey is conducted to gain insight into the impact that QOL-related variables have upon the reenlistment intentions of male and female junior Marines. 


\section{ORGANIZATION OF STUDY}

Chapter II provides a comprehensive review of QOL and retention literature. Chapter III consists of a conceptual model that identifies QOL programs and related domains that are hypothesized to contribute to the reenlistment intentions of junior enlisted Marines. Additionally, Chapter III provides descriptive statistical information about the sample observations used in this analysis. Chapter IV builds upon the basic information provided in the previous chapters by specifying a regression model for the conceptual model discussed in Chapter III. Explanatory variables and regression model results are provided in detail in Chapter IV. Conclusions and recommendations for future research are provided in Chapter V. 
THIS PAGE INTENTIONALLY LEFT BLANK. 


\section{LITERATURE REVIEW}

\section{A. WHAT IS "QUALITY OF LIFE"?}

Defining "quality of life" is difficult for most people. Quality of Life (QOL) definitions range from "coming home alive" (Fuentes, 1999) ${ }^{1}$ to more academically recognized versions that link the roots of QOL with the utilitarian doctrine of "happiness." Most Americans recognize that the "pursuit of happiness" is one of the fundamental rights of a democratic society. While the definition of "happiness" has changed from Thomas Jefferson's day to present, the fact remains that happiness and its pursuit are important tenets of American society. Campbell (1984) suggested that political economists have viewed happiness as a "measurable quantity" and that governments could be judged in terms of their success in creating public happiness.

According to Kerce (1998), satisfaction and happiness appear to be very similar, but there are underlying differences. Cheng (1988) states that, conceptually, "happiness is an appraisal of emotional experience, whereas satisfaction involves the comparison of objective conditions to some internal standards." Thus, it is possible to be "happy" and not satisfied and vice versa. Moreover, researchers have found that satisfaction and happiness measures change over time (Kerce, 1992). According to Kerce (1992), researchers have generally rejected the hypothesis that satisfaction and happiness ratings are equivalent measures of the same variable.

Rice (1984) defined QOL as being "the degree to which the experience of an individual's life satisfies that individual's wants and needs (both physical and psychological)." This broad definition was adopted by military QOL researcher Elyse Kerce (1992) and used throughout her groundbreaking USN and USMC QOL research during the 1990s.

Kerce (1992) found that a "common finding in quality of life research has been that people in disadvantaged circumstances frequently report higher than average levels of satisfaction." Thus, objective measures of QOL like per capita income or similar measures of affluence are not reliable indicators of QOL. Subjective measures of QOL, like self-reported 'satisfaction' with life domains, are likely to differ between people in

\footnotetext{
${ }^{1}$ The quote is attributed to Sgt Major of the Marine Corps Lewis G. Lee, who told a 1996 conference of the Defense Advisory Committee on Women in the Services (DACOWITS) that "Quality of Life is coming home alive." He didn't get invited back to the conference the following year.
} 
the same circumstances. Further, Kerce (1992) found evidence that "prior experience is also a factor in cognitive judgments of well-being; people who are more aware of possibilities tend to factor in cognitive judgments of well-being; people who are more aware of possibilities tend to show greater dissatisfaction when current circumstances are poor." Kerce (1992) concludes by stating "this may explain why people trapped in bleak situations seem able to find satisfaction, and why there is not more congruence between OQL (objective quality of life) and SQL (subjective quality of life) measures." An obvious military application of this hypothesis is the natural 'QOL transition' that occurs when Marines are deployed. In this scenario, it is likely that an individual's overall QOL will initially decline as the Marine adapts to the rigors of deployed life and absence of friends and family, privacy, climate-controlled living and work spaces, recreational opportunities, and the like. However, as time passes and the Marine becomes used to his or her circumstances, QOL is likely to rise.

Historically, the Marine Corps has taken a conservative view of QOL requirements and investment in QOL-related activities. The Marine Corps' approach to QOL was perhaps best exemplified during the early 1990s as it separated itself from the other services over the issue of changing enlisted barracks room configurations to provide more space and privacy to junior enlisted personnel at the possible expense of unit cohesion and degradation of competing military construction (MILCON) projects. Most Marine leaders were strongly against changing the favored open squad bay-type barracks into a dormitory-style configuration similar to what is found in most colleges in the U.S. This change is representative of the ongoing "pursuit" (and Congressional intent) of increasing QOL of our junior Marines, albeit at the expense of other programs some leaders believe may have a more direct relationship to increasing readiness.

As discussed earlier, the foundation of the concept of QOL is well-grounded in American culture and its supporting political and social systems. The current (year 2001) junior enlisted Marine generation cohort, known as the 'millennials', expects that employers will "have an appreciation for employee's QOL." (Birnbaum, Ezring, Howell, Shultz, Sutton, 2000, 18) Thus, accepting the fact that the Marine Corps is an extension of American society, the Marine Corps should expect that demand for QOL programs and the importance of QOL domains will increase. Therefore, it is important to determine the 
QOL programs and related domains that have the best return on investment in terms of increasing recruiting, retention, and readiness.

Koopman and Goldhaber (1997) conducted a cost-benefit analysis of Navy QOL programs and the impact these programs have upon the reenlistment decision. The methodology employed in this study compared the costs of QOL programs with programs that have a similar impact on retention, such as increasing pay and allowances. Additionally, the researchers used survey measures of satisfaction with QOL programs and actual continuation (retention) data to conduct multivariate analyses of overall satisfaction with QOL programs and retention. Koopman and Goldhaber (1997) compared the retention rate predicted by a previously studied program, the "Future Force Formulation Study", which found that $\$ 687$ million invested in a more "aged" force would increase retention by 3 percentage points. Since Koopman and Goldhaber (1997) found that Morale, Welfare, and Recreation (MWR) programs increase retention by 6.7 percentage points and Family Service Center (FSC) programs by 3.2 percentage points, they scaled up the continuation beneftis with the following result:

\begin{tabular}{lcc}
$\begin{array}{c}\text { QOL } \\
\text { Program }\end{array}$ & $\begin{array}{c}\text { Value of continuation } \\
\text { rate benefit }\end{array}$ & $\begin{array}{c}\text { Program } \\
\text { Cost }\end{array}$ \\
\hline MWR & $\begin{array}{l}\text { \$1,534 million } \\
\text { FSC }\end{array}$ & $\$ 241$ million \\
$\$ 733$ million & $\$ 39$ million
\end{tabular}

Source: Koopman and Goldhaber (1997)

Thus, Koopman and Goldhaber (1997) concluded that Family Service Centers (FSC) and Morale, Welfare, and Recreation (MWR) programs have positive net economic benefits.

\section{USMC QOL Programs}

In 1993, the Marine Corps undertook a comprehensive assessment of members' satisfaction with their quality of life, and confirmed the effect of QOL perceptions on readiness and retention (Kerce, 1999). Based on the results of this study, the Marine Corps formalized QOL planning and execution, creating a QOL Working Group to serve as "process owner" for all QOL Programs. Additionally, a QOL Master Plan was completed in 1996. In March, 1998, a pilot test was conducted at four Marine Corps installations (Kerce, 1998). Data were collected from the following 19 QOL programs via one page program-specific questionnaires:

- Child Care Program 
- Counseling Program (non-Family Advocacy Program-FAP)

- Deployment Support Program

- Exceptional Family Member Program

- Family Advocacy Program (FAP)

- Family Member Employment Assistance Program

- Financial Management Program

- Food and Hospitality Program

- Library Program

- Marriage Enrichment Program

- Physical Fitness Program

- Recreation Programs I (Bowling Centers and Golf Course)

- Recreation Programs II (Recreation Centers and Marine Lounges)

- Recreation Programs III (Auto Hobby Shops, IT\&T, Outdoor Recreation)

- Relocation Assistance Program

- Retail Operations

- Substance Abuse Program

- Voluntary Education Program

- Youth and Teen Program

The objective of the pilot test was to address the problem of linking individual programs to quality of life and military outcomes with minimal expense, providing a system that will be sustainable over time and yielding valid data that are easily accessible to decision makers at various levels of responsibility. (Kerce, 1999)

According to Kerce (1999), the questionnaire items were designed to assess a "program's ultimate impact on quality of life and family satisfaction with military life, as well as its success in reducing stress and tensions between military and family roles."

Additionally, respondents' perceptions of QOL programs as a "demonstration of Marine Corps concern" for members and family members were also measured. A total of 6,964 questionnaires were completed by active-duty Marines and spouses of active-duty Marines. According to Kerce (1999), programs that rate highest on multiple measures of impact included Youth and Teen Programs, USMC libraries, Temporary Lodging Facilities, 
Child Care, and Physical Fitness. Deployment Support Programs consistently received the lowest ratings. Additionally, the pilot test found inconsistencies with the objective program process data (programs were measuring internal processes vice external results). The test results provided the following findings:

- The program assessment system used in the pilot study can be used to link specific programs to QOL.

- Data obtained in this manner (via one-page questionnaire) will be adequate in both quantity and quality.

The pilot test also highlighted that data for objective QOL variables are needed to further explore the link between QOL programs and desired military outcomes (increased recruiting, retention, readiness).

\section{QOL Related Domains}

Rice (1984) found that the "degree to which individual wants and needs are satisfied within a particular domain of life is the quality of life for that domain; thus, we speak of quality of work life or quality of family life." Further, Baker and White (1998) found that QOL is a 'composite' of numerous domains instead of a single, unitary construct. Thus, in order to gain insight into the impact that QOL has upon the reenlistment intentions of junior enlisted Marines, it is necessary to explore the literature that pertains to related QOL dimensions.

\section{a. Work Life}

The Navy and Marine Corps periodically survey personnel to determine the quality of work life. According to a recent CNA study (Parcell and Moore, 2001), questions asked include topics such as leadership, work environment, job progression, and job satisfaction.

The work life dimension has been widely studied in both civilian and military turnover research. The following table provided by Kerr (1997) summarizes civilian and military turnover research with job satisfaction, work environment, and related variables: 
Table 2.1 Summary of Work Life Research (From Kerr, 1997)

\begin{tabular}{|c|c|c|}
\hline $\begin{array}{l}\text { Author } \\
\text { (Date) }\end{array}$ & $\begin{array}{c}\text { Categories of Explanatory } \\
\text { Variables }\end{array}$ & Significant Variables \\
\hline \multicolumn{3}{|l|}{ Civilian Studies } \\
\hline $\begin{array}{l}\text { Mobeley, Horner, } \\
\text { Hollingsworth (1978) }\end{array}$ & $\begin{array}{l}\text { General job satisfaction, } \\
\text { thoughts about quitting, } \\
\text { intention to quit, probability of } \\
\text { alternative employment, } \\
\text { biographical information }\end{array}$ & Intention to quit \\
\hline Steers and Mowday (1981) & Affective & $\begin{array}{c}\text { Job satisfaction, life outside } \\
\text { work, organizational } \\
\text { commitment, spousal } \\
\text { concerns, family influence }\end{array}$ \\
\hline Porter and Steers (1973) & $\begin{array}{c}\text { Organizational, work } \\
\text { environment, job-related, } \\
\text { personal }\end{array}$ & Met expectations \\
\hline Hulin (1968) & $\begin{array}{l}\text { Satisfaction with; pay, work, } \\
\text { supervision, promotions, and } \\
\text { co-workers }\end{array}$ & Job satisfaction \\
\hline Cotton and Tuttle (1986) & $\begin{array}{c}\text { External, work-related, } \\
\text { personal }\end{array}$ & $\begin{array}{l}\text { Pay, job satisfaction, age, } \\
\text { tenure, gender, education, } \\
\text { number of dependents, met } \\
\text { expectations, biographical }\end{array}$ \\
\hline \multicolumn{3}{|l|}{ Military Studies } \\
\hline Buddin (1984) & $\begin{array}{c}\text { Demographic, prior } \\
\text { experience, job match and } \\
\text { satisfaction, military } \\
\text { alternatives, socioeconomic }\end{array}$ & $\begin{array}{l}\text { age, education, work history, } \\
\text { experience }\end{array}$ \\
\hline Kocher and Thomas (1994) & $\begin{array}{l}\text { External market, work-related } \\
\text { personal/demographic }\end{array}$ & $\begin{array}{l}\text { Satisfaction: work and military } \\
\text { life, satisfaction: } \\
\text { location/assignment stability, } \\
\text { race, family status }\end{array}$ \\
\hline Evans (1995) & Downsizing & $\begin{array}{l}\text { Leader behavior, information, } \\
\text { commitment, stress \& family, } \\
\text { satisfaction, performance and } \\
\text { readiness, retention }\end{array}$ \\
\hline Hempel and Parshall (1989) & $\begin{array}{l}\text { Demographic, satisfaction, } \\
\text { intentions to quit }\end{array}$ & Intentions, spousal influence \\
\hline Finn (1988) & Opinion, demographic & $\begin{array}{l}\text { Time-in-service, rank, marital } \\
\text { status, education, race, job } \\
\text { satisfaction, probability of } \\
\text { finding a good civilian job }\end{array}$ \\
\hline Lempe (1989) & $\begin{array}{l}\text { Demographic, tenure, } \\
\text { economic, cognitive }\end{array}$ & $\begin{array}{c}\text { Sex, race, age, time from } \\
\text { separation, satisfaction }\end{array}$ \\
\hline
\end{tabular}

Source: From Kerr, 1997 
Accordingly, the majority of DoD surveys focus heavily upon these QOLrelated domains. It is from this body of information that the variables used to analyze the FY 2001 USMC Retention Survey will be developed in Chapter III of this thesis.

\section{b. The Marine Corps and the Family}

There has always been a dichotomy between military and family life. Military life will never be fully compatible with the demands of the family due to the periodic requirement for geographical separation of the active duty member from his or her family. According to Segal (1988), the military and family as 'greedy institutions' make great demands in terms of "commitments, loyalty, time, and energy."

Bowen (1989) states that a "dramatic change occurred in American society since the mid-1950s: a substantial growth in the labor force participation of married women, especially among mothers of pre-school children; the emergence of dual-career couples, for whom the careers of both the husband and wife are important, a decline in the share of households headed by married couples and an increase in the number of families headed by a single man or woman; a convergence on new, more egalitarian gender-role preferences among men and women; and the emergence of the 'new breed' worker, who is particularly likely to question the cost of success in the workplace, especially when success compromises opportunities for a quality family life." (Bowen, 1989)

In 1992, Commandant of the Marine Corps, General Carl Mundy (Lubold, 2001), received the wrath of the Clinton administration when he proposed that the Marine Corps bar married people from enlisting and suggested that first-term enlisted Marines should get approval from their commanding officer prior to tying the knot. General Mundy defended his proposal based upon the high divorce rate among young Marines and the cost of supporting family members (Lubold 2001). General Mundy's opinion (despite its lack of support from politicians) represented the 'corporate knowledge' of the Marine Corps regarding junior enlisted Marines and their families at that time, and provides a baseline from which to measure future changes in policy and attitudes toward the Marine and his/her family members.

Over seven years, the relationship of the Marine Corps and family members changed dramatically. In 1999, the Commandant of the Marine Corps, General 
J.L. Jones, has made improving the QOL of Marines and family members a high priority. One of his first orders (Jones, 1999) directed that Marines join him in "eliminating the term 'dependents' in referring to our family members." Furthermore, General Jones has consistently stated that Marines and their families are an integral part of the readiness of the Marine Corps. The following quotes provide insight into the importance the Marine Corps places on the role of the Marine and his/her family members:

The readiness of the Operating Forces is our highest priority. It rests upon four pillars: (1) Marines and their families, (2) "legacy" systems, (3) infrastructure, and (4) modernization. Our challenge is to maintain the individual strength of each, while achieving a proper balance in our application of resources among the four. "People will continue to be the most important pillar of our readiness. We continually develop and sustain preparedness for immediate deployment. This requires attention to the physical readiness of Marines and their equipment, as well as "family readiness." We accomplish the former through physical means, primarily, rigorous training. The latter is the product of instilling in our Marines unquestionable confidence that their families are adequately supported in terms of pay, health care, housing, and schools - especially during deployments (Jones, March 2000).

Our greatest assets are dedicated, loyal, selfless Marines who are well educated and trained in the ways of the Corps. Their effectiveness is dependent, in large measure, on the support provided by their families. Consequently, our families are vital to any discussion concerning readiness. Our success in building cohesion and loyalty among Marines has contributed to improved retention rates (Jones, September 2000).

Thus, Marine Corps leadership has embraced the "family" as an important factor in recruiting, readiness, and retention. Moreover, research has established that spouse satisfaction with military life and member retention are significantly correlated (Bland, 1990). Programs that are proven to increase the QOL of Marines and their family members are therefore likely to improve recruiting, retention, and readiness.

\section{c. Sense of Community}

QOL programs "help maintain a high quality of life in the military services, and a high quality of life is viewed as important for readiness and retention reasons." (Van Laar, 1999) According to Van Laar (1999), an important aspect of quality of life is a "sense of community." Thus, a key component of efforts to improve QOL should include the effect that the Marine Corps "community" has upon recruiting, retention, and readiness.

Van Laar (1999) states "a number of social science studies show that a strong sense of community fosters a wide range of positive outcomes, including a sense of well-being and lower incidence of spouse problems and other family problems." Three interlocking sources are identified by Van Laar (1999) as primary factors of "sense of 
community": an attachment to people, developed through social interactions and supportive relationships; an attachment to a workgroup, fostered through involvement in similar tasks; and an attachment to an organization, created as an individual identifies with the values of an organization. Thus, Van Laar (1999) defines "sense of community" as consisting of two elements: an emotional connection among members and identification with the communitythe sense of belonging to a group. Van Laar (1999) states that the following factors increase "sense of community":

Table 2.2

\section{Community Factors with USMC related example}

\begin{tabular}{|c|c|}
\hline Community Factor & USMC related example \\
\hline Group Symbols & $\begin{array}{l}\text { Ceremonies that bring communities } \\
\text { together; USMC birthday ball/birthday } \\
\text { celebrations (Source: Author), military unit } \\
\text { family day, picnics/"field meets" where unit } \\
\text { mascot is prominently displayed. Air shows, } \\
\text { military bands/drill teams are also common } \\
\text { examples. }\end{array}$ \\
\hline Rewards and Honors & $\begin{array}{l}\text { Honoring those that make noteworthy } \\
\text { contributions to the community; volunteers, } \\
\text { Yard of the Month, commanders that } \\
\text { recognize family events-birthdays, } \\
\text { anniversaries, kid's scholastic achievements. }\end{array}$ \\
\hline Common External Threat & $\begin{array}{l}\text { Sports leagues that compete against other } \\
\text { communities; intra-unit athletic } \\
\text { competitions; well-run unit "family } \\
\text { readiness programs" could assist with } \\
\text { defending family members from threat } \\
\text { represented by upcoming deployment of } \\
\text { active duty spouse. }\end{array}$ \\
\hline Making Military Membership Attractive & $\begin{array}{l}\text { Overall military benefits, well-run QOL } \\
\text { programs, unit spouses clubs. }\end{array}$ \\
\hline Group Size and Individuality & $\begin{array}{l}\text { Group loyalities are strongest when } \\
\text { members are neither too personalized or } \\
\text { anonymous; group facilitators should be } \\
\text { aware of this and make adjustments as } \\
\text { needed to find the correct balance }\end{array}$ \\
\hline Personal Influence & $\begin{array}{l}\text { "Town meetings" such as Military } \\
\text { Community Residents Association; }\end{array}$ \\
\hline
\end{tabular}




\begin{tabular}{|c|l|}
\hline & $\begin{array}{l}\text { opportunities for shareholders to provide } \\
\text { feedback. Well-run unit family readiness } \\
\text { program will provide this opportunity } \\
\text { during pre-deployment family meetings. }\end{array}$ \\
\hline Personal Investment & $\begin{array}{l}\text { Command sponsorship programs, where } \\
\text { newly arrived active duty/families are } \\
\text { provided with information and assistance } \\
\text { by experienced members. }\end{array}$ \\
\hline Contact and Proximity & $\begin{array}{l}\text { Use of on base QOL programs, including } \\
\text { housing. Military members that live off } \\
\text { base can also use these facilities. }\end{array}$ \\
\hline Group Activities & $\begin{array}{l}\text { Fund raising-birthday ball bake sales, car } \\
\text { washes; inter/intra unit competitions. }\end{array}$ \\
\hline Souns
\end{tabular}

Source: From Van Laar (1999)

Van Laar (1999) also addresses "targeted subgroups"; members living off post, recently relocated members, those living abroad or in isolated areas, and deployed personnel and their families. Van Laar's recommendations are intriguing, because the factors identified are controllable or can be influenced by unit level (battalion/squadron) commanders and staffs.

\section{B. THE RETENTION DECISION}

The retention decision has most often been described as dichotomous; a person must choose to either stay or leave. While actual behavior is usually the best choice when trying to model the reenlistment decision, in some cases, this data may not be available. For this thesis, the 2001 USMC Retention Survey is used as the primary source of data to model the impact that QOL programs and related QOL-domains have upon the reenlistment intentions of junior enlisted Marines.

According to CNA researchers (Moore and Parcell, 2001), surveys are a good way to determine why people behave in a certain way (e.g., stay or leave the service), but are a bad way to estimate time trends in retention or to predict how many people are going to leave. Moore and Parcell (2001) also found that, though far from perfect, stated intention from survey data is the best predictor of behavior.

Hempel and Parshall (1989) found that service member intentions are a good 
predictor of reenlistment behavior. Siggerud (1981) also found that retention intentions were a good predictor of actual behavior. Both studies used the following guidelines from Aizen and Fishbein (1980) in their respective studies:

1. There must be correspondence between the measure of intention and the measure of behavior as to the target, action, time, and context.

2. Intentions change over time. The longer the time interval, the less accurate is the prediction of behavior from intention. In other words, the closer to the decision point, the more accurate is the intention as a predictor of behavior.

3. Aggregate intentions are much more stable than individual intentions over time, because incidents--like injuries, illness, pregnancy, money losses, etc.-are likely to balance out at the aggregate level. Predictions of behavior from intentions at the aggregate level are therefore often remarkably accurate. (Aizen and Fishbein, 1980).

Finn (1988) tested the validity of using an individual's reported intention to reenlist as a predictor of reenlistment behavior. Finn's research was based upon the findings of Chow and Polich (1980), who found that an "individual's self-reported probability of reenlistment correlated closely with his actual behavior and concluded that, in the absence of actual reenlistment behavior, survey intentions can be used as accurate predictors of reenlistment behavior." (Finn, 1988) Finn (1988) determined that categorizing respondents as stayers or leavers by their intentions was highly reliable out to two years before their expiration of active service (EAS).

The FY 1999 USMC Retention Survey provides a rich source of data concerning the impact that QOL programs and related domains have on the reenlistment intentions of junior enlisted Marines. Variables included in tables 2.2 through 2.5 were measured using the following scale: How important was each of the following to your desire to stay in the Marine Corps?

$$
\begin{aligned}
& 4=\text { very important } \\
& 3=\text { important } \\
& 2=\text { somewhat important } \\
& 1=\text { not important }
\end{aligned}
$$

According to Kocher and Thomas (2000), the following dimensions were found to be the strongest reasons for junior enlisted (first term) Marines to stay in the Marine Corps: 
Table 2.3

Reasons to Stay in the USMC

Ranked by FY 1999 Survey Response Mean

(Males, $\mathrm{N}=6 \mathbf{6 8 4 6}$ )

\begin{tabular}{|l|c|}
\hline \multicolumn{1}{|c|}{ Dimension } & Mean \\
\hline Pay & 3.04 \\
\hline Medical and Retirement Benefits & 2.99 \\
\hline USMC pride/values & 2.97 \\
\hline Friends & 2.95 \\
\hline Advancement Opportunities & 2.92 \\
\hline
\end{tabular}

Source: From Kocher and Thomas (2000)

Table 2.4

Reasons to Stay in the USMC

Ranked by FY 1999 Survey Response Mean

(Females, $\mathrm{N}=663$ )

\begin{tabular}{|l|c|}
\hline \multicolumn{1}{|c|}{ Dimension } & Mean \\
\hline Pay & 3.07 \\
\hline Friends & 2.99 \\
\hline Retirement and Medical Benefits & 2.97 \\
\hline Advancement Opportunities & 2.97 \\
\hline USMC Pride/values & 2.95 \\
\hline
\end{tabular}

Source: From Kocher and Thomas (2000)

Conversely, using the same scale as Tables 2.4 and 2.5 (substituting 'leave' for 'stay'), the following dimensions were found by Kocher and Thomas (2000) to be the strongest reasons for junior enlisted (first term) Marines to leave the Marines Corps:

Table 2.5

Reasons to Leave the USMC

(Males, $\mathrm{N}=6846$ )

\begin{tabular}{|l|c|}
\hline \multicolumn{1}{|c|}{ Dimension } & Mean \\
\hline Pay & 3.52 \\
\hline Personal Freedom & 3.33 \\
\hline Civilian career opportunities & 3.27 \\
\hline
\end{tabular}




\begin{tabular}{|l|c|}
\hline Education benefits & 3.19 \\
\hline Incentive pay & 3.18 \\
\hline
\end{tabular}

Source: From Kocher and Thomas (2000)

Table 2.6

Reasons to Leave the USMC

(Females, $\mathrm{N}=663$ )

\begin{tabular}{|l|c|}
\hline \multicolumn{1}{|c|}{ Dimension } & Mean \\
\hline Pay & 3.54 \\
\hline Personal freedom & 3.40 \\
\hline Education benefits & 3.33 \\
\hline Unit Morale & 3.27 \\
\hline Civilian career opportunities & 3.25 \\
\hline
\end{tabular}

Source: From Kocher and Thomas (2000)

Thus, the FY 1999 USMC Retention Survey provides a reference point from which to assess the impact that QOL programs and domains have upon the reenlistment intentions of junior enlisted Marines. According to Kocher and Thomas (2000), occupation, geographic location, race/ethic group membership, deployment status, family status, and other characteristics of the survey respondents should be investigated to evaluate their influence on opinions about many facets of Marine Corps life and on career intentions.

Hall (2001) used data from the 1999 USMC retention survey to analyze the job satisfaction of first-term male enlisted Marines. Results of this study indicated that over one-third of the respondents are dissatisfied with their job, a majority feel they have to "pick up the load" because the unit is understaffed, and over sixty percent feel their original expectations of the job have not been met (Hall, 2001).

This thesis will explore the relationship that QOL programs and QOL domains have upon the reenlistment intentions of junior (E-2 through E-4) Marines. In Chapter III, a conceptual model for reenlistment will be developed using the knowledge gained through the research discussed in this chapter and the author's personal experience. 
THIS PAGE INTENTIONALLY LEFT BLANK. 


\section{MODEL DEVELOPMENT}

\section{A. CONCEPTUAL MODEL}

Based upon the literature review and the author's personal experience, a theoretical model of retention was developed in which actual staying behavior (retention) was modeled as a function of four broad explanatory variable categories. As noted in the literature review, recent studies have failed to provide the partial effects of QOL programs on retention. The FY 2001 USMC Retention Survey offers a rich source of recent data that can be used to determine the effect that broad QOL programs (e.g., MWR programs, Family Housing, medical and dental benefits, voluntary education) and QOL-domains (e.g., work conditions, job satisfaction, sense of community) have upon the reenlistment intentions of junior enlisted (E-2 through E-4) Marines. The demographic variables used in this model include paygrade, age, race, and marital status. QOL-programs and domains variables measure the influence that MWR programs, military career, working conditions, personal/family life, USMC culture and sense of community have on the retention intentions of junior enlisted Marines. Civilian employment opportunities measure the effect of respondent beliefs of finding employment that compensates as well as the Marine Corps and the ability to successfully transition from military to civilian life. The conceptual model is presented below:

\section{Retention=f(Demographic characteristics,QOL-programs/domains,Civilian employment opportunities)}

\section{B. DATA SOURCE, RESTRICTIONS, AND SURVEY SCALE RELIABILITY \\ 1. Data Source}

The data used for this thesis were drawn from the FY 2001 USMC Retention Survey. The survey was conducted by the Navy Personnel Research, Studies, and Technology (White, 2000). The survey is organized into ten sections and, in addition to personal information (paygrade, demographic), provides information on leadership, career, current military job/working conditions, personal/family life, benefits, culture, and reenlistment intentions. The FY 2001 Retention survey was a modified 'pencil and paper' version of the FY 1999 on-line retention survey (America, 2000). The FY 2001 USMC Retention Survey is provided in Appendix A. 
The survey was conducted by mail from October, 2000 through June, 2001, and was sent to all active duty (officer and enlisted) Marines (America, 2000). According to a HQMC representative, 150,000 surveys were mailed (America, 2001). Overall, 40,053 responses were received, providing a response rate of approximately 30 percent. Since approximately 70 percent of the population did not respond, the data may be affected by non-response bias.

According to Edwards, et al. (1997), a common way to address non-response error is to compare key demographic characteristics of respondents to the demographics of the population. Table 3.1 compares FY 2001 USMC Retention Survey demographic characteristics with data for the entire USMC population.

Table 3.1

\section{Comparison of selected FY 2001 USMC Retention Survey and USMC Demographic Characteristics (By Percentage)}

(Note: Figures in parentheses are base Ns for adjacent percentages.)

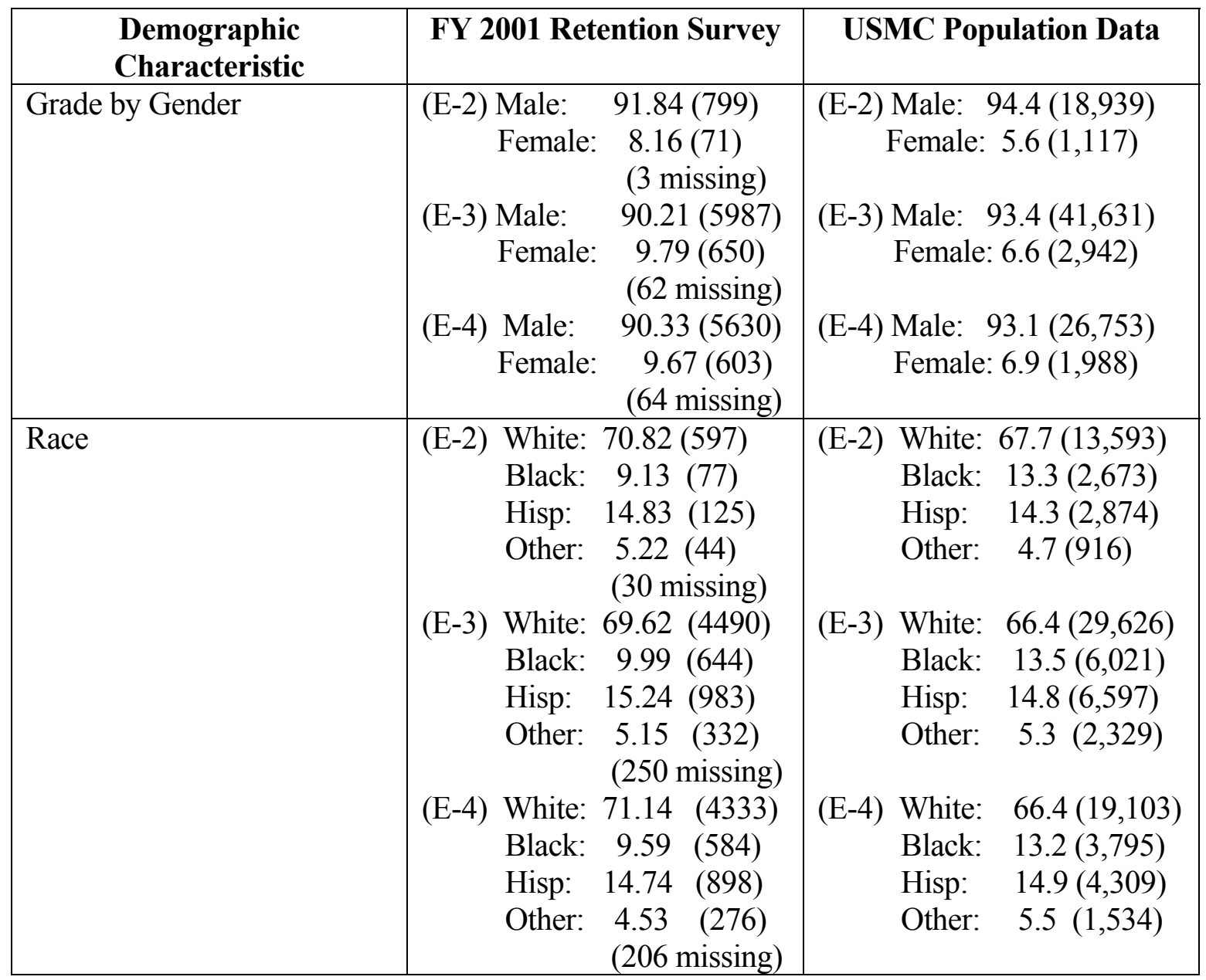




\begin{tabular}{|c|c|c|}
\hline Age (Mean) & $\begin{array}{ll}(E-2) & 20.65 \\
(E-3) & 21.30 \\
(E-4) & 22.65\end{array}$ & $\begin{array}{ll}(E-2) & 20.06 \\
(E-3) & 21.15 \\
(E-4) & 22.66\end{array}$ \\
\hline Marital Status & $\begin{array}{ll}\text { E-2) Single: } & 82.09(714) \\
\text { Married: } & 17.91(156) \\
\text { Missing: } & (2) \\
\text { (E-3) Single: } & 73.8 \text { (4937) } \\
\text { Married: } & 26.20(1753) \\
\text { Missing: } & (9) \\
\text { (E-4) Single: } & 64.33(4046) \\
\text { Married: } & 35.67(2244) \\
\text { Missing: } & (6)\end{array}$ & $\begin{array}{r}\text { (E-2) Single: } 89.91(18,032) \\
\text { Married: } 10.09(2,024) \\
\text { (E-3) Single: } 75.8(33,778) \\
\text { Married: } 24.2(10,794) \\
\text { (E-4) Single: } 60.7(17,425) \\
\text { Married: } 39.3(11,315)\end{array}$ \\
\hline
\end{tabular}

Source: Author, Computed from FY 2001 Retention Survey, USMC Data (HQMC)

Based on Table 3.1, it appears that the FY 2001 USMC Retention Survey is, with a few exceptions, representative of the actual target population (enlisted paygrade E-2 through E4). The exceptions are that males and blacks are slightly under-represented, and females and married E-2s are slightly over-represented.

As discussed in the literature review, reenlistment intentions are a good predictor of actual reenlistment behavior provided three conditions are met:

1. There must be correspondence between the measure of intention and the measure of behavior as to the target, action, time, and context.

2. Intentions change over time. The longer the time interval, the less accurate is the prediction of behavior from intention. In other words, the closer to the decision point, the more accurate is the intention as a predictor of behavior.

3. Aggregate intentions are much more stable than individual intentions over time, because incidents--like injuries, illness, pregnancy, money losses, etc.,--are likely to balance out at the aggregate level. Predictions of behavior from intentions at the aggregate level are therefore often remarkably accurate. (Aizen and Fishbein, 1980).

Since the FY 2001 Retention Survey data set did not have respondent social security numbers, the author was unable to obtain certain demographic information such as expiration of active service (EAS) dates and related contract information about the survey respondents. Therefore, the data restrictions discussed in the next section were used to format the data for more detailed analysis. 


\section{Restrictions Imposed}

First, respondents used in this analysis had Active Duty Base Dates (ADBD) between calendar year (CY) 1998 and 1999. This constraint was needed to increase the likelihood of capturing first term Marines who are within two years of making the reenlistment decision. According to Hall (2001), the majority of first-term enlistee contracts range from 3 to 6 years, the majority being 4-year contracts. Thus, CY 1998 and 1999 respondents' time in service at the time of completing the survey (October 2000-June, 2001) would range from 3 years, 6 months to 0 years, 10 months. While the CY 1998 and CY 1999 responses certainly contain data from Marines who have either made the reenlistment decision or are beyond two years from making a decision, data from this timeframe can be characterized as useful since all of these Marines are potentially 'career' Marines. As discussed during the literature review, the First Term Alignment Plan (FTAP) has transformed all Commanders and leaders into career force recruiters. As will be discussed later in this thesis, the impact that these leaders have upon the reenlistment intentions of junior enlisted Marines can be sizable.

Age was also restricted to respondents less than 31 years of age. The mean age of Marine E-4s in this survey is about 23 years. Therefore, junior enlisted Marines older than 30 are not common and certainly do not represent the target population. Finally, data sets were created for male and female junior enlisted Marines. The final male data set contains 6834 observations and the final female data set contains 736 observations.

\section{Survey Scale Reliability}

The FY 2001 Retention Survey (Appendix A) has twelve clearly labeled dimensions (scales) that provide the basis from which to further analyze the 96 variables chosen for preliminary analysis. The twelve survey dimensions are:

1. Leadership

2. Career

3. Current Military Job/Working Conditions

4. Personal/Family Life

5. Benefits

6. Culture

7. USMC Values 


\section{USMC Sense of Community}

9. Career Alternatives

10. Education/Training

11. Satisfaction with USMC

12. Other Employment Opportunities

The questions asked within these sections are, for the most part, very similar. Multiple questions about the same topic are necessary because the response to any single closedended item on a survey may not be an accurate indicator about what people feel about a topic (Edwards, et al, 1997). The grouping of questions (survey items) is referred to as a dimension, an index, or a scale (Converse and Presser, 1986). The extent to which a dimension has homogenous content, or internal-consistency, provides an important indication about how well variables perform within the respective dimension. For example, the FY 2001 USMC Retention Survey leadership dimension has nine questions, ranging from "The quality of leadership at the senior officer level" (V18) to "The quality of senior civilian leadership of the military" (V26). These questions appear to be measuring the influence that "leadership" related areas have on the career intentions of the respondent (Appendix A, FY 2001 USMC Retention Survey). Since the goal of this thesis is to develop a conceptual model that explains the reenlistment intentions of junior enlisted Marines, it is important that the dimensions used within the FY 2001 USMC Retention survey are reliable.

According to Hatcher (1994), assessing scale reliability with coefficient alpha should be one of the first tasks completed when conducting questionnaire research; if the scales used are not reliable, there is no point performing additional analyses. The Cronbach-Alpha test (Cronbach, 1951) is used to assess the internal consistency reliability of survey data. According to Nunnally (1978), a coefficient alpha score greater than .70 suggests that the variables within the section (underlying construct) are reliable measurements. Coefficient alpha scores below .70 deserve further investigation through exploratory factor analysis to determine which items tend to group together empirically. As depicted by the below table, most survey constructs achieved coefficient alpha scores greater than .70, which suggests that the scale reliability is acceptable (Nunnally, 1978). 
Table 3.2

Coefficient Alpha Reliability Estimates for FY 2001

USMC Retention Dimensions

\begin{tabular}{|l|c|}
\hline \multicolumn{1}{|c|}{ Survev Dimensions } & Coeff. Alpha \\
\hline Leadership (Variables V18-V26) & .825 \\
\hline Career (Variables V27-V40) & .877 \\
\hline $\begin{array}{l}\text { Current Military Job/Working Conditions } \\
\text { (Variables V41-V61) }\end{array}$ & .921 \\
\hline Personal/Family Life (Variables V62-V77) & .837 \\
\hline Benefits (Variables V78-V89) & .893 \\
\hline Culture (Variables V90-V99) & .863 \\
\hline USMC Values (V100-V103) & .8025 \\
\hline USMC Sense of Community (V104-106) & .860 \\
\hline Career Alternatives (V107-V110) & .700 \\
\hline Education/Training (V111-V115) & .529 \\
\hline Satisfaction with USMC (V118-V128) & .8208 \\
\hline Civilian Employment Opportunities (V130- \\
V131) & .313 \\
\hline Sin
\end{tabular}

Source: Author, Computed from FY 2001 USMC Retention Survey

Thus, the variables within dimensions that achieved coefficient alpha scores in excess of the .70 cutoff are likely to be appropriate measures of that dimension. For the dimensions that did not achieve coefficient alpha scores greater than .70, further tests such as factor analysis should be used to determine appropriate scales or dimensions these variables may comprise.

\section{CANDIDATE EXPLANATORY VARIABLES}

There were 131 explanatory variables available for analysis from the FY 2001 USMC Retention Survey, and 98 candidate explanatory variables that support the conceptual model were selected for further analysis. Candidate demographic variables are: race, marital status, dependents (family members), paygrade, current location (CONUS/OCONUS), and current age. QOL-program variables selected for consideration are Morale, Welfare, and Recreation (MWR) programs, housing, dental and medical benefits, and voluntary education. QOL-related domain variables include measures of influence on the respondent's retention intentions and satisfaction with Marine Corps leadership, career, current military job, working conditions, personal/family life, USMC culture, and sense of community. Civilian employment opportunities assess the difficulty 
junior enlisted Marines expected in obtaining a job that pays as well as the Marine Corps and the adjustment to civilian life.

\section{Categorical Variables}

Tables 3.3 and 3.4 provide descriptive information about initial sample members from the FY 2001 USMC Retention Survey. With the exception of paygrade (v8), responses provided in Tables 3.3 and 3.4 represent the cumulative responses of paygrades E2 through E-4 for each variable.

Demographically, the male and female data sets were largely similar. Blacks were more heavily represented in the female sample (13.88 percent) than the male sample $(8.62$ percent). More female junior enlisted Marines were married (37.09 percent) than their male peers (26.24 percent). Both groups were similar in all other demographic areas. With regard to "Civilian Employment Opportunities ," a higher proportion of male junior Marines responded that it was 'easy to find employment that compensates as well as the Marine Corps' (68.45 percent) than female Marines (57.98 percent). Both male and female junior enlisted Marines responded similarly to the remaining questions in this category.

Table 3.3

Frequency Distributions of Categorical Variables, Junior Enlisted Males $(\mathrm{N}=\mathbf{6 8 3 4})$

\begin{tabular}{|l|c|c|c|}
\hline \multicolumn{1}{|c|}{ Variable (Name) } & Frequency & Percent & Missing \\
\hline DEMOGRAPHIC & & & \\
\hline Race (V5) & & & \\
\hline White & 4794 & 71.72 & 219 \\
\hline Asian/Pacific & 239 & 8.62 & 219 \\
\hline Black/African American & 570 & 8.62 & 219 \\
\hline Other/Hisp & 1012 & 15.29 & 219 \\
\hline \multicolumn{1}{|c|}{ Marital Status (V6) } & & & \\
\hline Married Paygrade (V8) & 1792 & 26.24 & 6 \\
\hline Married/Separated & 172 & 2.52 & 6 \\
\hline Single Children/Legal Wards (V7) & 4864 & 71.24 & 6 \\
\hline None & 5165 & 80.70 & 434 \\
\hline 1 or more & 1235 & 19.30 & 434 \\
\hline & & & \\
\hline E2 & 209 & 3.06 & 9 \\
\hline E3 & 4305 & 63.08 & 9 \\
\hline E4 & 2311 & 33.86 & 9 \\
\hline & & & \\
\hline CONUS & 5632 & 83.75 & 109 \\
\hline
\end{tabular}




\begin{tabular}{|l|c|c|c|}
\hline OCONUS & 1093 & 16.25 & 109 \\
\hline CIVILIAN EMPLOYMENT & & & \\
\hline Easy to find employment that & Yes (4657) & Yes (68.45) & 30 \\
compensates as well as the Marines? & No (1073) & No (15.77) & 30 \\
(V130) & Don't Know & Don't Know & 30 \\
& $(1074)$ & $(15.78)$ & \\
\hline $\begin{array}{l}\text { Marine Corps is best current job } \\
\text { choice? (V129) }\end{array}$ & Yes (2012) & Yes (29.58) & 32 \\
& No (3796) & No (55.81) & 32 \\
\hline Easy to adjust to life as a civilian? & Don't Know & Don't Know & 32 \\
(V131) & Yes (549) & $(14.61)$ & \\
& No (627) & Yes (80.67) & 30 \\
& Don't Know & Don't Know & 30 \\
\hline
\end{tabular}

Source: Author, Computed from FY 2001 USMC Retention Survey

Table 3.4

Frequency Distribution of Categorical Variables

Junior Enlisted Females (N=736)

\begin{tabular}{|c|c|c|c|}
\hline Variable (Name) & Frequency & Percent & Missing \\
\hline \multicolumn{4}{|l|}{ DEMOGRAPHIC } \\
\hline \multicolumn{4}{|l|}{ Race (V5) } \\
\hline White & 435 & 61.01 & 23 \\
\hline Asian/Pacific & 30 & 4.21 & 23 \\
\hline Black/African American & 99 & 13.88 & 23 \\
\hline Other/Hisp & 149 & 20.90 & 23 \\
\hline \multicolumn{4}{|l|}{ Marital Status (V6) } \\
\hline Married & 273 & 37.09 & 0 \\
\hline Divorced/Separated & 56 & 7.61 & 0 \\
\hline Single (Never married) & 407 & 55.30 & 0 \\
\hline \multicolumn{4}{|l|}{ Children/Legal Wards (V7) } \\
\hline None & 506 & 75.5 & 66 \\
\hline 1 or more & 164 & 24.5 & 66 \\
\hline \multicolumn{4}{|l|}{ Paygrade (V8) } \\
\hline E2 & 18 & 2.45 & 0 \\
\hline E3 & 453 & 61.55 & 0 \\
\hline E4 & 265 & 36.01 & 0 \\
\hline \multicolumn{4}{|l|}{ Current Location (V12) } \\
\hline CONUS & 615 & 84.71 & 10 \\
\hline OCONUS & 111 & 15.29 & 10 \\
\hline \multicolumn{4}{|l|}{$\begin{array}{l}\text { CIVILIAN EMPLOYMENT } \\
\text { OPPORTUNITIES }\end{array}$} \\
\hline Easy to find employment that & Yes (421) & Yes (57.98) & 3 \\
\hline compensates as well as the Marines? & No (153) & No $(20.87)$ & 3 \\
\hline
\end{tabular}




\begin{tabular}{|l|l|l|c|}
\hline (V130) & $\begin{array}{l}\text { Don't Know } \\
(155)\end{array}$ & $\begin{array}{l}\text { Don't Know } \\
(27.15)\end{array}$ & 3 \\
\hline $\begin{array}{l}\text { Marine Corps is best current job } \\
\text { choice? (V129) }\end{array}$ & Yes (222) & Yes (30.29) \\
& No (390) & No (53.21) & 3 \\
& Don't Know & $\begin{array}{l}\text { Don't Know } \\
(16.51)\end{array}$ & 3 \\
\hline $\begin{array}{l}\text { Easy to adjust to life as a civilian? } \\
(131)\end{array}$ & Yes (592) & Yes (80.76) & 3 \\
& No (67) & No (9.14) & 3 \\
& Don't Know & Don't Know & 3 \\
\hline
\end{tabular}

Source: Author, Computed from FY 2001 USMC Retention Survey

\section{Continuous Variables}

Tables 3.5 through 3.10 provide descriptive information about the initial sample members for continuous variables from the FY 2001 USMC Retention Survey. Tables 3.5 (Variable Means in Descending Order, Males) and 3.6 (Variable Means in Descending Order, Females) describe preliminary variables chosen from survey questions 18 through 99 (see Appendix A). The variables that apply to these questions are denoted by a ' $v$ ' followed by the survey question (e.g., variable v18 represents survey question 18--Quality of Leadership at the senior officer level). This convention is used throughout this thesis. Tables 3.7 (Variable Means in Descending Order, Males) and 3.8 (Variable Means in Descending Order, Females) pertain to preliminary variables chosen from survey questions 100 through 115. Readers should note that some of the questions are positively worded and some are negatively worded, thus affecting the means accordingly. Tables 3.9 (Males) and 3.10 (Females) also provide means in descending order for preliminary variables chosen from survey questions 117 through 128. The average age and grade for both male and female respondents was about 21 years and E-3 (Lance Corporal), respectively. The midrange response of males for survey questions 18-99 (variables V18-V99) was 3.75 of a 7-point Likert scale (influence on leave/stay intentions). The midrange response of female junior enlisted Marines to these variables was 3.83. The mean response of males for survey questions 100-114 (variables V100-V114) was 3.42; for females the mean response was 3.38 of a 5-point Likert scale (strength of agreement with statement). Finally, the mean response of males for survey questions 118-128 (variables V118-V128) was 3.03 and 3.11 for females (5-point Likert satisfaction scale). Readers should note that variables for survey 
questions 18 through 115 and 117 through 128 (Appendix A) were recoded in reverse order (e.g., 1 is equal to 7) to calculate means as described above and to facilitate further analysis.

Appendix B, Tables B.1 and B.2, provides means and standard deviations for all preliminary continuous variables. All continuous variables are measured using a Likert scale that is noted in each table heading.

'Job Security' (Table 3.5) received the highest mean response (4.8) from male Marines for preliminary variables chosen from survey questions 18 through 99 . 'Quality of Education Benefits' (Table 3.6) received the highest mean response (4.81) from female junior enlisted Marines for preliminary variables chosen from the same range of survey questions. Conversely, 'time away from home' (mean=2.7) was the lowest scoring variable for males (Table 3.5); 'quality of military housing' (mean=2.85) was the lowest scoring variable for females (Table 3.6).

\section{Table 3.5}

\section{Variable Means in Descending Order Male Junior Enlisted Marines $(\mathrm{N}=6834)$ (Likert Scale, 1-7: $1=$ Influence to Leave, $7=$ Influence to Stay)}

\begin{tabular}{c} 
Variable \\
\hline V27 \\
V25 \\
V57 \\
V73 \\
V74 \\
V77 \\
V95 \\
V58 \\
V20 \\
V85 \\
V76 \\
V23 \\
V34 \\
V42 \\
V29 \\
V18 \\
V92 \\
V21 \\
V75 \\
V51 \\
V93 \\
V86
\end{tabular}

$\begin{array}{cc}\text { Label } & \text { Mean } \\ \text { YOUR JOB SECURITY } & 4.80 \\ \text { YOUR COMMITMENT TO SUBORDINATES } & 4.71 \\ \text { JOB RESPONSIBILITY } & 4.41 \\ \text { FAMILY MEDICAL CARE } & 4.39 \\ \text { FAMILY DENTAL CARE } & 4.31 \\ \text { MWR PROGRAMS } & 4.28 \\ \text { INTERACTION BTWN RACES } & 4.27 \\ \text { SENSE OF JOB ACCOMPLISHMENT } & 4.26 \\ \text { WARRANT OFFICER LEADERSHIP } & 4.25 \\ \text { QUALITY OF EDUCATIONAL BENEFITS } & 4.24 \\ \text { FAMILY SERVICE CENTERS } & 4.21 \\ \text { IMMEDIATE SUPERVISOR LEADERSHIP } & 4.19 \\ \text { ASSIGNMENTS TO LEADERSHIP POSITIONS } & 4.18 \\ \text { SAFETY IN UNIT } & 4.16 \\ \text { PROFESSIONAL DEVELOPMENT OPPORTUNITIES } & 4.14 \\ \text { SENIOR OFFICER LEADERSHIP } & 4.05 \\ \text { FAIRNESS OF PHYSICAL TRAINING STANDARDS } & 4.05 \\ \text { SNCO (E6-E9) LEADERSHIP } & 4.02 \\ \text { AVAILABILITY OF DAY CARE } & 3.99 \\ \text { TECHNICAL COMPETENCE OF IMMEDIATE SUPERVISOR } & 3.99 \\ \text { FAIRNESS OF WEIGHT STANDARDS } & 3.99 \\ \text { AVAILABILITY OF EDUCATION BENEFITS } & 3.95\end{array}$




\begin{tabular}{|c|c|c|}
\hline V19 & JUNIOR OFFICER LEADERSHIP & 3.95 \\
\hline V28 & PROMOTION OPPORTUNITY & 3.93 \\
\hline V52 & CURRENT JOB & 3.92 \\
\hline V26 & SENIOR CIVILIAN LEADERSHIP & 3.90 \\
\hline V56 & AUTHORITY TO DO JOB & 3.80 \\
\hline V38 & CAREER GUIDANCE FROM SUPERVISORS & 3.78 \\
\hline V47 & RESPECT FROM SUPERIORS & 3.76 \\
\hline V66 & LOCATION OF OFF BASE HOUSING & 3.76 \\
\hline V24 & TRUST IN MARINE LEADERSHIP & 3.72 \\
\hline V96 & INTERACTION BETWEEN SEXES & 3.72 \\
\hline V22 & NCO (E4-E5) LEADERSHIP & 3.70 \\
\hline V63 & FAMILY INFLUENCE ON CAREER & 3.70 \\
\hline V98 & ZERO DEFECT MENTALITY & 3.70 \\
\hline V40 & OPPORTUNITY FOR OFF-DUTY EDUCATION & 3.67 \\
\hline V41 & YOUR MORALE & 3.67 \\
\hline V94 & ADMINISTRATION OF MORAL STANDARDS & 3.67 \\
\hline V99 & CAREERISM BY SNCO/OFFICERS & 3.67 \\
\hline V55 & TOOL AVAILABILITY & 3.62 \\
\hline V97 & INTERACTION BETWEEN OFFICERS \& ENLISTED & 3.62 \\
\hline V50 & UNIT DEPLOYMENTS & 3.61 \\
\hline V49 & MANNING LEVELS IN UNIT & 3.58 \\
\hline V35 & CHOICE OF DUTY STATIONS & 3.51 \\
\hline V46 & COMPETENCE OF CO-WORKERS & 3.51 \\
\hline V54 & EQUIPMENT AVAILABILITY & 3.51 \\
\hline V72 & IMPACT OF MILITARY SERVICE ON SPOUSES CAREER & 3.51 \\
\hline V64 & AVAILABILITY OF MILITARY HOUSING & 3.50 \\
\hline V53 & MATERIAL AVAILABILITY & 3.48 \\
\hline V67 & COST OF OFF BASE HOUSING & 3.46 \\
\hline V44 & DISCIPLINE IN UNIT & 3.45 \\
\hline V91 & ADMINISTRATION OF DISCIPLINE & 3.44 \\
\hline V68 & LIVING CONDITIONS DURING DEPLOYMENT & 3.43 \\
\hline V69 & FREQUENCY OF MOVES & 3.43 \\
\hline V70 & IMPACT OF MOVES ON FAMILY & 3.39 \\
\hline V90 & ADMINISTRATION OF REGULATIONS & 3.39 \\
\hline V59 & RED TAPE AT JOB & 3.29 \\
\hline V33 & CONTROL OVER JOB ASSIGNMENTS & 3.22 \\
\hline V48 & RECOGNITION OF ACCOMPLISHMENTS & 3.21 \\
\hline V60 & WORKLOAD DISTRIBUTION & 3.17 \\
\hline V43 & UNIT MORALE & 3.15 \\
\hline V45 & MILITARY JOB HOURS WORKED & 3.14 \\
\hline V62 & WORK/PERSONAL TIME BALANCE & 3.02 \\
\hline V61 & ABILITY TO TRANSFER & 3.01 \\
\hline V65 & QUALITY OF MILITARY HOUSING & 2.95 \\
\hline V71 & DISTANCE FROM DUTY STATION & 2.88 \\
\hline V32 & TIME AWAY FROM HOME & 2.70 \\
\hline
\end{tabular}

Source: Author, Computed from FY 2001 USMC Retention Survey 


\section{Table 3.6 \\ Variable Means (V18-V99) in Descending Order \\ Female Junior Enlisted Marines ( $\mathbf{N = 7 3 6 )}$ \\ (Likert Scale, 1-7: \\ 1=Influence to Leave, $7=$ Influence to Stay)}

\begin{tabular}{l} 
Variable \\
\hline V85 \\
V27 \\
V74 \\
V73 \\
V86 \\
V25 \\
V77 \\
V40 \\
V95 \\
V57 \\
V76 \\
V20 \\
V58 \\
V42 \\
V29 \\
V23 \\
V18 \\
V96 \\
V68 \\
V47 \\
V30 \\
V34 \\
V26 \\
V99 \\
V51 \\
V55 \\
V56 \\
V19 \\
V75 \\
V53 \\
V53
\end{tabular}

\begin{tabular}{|c|c|}
\hline Label & Mean \\
\hline QUALITY OF ED BENEFITS & 4.81 \\
\hline JOB SECURITY & 4.81 \\
\hline FAMILY DENTAL CARE & 4.58 \\
\hline FAMILY MEDICAL CARE & 4.56 \\
\hline AVAILABILITY OF EDUCATION BENEFITS & 4.56 \\
\hline YOUR COMMITMENT TO SUBORDINATES & 4.56 \\
\hline MWR PROGRAMS & 4.38 \\
\hline OPPORTUNITY FOR OFF-DUTY EDUCATION & 4.33 \\
\hline INTERACTION BETWEEN RACES & 4.32 \\
\hline JOB RESPONSIBILITY & 4.31 \\
\hline FAMILY SERVICE CENTERS & 4.30 \\
\hline WARRANT OFFICER LEADERSHIP & 4.29 \\
\hline SENSE OF JOB ACCOMPLISHMENT & 4.16 \\
\hline SAFETY IN UNIT & 4.14 \\
\hline PROFESSION DEVELOPMENT OPPORTUNITY & 4.10 \\
\hline IMMEDIATE SUPERVISOR LEADERSHIP & 4.08 \\
\hline SENIOR OFFICER LEADERSHIP & 4.04 \\
\hline ASSIGNMENT TO LEADERSHP POSITIONS & 3.97 \\
\hline SENIOR CIVILIAN LEADERSHIP & 3.96 \\
\hline TECHNICAL COMPETENCE OF IMMEDIATE SUPERVISOR & 3.90 \\
\hline TOOL AVAILABILITY & 3.89 \\
\hline AUTHORITY TO DO JOB & 3.89 \\
\hline JUNIOR OFFICER LEADERSHIP & 3.86 \\
\hline AVAILABILITY OF DAY CARE & 3.85 \\
\hline PROMOTION OPPORTUNITY & 3.83 \\
\hline MATERIAL AVAILABILITY & 3.83 \\
\hline EQUIPMENT AVAILABILITY & 3.83 \\
\hline FAIRNESS OF PHYSICAL TRAINING STANDARDS & 3.77 \\
\hline ZERO DEFECT MENTALITY & 3.77 \\
\hline SNCO (E6-E9) LEADERSHIP & 3.76 \\
\hline CURRENT JOB & 3.76 \\
\hline LOCATION OF OFF BASE HOUSING & 3.76 \\
\hline CAREERISM BY SNCO/OFFICERS & 3.73 \\
\hline CAREER GUIDANCE FROM SUPERIORS & 3.71 \\
\hline UNIT DEPLOYMENTS & 3.69 \\
\hline FAMILY INFLUENCE ON CAREER & 3.65 \\
\hline RESPECT FROM SUPERIORS & 3.62 \\
\hline MANNING LEVELS IN UNIT & 3.62 \\
\hline ADMINISTRATION OF MORAL STANDARDS & 3.62 \\
\hline INTERACTION BETWEEN SEXES & 3.62 \\
\hline LIVING CONDITIONS DURING DEPLOYMENTS & 3.61 \\
\hline
\end{tabular}




\begin{tabular}{|c|c|c|}
\hline V97 & INTERACTION BETWEEN OFFICERS \& ENLISTED & 3.61 \\
\hline V59 & RED TAPE AT JOB & 3.60 \\
\hline V35 & CHOICE OF DUTY STATIONS & 3.57 \\
\hline V93 & FAIRNESS OF WEIGHT STANDARDS & 3.57 \\
\hline V72 & IMPACT OF MILITARY SERVICE ON SPOUSES CAREER & 3.56 \\
\hline V41 & MORALE & 3.48 \\
\hline V69 & FREQUENCY OF MOVES & 3.47 \\
\hline V22 & NCO (E4-E5) LEADERSHIP & 3.44 \\
\hline V64 & AVAILABILITY OF MILITARY HOUSING & 3.43 \\
\hline V46 & COMPETENCE OF CO-WORKERS & 3.42 \\
\hline V70 & IMPACT OF MOVES ON FAMILY & 3.42 \\
\hline V91 & ADMINISTRATION OF DISCIPLINE & 3.40 \\
\hline V45 & MILITARY JOB HOURS WORKED & 3.37 \\
\hline V90 & ADMINISTRATION OF REGULATIONS & 3.36 \\
\hline V24 & TRUST IN MARINE LEADERSHIP & 3.34 \\
\hline V67 & COST OF OFF BASE HOUSING & 3.32 \\
\hline V44 & DISCIPLINE IN UNIT & 3.22 \\
\hline V60 & WORKLOAD DISTRIBUTION & 3.22 \\
\hline V61 & ABILITY TO TRANSFER & 3.20 \\
\hline V33 & CONTROL OVER JOB ASSIGNMENTS & 3.16 \\
\hline V48 & RECOGNITION OF ACCOMPLISHMENTS & 3.15 \\
\hline V43 & UNIT MORALE & 3.05 \\
\hline V62 & WORK/PERSONAL TIME BALANCE & 3.05 \\
\hline V71 & DISTANCE FROM DUTY STATION & 3.05 \\
\hline V32 & TIME AWAY FROM HOME & 2.87 \\
\hline V65 & QUALITY OF MILITARY HOUSING & 2.85 \\
\hline
\end{tabular}

Source: Author, Computed from FY 2001 USMC Retention Survey

A higher proportion of male and female Marines agreed with survey question 111 ('I want more education/training so that I can get out and get a better job') than all other questions listed illustrated in Tables 3.7 and 3.8. At the opposite end of the spectrum, male and female junior enlisted Marines generally disagreed with survey question 103, 'I would be very happy to spend the rest of my career in the Marine Corps.'

\section{Table 3.7}

Variable Means in Descending Order

Male Junior Enlisted Marines (N=6834)

(Likert Scale, 1-5:

1=Strongly Disagree, 5=Strongly Agree)

\begin{tabular}{crr} 
Variable & Label & $\underline{\text { Value }}$ \\
\hline V111 & I want more education/training so that I can get out and get a better job. & 4.11 \\
V112 & I want more education/training because it makes me a better Marine/person. & 4.10 \\
V100 & What Marine Corps stands for is important to me. & 4.06 \\
V102 & Overall, I'm proud that I joined the Marine Corps. & 4.05 \\
V115 & I intend to get out of the Marine Corps so that I can get better technical training/education. & 3.71
\end{tabular}




$\begin{array}{lrr}\text { V113 } & \text { More technical education/training would encourage me to seek civilian job opportunities. } & 3.70 \\ \text { V101 } & \text { My attachment to Marine Corps is primarily based on the similarity of values } & 3.45 \\ \text { V114 } & \text { More education opportunities would encourage me to re-enlist or remain in the service. } & 3.11 \\ \text { V105 } & \text { I do not feel emotionally attached to the Marine Corps. } & 2.99 \\ \text { V104 } & \text { I do not feel "part of the family" in the Marine Corps } & 2.78 \\ \text { V106 } & \text { I do not feel a strong sense of belonging to the Marine Corps } & 2.74 \\ \text { V103 } & \text { I would be very happy to spend the rest of my career in the Marine Corps. } & 2.24\end{array}$

Source: Author, Computed from FY 2001 USMC Retention Survey

\section{Table 3.8}

Variable Means in Descending Order Female Junior Enlisted Marines (N=736)

(Likert Scale, 1-5:

1=Strongly Disagree, 5=Strongly Agree)

\begin{tabular}{c} 
Variable \\
\hline V111 \\
V112 \\
V102 \\
V100 \\
V113 \\
V115 \\
V101 \\
V105 \\
V114 \\
V104 \\
V106 \\
V103
\end{tabular}

$\begin{array}{cc}\text { Label } & \underline{\text { Value }} \\ \begin{array}{c}\text { I want more education/training so that I can get out and get a better job. } \\ \text { I want more education/training because it makes me a better Marine/person. }\end{array} \\ \text { Overall, I'm proud that I joined the Marine Corps. } \\ \text { What Marine Corps stands for is important to me. } & 4.04 \\ \text { More technical education/training would encourage me to seek civilian job opportunities. } & 3.92 \\ \text { I intend to get out of the Marine Corps so that I can get better technical training/education. } & 3.88 \\ \text { My attachment to Marine Corps is primarily based on the similarity of values } & 3.71 \\ \text { I do not feel emotionally attached to the Marine Corps. } & 3.58 \\ \text { More education opportunities would encourage me to re-enlist or remain in the service. } & 3.25 \\ \text { I do not feel "part of the family" in the Marine Corps } & 3.05 \\ \text { I do not feel a strong sense of belonging to the Marine Corps } & 3.05 \\ \text { I would be very happy to spend the rest of my career in the Marine Corps. } & 2.97\end{array}$

Medical benefits (Table 3.9) received the strongest satisfaction ranking from males for preliminary variables chosen from survey questions 117 through 128. Education benefits (Table 3.10) received the highest mean response from female junior enlisted Marines. Both male and female junior enlisted Marines were generally dissatisfied with 'family life in the Marine Corps' (survey question 123), as this variable received the lowest mean satisfaction rating for preliminary variables chosen from survey questions 117 through 128.

Table 3.9

\section{Variable Means in Descending Order \\ Male Junior Enlisted Marines ( $\mathbf{N}=6834)$ (Likert Scale, 1-5: 1=Highly Dissatisfied, 5=Highly Satisfied)}




$\begin{array}{lcl}\text { V119 } & \text { Your primary MOS assignment } & 3.32 \\ \text { V118 } & \text { Your Marine Corps Career } & 3.17 \\ \text { V128 } & \text { The culture of the Marine Corps } & 3.17 \\ \text { V120 } & \text { Your current duty station } & 3.13 \\ \text { V127 } & \text { Your educational benefits while in the Marine Corps } & 3.09 \\ \text { V121 } & \text { Your working conditions in the Marine Corps } & 2.93 \\ \text { V117 } & \text { Leadership in the Marine Corps } & 2.91 \\ \text { V122 } & \text { Your personal life while in the Marine Corps } & 2.57 \\ \text { V123 } & \text { Your family life while in the Marine Corps } & 2.49\end{array}$

\section{Table 3.10}

\section{Variable Means in Descending Order Female Junior Enlisted Marines ( $\mathbf{N}=\mathbf{7 3 6}$ ) (Likert Scale, 1-5: 1=Highly Dissatisfied, 5=Highly Satisfied)}

\begin{tabular}{ccc} 
Variable & Label & Value \\
\cline { 1 - 3 } V127 & Your educational benefits while in the Marine Corps & 3.50 \\
V126 & Your Medical benefits while in the Marine Corps & 3.48 \\
V120 & Your current duty station & 3.26 \\
V128 & The culture of the Marine Corps & 3.14 \\
V119 & Your primary MOS assignment & 3.08 \\
V118 & Your Marine Corps Career & 3.05 \\
V121 & Your working conditions in the Marine Corps \\
V122 & Your personal life while in the Marine Corps & 3.00 \\
V117 & Leadership in the Marine Corps & 2.80 \\
V123 & Your family life while in the Marine Corps & 2.69 \\
&
\end{tabular}

Tables 3.3 through 3.10 provide a wealth of information about junior enlisted Marines. However, more detailed analysis is required in order to draw meaningful conclusions from this data. Accordingly, the next section will subject variables that support the preliminary conceptual model presented earlier to further analysis so that a final conceptual model for retention intentions of junior enlisted Marines can be achieved.

\section{EXPLORATORY ANALYSIS OF PRELIMINARY EXPLANATORY VARIABLES}

According to Edwards, et al., (1997), when survey teams want to look at the responses of two or more variables at a time, they conduct cross-tabulation (or cross-tab) analyses. The following tables depict how QOL programs and selected QOL-domains that support the conceptual model were perceived by junior enlisted Marines, cross-tabulated by gender, race, marital status, and geographic location (CONUS or outside CONUS). For 
the purpose of parsimony, the highest and lowest ranked variables by mean within each QOL-domain were chosen for further analysis. Due to the focus of this thesis, all QOL program variables were chosen for further analysis in this section.

To facilitate this analysis, continuous variables were transformed into categorical variables. For variables v18-v99, responses coded as 1-3 were recoded as 'influence to leave', 4 was coded as 'no effect', and 5-7 were coded as ' influence to stay.' Variables v100-v115 with responses coded as 1 or 2 were recoded as 'disagree', 3 was recoded as 'neutral' and 4 or 5 was recoded as 'agree.' Variables v117-v128 coded as 1 or 2 were recoded as 'dissatisfied', 3 was recoded as 'neutral', and 4 or 5 was recoded as 'satisfied.' In order to readily compare male and female responses, each table features a separate column for males (noted by 'M') and females ('F').

Subgroups were created so that meaningful comparisons can be made between junior enlisted Marines of different races, marital status, and geographic location. The subgroups used for race are white, black, and Hispanic. Marital status subgroups are single and married. Geographic subgroups are CONUS (Continental United States) and OCONUS (outside CONUS).

Subgroup observations for the cross-tabulations discussed in this chapter exceed 100. Rea and Parker (1992) suggest "that, as a rule of thumb, a 10 percent margin of error is the maximum error that should be tolerated for any sample stratum or substratum." According to Rea and Parker (1992), to achieve a 10 percent margin of error, data from at least 100 people must be gathered. Due to the low number $(<100)$ of observations, Native American and Asian American responses were deleted. Additionally, divorced/separated responses were deleted for the same reason. Future surveys should include larger sample sizes for these sub-groups.

The cross-tabulations presented are intended to provide a preliminary analysis of the relationship between QOL-programs and QOL-domains with the reenlistment intentions, agreement, and satisfaction perceptions of junior enlisted Marines. This analysis will enable the author to finalize the conceptual model presented earlier in this chapter, resulting in a final conceptual model for retention that will be subjected to multivariate analysis in Chapter IV of this thesis. 


\section{Retention Intentions}

To provide a baseline regarding stated reenlistment intentions, variable V116 ("Please describe your career intentions") is cross-tabulated by demographic categories in tables 3.11 through 3.14. Tables 3.11 through 3.14 depict a challenging retention environment since junior enlisted Marines in all demographic categories overwhelmingly responded that their intention was to "leave" the Marine Corps. As shown by Table 3.11, male and female junior enlisted Marines provided similar responses, with over 50 percent responding that they intend to leave the Marine Corps when their current obligation is complete. Further, Table 3.12 shows that white males and females (60.46 and 62.85 percent, respectively) were more likely to leave than black males and females (52.65 and 56.25 percent, respectively). Moreover, Table 3.13 depicts that single males were more likely to leave the Marine Corps than single females, but that 67 percent of married junior enlisted females intend to leave the Marine Corps as compared to 55 percent of the married females. Finally, Table 3.14 shows that CONUS males and females (60.1 and 62.0 percent, respectively) were more likely to leave the Marine Corps than OCONUS males and females (54.8 and 51.8 percent, respectively).

Table 3.11

Reenlistment Intentions by Gender

\begin{tabular}{|l|c|c|}
\hline & $\frac{\text { Male }(\mathbf{N}=6679)}{\text { Percent }}$ & $\frac{\text { Female (N=721) }}{\text { Percent }}$ \\
\hline Leave & 59.3 & 60.47 \\
\hline Undecided & 29.58 & 26.77 \\
\hline Stay & 11.12 & 12.76 \\
\hline
\end{tabular}

Source: Author, Computed from FY 2001 USMC Retention Survey 
Table 3.12

Reenlistment Intentions Cross-Tabulation Percentage:

Race

(Male, $\mathrm{N}=6151)($ Female, $\mathrm{N}=650)$

\begin{tabular}{|l|c|c|c|c|c|c|}
\hline & \multicolumn{2}{|c|}{ White } & \multicolumn{2}{c|}{ Black } & \multicolumn{2}{c|}{ Hispanic } \\
& M & F & M & F & M & F \\
\hline Leave & 60.46 & 62.85 & 52.65 & 56.25 & 56.45 & 60.32 \\
& & & & & & \\
\hline Undecided & 29.51 & 27.57 & 28.70 & 30.21 & 29.77 & 22.22 \\
& & & & & & \\
\hline Stay & 10.03 & 9.58 & 18.65 & 13.54 & 13.78 & 17.46 \\
& & & & & & \\
\hline
\end{tabular}

Source: Author, Computed from FY 2001 USMC Retention Survey

Table 3.13

Reenlistment Intentions Cross-Tabulation Percentage: Marital Status Male $(\mathrm{N}=6508)$, Female $(\mathrm{N}=666)$

\begin{tabular}{|l|c|c|c|c|}
\hline & \multicolumn{2}{|c|}{ Single } & \multicolumn{2}{c|}{ Married } \\
\hline Leave & 60.94 & 56.39 & 54.89 & 67.04 \\
\hline Undecided & 29.35 & 31.33 & 30.07 & 19.85 \\
\hline Stay & 9.71 & 12.28 & 15.04 & 13.11 \\
\hline
\end{tabular}

Source: Author, Computed from FY 2001 USMC Retention Survey

Table 3.14

Reenlistment Intentions Cross-Tabulation Percentage:

Geographic Location (CONUS and OCONUS)

Male $(\mathrm{N}=6575)$, Female $(\mathrm{N}=711)$

\begin{tabular}{|l|c|c|c|c|}
\hline & \multicolumn{2}{|c|}{ CONUS } & \multicolumn{2}{c|}{ OCONUS } \\
\hline Leave & M & 62.0 & 54.8 & 51.8 \\
\hline Undecided & 60.1 & 25.7 & 32.3 & 32.4 \\
\hline Stay & 10.7 & 12.2 & 12.8 & 15.7 \\
\hline
\end{tabular}

Source: Author, Computed from FY 2001 USMC Retention Survey

Since the 'career intention' variable from the FY 1999 USMC Retention Survey was not available for analysis due to technical problems (Kocher and Thomas, 2000), the FY 
1999 DoD Active Duty Survey of Members (Table 3.15) provides the following data regarding 'career intentions' of male and female personnel in E1-E4 of all services:

Table 3.15

FY 1999 DoD Active Duty Survey of Members

Likelihood of Choosing to Stay on Active Duty:

Members by Paygrade (E1-E3 and E-4)

\begin{tabular}{|l|c|c|}
\hline & $\begin{array}{c}\text { E1-E3 } \\
\mathrm{N}=240,461\end{array}$ & $\begin{array}{c}\text { E4 } \\
\mathrm{N}=279,565\end{array}$ \\
\hline $\begin{array}{l}\text { Unlikely/Very Unlikely } \\
\text { (Leave) }\end{array}$ & 50.0 & 48.2 \\
\hline $\begin{array}{l}\text { Neither likely or unlikely } \\
\text { (Undecided) }\end{array}$ & 21.5 & 16.3 \\
\hline Very Likely/Likely (Stay) & 28.5 & 35.5 \\
\hline
\end{tabular}

Source: DMDC, 2000

By contrasting the responses from Tables 3.14 and 3.15, we find that 59.39 percent of junior enlisted Marines said they intended to leave (Table 3.14) compared to 49.04 percent of E1E4s from all services (Table 3.15).

While on the surface these data seem to paint a very bleak picture for retention and development of the career enlisted force, the Marine Corps is unique in its career force manpower requirements. Unlike the other services, Marine Corps enlisted manpower requirements are more heavily weighted toward the junior enlisted ranks (E-2 through E-4). Thus, higher turnover (lower retention) compared to the other services is expected. Historically, the Marine Corps has successfully met recruiting goals and career force manning requirements. In fact, less than two months into the fiscal year, the First Term Alignment Plan (FTAP) for FY 2002 was 59 percent complete with 33 MOSs closed to new reenlistments (HQMC, 2001). So, should USMC leaders and retention planners care if almost 60 percent of junior enlisted Marines intend to leave the Marine Corps?

As discussed earlier in this thesis, the Marine Corps and all of the services invest millions of dollars annually in QOL programs based upon their contribution to readiness goals, including retention. A better understanding of the QOL programs that are perceived by junior enlisted Marines to influence the decision to stay or leave the Marine Corps can be valuable as the Marine Corps makes resource allocation decisions. Furthermore, commanders are required to meet FTAP reenlistment goals, resulting in all leaders being either directly or implicitly tasked with supporting retention efforts. While economic factors 
such as civilian job opportunities and the military-civilian pay gap are beyond the influence of most commanders and leaders, QOL domains such as working conditions are heavily influenced by leaders. The next section will evaluate the effect that QOL programs have on the retention decision of junior enlisted Marines.

\section{QOL Programs}

\section{a. MWR Program Availability}

As discussed previously in this thesis, the positive relationship expected between MWR programs and reenlistment behavior is supported by previous studies (Kerce, 1999; Koopman and Goldhaber, 1997). Overall, availability of MWR programs was ranked fifth (mean value of 4.28) amongst males and seventh (mean value of 4.38) amongst females of the 67 variables discussed in Tables 3.5 through 3.6.

Tables 3.16 through 3.19 provide information about what junior enlisted Marines had to say about MWR program availability. The availability of MWR programs is a broad measure that is intended to capture the influence that overall MWR programs, such as commissaries, exchanges, fitness centers, and auto-repair shops have on the decision to stay or leave the Marine Corps. Regardless of demographic makeup, junior enlisted Marines who expressed strong opinions (opinions other than 'no effect') responded that MWR program availability was an influence to stay. According to Table 3.16, males (33.0 percent) were slightly more likely than females (31.25 percent) to say that MWR program availability was an influence to stay. Table 3.17 shows that black males were more likely than black females (35.6 and 27.36 percent, respectively) to say that MWR program availability was an influence to stay. Table 3.17 also shows that Hispanic males and females had opinions that are similar to their black peers. According to Table 3.18, married males (36.9 percent) were more likely than married females ( 29.30 percent) to say that MWR program availability was an influence to stay. Finally, Table 3.19 shows that OCONUS junior enlisted Marines were more likely than CONUS-based junior enlisted Marines to say that MWR program availability was an influence to stay in the Marine Corps. There were no strong percentage differences between demographic categories concerning MWR program availability as an influence to leave. 
Table 3.16

QOL PROGRAMS

MWR Program Availability (V77): Gender

\begin{tabular}{|l|c|c|}
\hline & $\frac{\text { Male }(\mathbf{N}=\mathbf{6 7 6 5})}{\text { Percent }}$ & $\frac{\text { Female }(\mathbf{N}=\mathbf{7 2 3})}{\text { Percent }}$ \\
\hline Influence to Leave & 11.20 & 6.50 \\
\hline No effect & 55.73 & 62.24 \\
\hline Influence to Stay & 33.0 & 31.25 \\
\hline
\end{tabular}

Source: Author, Computed from FY 2001 USMC Retention Survey

Table 3.17

MWR Program Availability (V77) Cross-Tabulation Percentage:

Race

Male $(\mathrm{N}=6232)$, Female $(\mathrm{N}=649)$

\begin{tabular}{|l|c|c|c|c|c|c|}
\hline & \multicolumn{2}{|c|}{ White } & \multicolumn{2}{c|}{ Black } & \multicolumn{2}{c|}{ Hispanic } \\
& M & \multicolumn{1}{c|}{ M } & F & \multicolumn{1}{c|}{ M } & F \\
\hline $\begin{array}{l}\text { Influence to } \\
\text { Leave }\end{array}$ & 11.67 & 5.34 & 10.23 & 7.36 & 9.20 & 8.88 \\
\hline No Effect & 55.49 & 61.64 & 54.17 & 65.28 & 57.40 & 66.12 \\
\hline $\begin{array}{l}\text { Influence to } \\
\text { Stay }\end{array}$ & 32.84 & 33.02 & 35.6 & 27.36 & 33.4 & 25.0 \\
\hline
\end{tabular}

Source: Author, Computed from FY 2001 USMC Retention Survey

Table 3.18

MWR Program Availability (V77) Cross-Tabulation Percentage:

Marital Status

Male $(\mathrm{N}=6589)$, Female $(\mathrm{N}=668)$

\begin{tabular}{|l|c|c|c|c|}
\hline & \multicolumn{2}{|c|}{ Single } & \multicolumn{2}{c|}{ Married } \\
\hline Influence to Leave & 11.76 & 6.76 & 9.60 & 6.31 \\
\hline No Effect & 56.39 & 60.24 & 53.50 & 64.39 \\
\hline Influence to Stay & 31.85 & 33.0 & 36.90 & 29.30 \\
\hline
\end{tabular}

Source: Author, Computed from FY 2001 USMC Retention Survey 
Table 3.19

MWR Program Availability (V77) Cross-Tabulation Percentage:

Geographic Location (CONUS and OCONUS)

Male $(\mathrm{N}=6658)$, Female $(\mathrm{N}=714)$

\begin{tabular}{|c|c|c|c|c|}
\hline & \multicolumn{2}{|c|}{ CONUS } & \multicolumn{2}{c|}{ OCONUS } \\
\hline Influence to Leave & 11.0 & 5.95 & 12.40 & 10.09 \\
\hline No Effect & 56.70 & 64.15 & 50.80 & 52.30 \\
\hline Influence to Stay & 32.3 & 29.9 & 36.80 & 37.61 \\
\hline
\end{tabular}

Source: Author, Computed from FY 2001 USMC Retention Survey

\section{b. Availability of Day Care}

Tables 3.20 through 3.23 provide information about what junior enlisted Marines had to say about the availability of daycare services. Since approximately 30 percent of junior enlisted Marines are married and the majority of career Marines (E-5 and above) are married, the availability of day care is hypothesized to have a positive effect upon reenlistment intentions of junior enlisted Marines. According to Table 3.20, females (12.29 percent) were slightly more likely than males (9.93 percent) to say that the availability of day care was an influence to stay in the Marine Corps. Black males (16.19 percent, Table 3.21) were more likely than males or females of other races to say that the availability of day care was an influence to stay. As depicted by Table 3.22, of junior Marines who expressed an opinion, married males and females (23.61 percent and 33.33 percent, respectively) said that the availability of day care was an influence to leave. Furthermore, according to Table 3.23, the majority of CONUS-based females (21.45 percent) who have an opinion about the availability of day care perceived it as an influence to leave. These findings suggest that day care programs aboard or in the vicinity of USMC bases and stations may be perceived as not providing adequate service capacity expected by married junior enlisted Marines. What is not known from the data are the number of respondents that use day care facilities aboard USMC installations and their responses to this question. Kerce (1999) found that, of Marines and spouses who use the program, USMC day care facilities were amongst the highest rated in terms of impact upon quality of life. 
Table 3.20

QOL PROGRAMS

Availability of Day Care (V75): Gender

\begin{tabular}{|l|c|c|}
\hline & $\frac{\text { Male (N=6761) }}{\text { Percent }}$ & $\frac{\text { Female (N=724) }}{\text { Percent }}$ \\
\hline Influence to Leave & 9.21 & 9.93 \\
\hline No effect & 80.86 & 77.78 \\
\hline Influence to Stay & 9.93 & 12.29 \\
\hline
\end{tabular}

Source: Author, Computed from FY 2001 USMC Retention Survey

Table 3.21

Availability of Day Care (V75) Cross-Tabulation Percentage:

Race

Male $(\mathrm{N}=6232)$, Female $(\mathrm{N}=652)$

\begin{tabular}{|l|c|c|c|c|c|c|}
\hline & \multicolumn{2}{|c|}{ White } & \multicolumn{2}{c|}{ Black } & \multicolumn{2}{c|}{ Hispanic } \\
\hline $\begin{array}{l}\text { Influence to } \\
\text { Leave }\end{array}$ & 8.78 & 20.23 & 10.32 & 18.36 & 11.17 & 20.16 \\
\hline No Effect & 82.84 & 68.61 & 73.49 & 68.38 & 75.70 & 65.33 \\
\hline $\begin{array}{l}\text { Influence to } \\
\text { Stay }\end{array}$ & 8.38 & 11.16 & 16.19 & 13.26 & 13.12 & 14.51 \\
\hline
\end{tabular}

Source: Author, Computed from FY 2001 USMC Retention Survey

Table 3.22

Availability of Day Care (V75) Cross-Tabulation Percentage: Marital Status

Male $(\mathrm{N}=6584)$, Female $(\mathrm{N}=669)$

\begin{tabular}{|l|c|c|c|c|}
\hline & \multicolumn{2}{|c|}{ Single } & \multicolumn{2}{c|}{ Married } \\
\hline Influence to Leave & 3.45 & 9.77 & 23.61 & 33.33 \\
\hline No Effect & 88.93 & 79.21 & 60.47 & 53.34 \\
\hline Influence to Stay & 7.62 & 11.02 & 15.92 & 13.33 \\
\hline
\end{tabular}

Source: Author, Computed from FY 2001 USMC Retention Survey 
Table 3.23

Availability of Day Care (V75) Cross-Tabulation Percentage: Geographic Location (CONUS and OCONUS)

Male $(\mathrm{N}=6653)$, Female $(\mathrm{N}=716)$

\begin{tabular}{|c|c|c|c|c|}
\hline & \multicolumn{2}{|c|}{ CONUS } & \multicolumn{2}{c|}{ OCONUS } \\
\hline Influence to Leave & 9.24 & 21.45 & 4.70 & 7.27 \\
\hline No Effect & 80.73 & 66.18 & 85.89 & 81.83 \\
\hline Influence to Stay & 10.03 & 12.37 & 9.41 & 10.90 \\
\hline
\end{tabular}

Source: Author, Computed from FY 2001 USMC Retention Survey

c. QOL Programs: Availability of Family Support Services

Family support services consist primarily of family readiness programs offered through Marine Corps Family Team Building (MCFTB) like Key Volunteers and Lifestyle Insights, Networking, Knowledge, and Skills (LINKS). Family readiness programs exist because of their causal link between spousal career support and retention (Kerce, 1999). Kerce (1999) found that USMC deployment support programs were rated lowest in terms of impact upon QOL of program participants compared to other QOL programs. Since family support services are focused primarily upon Marines with family members (dependents), the responses of married Marines is of particular interest.

Tables 3.24 through 3.27 suggest that Family Support Services are perceived by junior enlisted Marines from all demographic categories that have an opinion as an influence to stay in the Marine Corps. Table 3.24 shows that females (23.72 percent) were more likely than males (19.92 percent) to say that the availability of family support services was an influence to stay. Black (26.5 percent) and Hispanic (26.6 percent) females were slightly more likely than white females (22.04 percent) to say that availability of family support services was an influence to stay (Table 3.25). As shown by Table 3.26, married males (36.77 percent) provided the strongest response that Family Support Services were perceived as an influence to stay. There were no strong differences between CONUS and OCONUS respondents (Table 3.27). 
Table 3.24

QOL PROGRAMS

Availability of Family Support Services (V76): Gender

\begin{tabular}{|l|c|c|}
\hline & $\frac{\text { Male (N=6764) }}{\text { Percent }}$ & $\frac{\text { Female (N=725) }}{\text { Percent }}$ \\
\hline Influence to Leave & 6.00 & 6.89 \\
\hline No effect & 74.08 & 69.39 \\
\hline Influence to Stay & 19.92 & 23.72 \\
\hline
\end{tabular}

Source: Author, Computed from FY 2001 USMC Retention Survey

Table 3.25

Availability of Family Support Services (V76) Cross-Tabulation Percentage:

Race

Male $(\mathrm{N}=6232)$, Female $(\mathrm{N}=653)$

\begin{tabular}{|l|c|c|c|c|c|c|}
\hline & \multicolumn{2}{|c|}{ White } & \multicolumn{2}{c|}{ Black } & \multicolumn{2}{c|}{ Hispanic } \\
& M & F & M & M & F \\
\hline Influence to & 5.62 & 6.49 & 6.6 & 7.14 & 7.0 & 8.06 \\
\hline No Effect & 75.91 & 71.47 & 69.08 & 66.36 & 68.30 & 65.34 \\
\hline $\begin{array}{l}\text { Influence to } \\
\text { Stay }\end{array}$ & 18.47 & 22.04 & 24.32 & 26.5 & 24.70 & 26.6 \\
\hline
\end{tabular}

Source: Author, Computed from FY 2001 USMC Retention Survey

Table 3.26

Availability of Family Support Services (V76) Cross-Tabulation Percentage:

Marital Status

Male $(\mathrm{N}=6586)$, Female $(\mathrm{N}=670)$

\begin{tabular}{|l|c|c|c|c|}
\hline & \multicolumn{2}{|c|}{ Single } & \multicolumn{2}{c|}{ Married } \\
& M & F & M & F \\
\hline Influence to Leave & 3.83 & 5.0 & 11.09 & 9.25 \\
\hline No Effect & 82.64 & 73.75 & 52.14 & 63.72 \\
\hline Influence to Stay & 13.53 & 21.25 & 36.77 & 27.03 \\
\hline
\end{tabular}

Source: Author, Computed from FY 2001 USMC Retention Survey 
Table 3.27

Availability of Family Support Services (V76) Cross-Tabulation Percentage: Geographic Location (CONUS and OCONUS)

Male $(\mathrm{N}=6658)$, Female $(\mathrm{N}=717)$

\begin{tabular}{|c|c|c|c|c|}
\hline & \multicolumn{2}{|c|}{ CONUS } & \multicolumn{2}{c|}{ OCONUS } \\
\hline Influence to Leave & 6.3 & 7.41 & 4.2 & 4.54 \\
\hline No Effect & 73.40 & 69.29 & 77.9 & 70.01 \\
\hline Influence to Stay & 20.3 & 23.3 & 17.9 & 25.45 \\
\hline
\end{tabular}

Source: Author, Computed from FY 2001 USMC Retention Survey

\section{d. QOL Programs: Your Family's Medical Care (V73)}

Due to the scope of this question, it is expected that married respondents will provide stronger responses than single respondents. The FY 1999 USMC Retention Survey (Kocher and Thomas, 2000) identified medical benefits as being a reason to stay for firstterm enlisted men and women. Tables 3.5 and 3.6, respectively, identify family medical care as the being the fourth highest ranked variable for men (mean=4.39) and women $($ mean=4.56).

Table 3.28 shows that females (40.22 percent) were more likely than males (32.56 percent) to say that family medical care was an influence to stay. According to Table 3.29, white females (41.99 percent) were more likely than Hispanic and black females (40.0 and 31.63 percent, respectively) to say that family medical care was an influence to stay. As shown in Table 3.30, married males (63.98 percent) and married females (56.45 percent) had the highest percentages of those who said that family medical care was an influence to stay. Ironically, married males (22.21 percent) and married females (20.29 percent) also responded that family medical care was an influence to leave. Table 3.31 shows that CONUS based junior enlisted Marines were more likely than OCONUS based peers to say that family medical care was an influence to stay. 
Table 3.28

QOL PROGRAMS

Your Family's Medical Care (V73): Gender

\begin{tabular}{|l|c|c|}
\hline & $\frac{\text { Male }(\mathbf{N}=6778)}{\text { Percent }}$ & $\frac{\text { Female (N=726) }}{\text { Percent }}$ \\
\hline Influence to Leave & 11.16 & 12.80 \\
\hline No effect & 56.28 & 46.98 \\
\hline Influence to Stay & 32.56 & 40.22 \\
\hline
\end{tabular}

Source: Author, Computed from FY 2001 USMC Retention Survey

Table 3.29

Your Family's Medical Care (V73) Cross-Tabulation Percentage:

Race

Male $(\mathrm{N}=6245)$, Female $(\mathrm{N}=654)$

\begin{tabular}{|l|c|c|c|c|c|c|}
\hline & \multicolumn{2}{|c|}{ White } & \multicolumn{2}{c|}{ Black } & \multicolumn{2}{c|}{ Hispanic } \\
& M & M & F & M & F \\
\hline $\begin{array}{l}\text { Influence to } \\
\text { Leave }\end{array}$ & 11.41 & 12.29 & 9.05 & 14.28 & 10.91 & 13.60 \\
\hline No Effect & 56.71 & 45.72 & 53.30 & 54.09 & 52.45 & 46.40 \\
\hline $\begin{array}{l}\text { Influence to } \\
\text { Stay }\end{array}$ & 31.88 & 41.99 & 37.65 & 31.63 & 36.64 & 40.0 \\
\hline
\end{tabular}

Source: Author, Computed from FY 2001 USMC Retention Survey

Table 3.30

Your Family's Medical Care (V73) Cross-Tabulation Percentage:

Marital Status

Male $(\mathrm{N}=6601)$, Female $(\mathrm{N}=671)$

\begin{tabular}{|l|c|c|c|c|}
\hline & \multicolumn{2}{|c|}{ Single } & \multicolumn{2}{c|}{ Married } \\
\hline Influence to Leave & 6.77 & 8.75 & 22.21 & 20.29 \\
\hline No Effect & 72.75 & 63.75 & 13.81 & 23.26 \\
\hline Influence to Stay & 20.48 & 27.50 & 63.98 & 56.45 \\
\hline
\end{tabular}

Source: Author, Computed from FY 2001 USMC Retention Survey 
Table 3.31

Your Family's Medical Care (V73) Cross-Tabulation Percentage: Geographic Location (CONUS and OCONUS) Male $(\mathrm{N}=6658)$, Female $(\mathrm{N}=717)$

\begin{tabular}{|c|c|c|c|c|}
\hline & \multicolumn{2}{|c|}{ CONUS } & \multicolumn{2}{c|}{ OCONUS } \\
& M & F & 7.21 & 6.36 \\
\hline Influence to Leave & 11.98 & 14.16 & 66.43 & 56.37 \\
\hline No Effect & 54.32 & 44.99 & 26.36 & 37.27 \\
\hline Influence to Stay & 33.70 & 40.85 & \\
\hline
\end{tabular}

Source: Author, Computed from FY 2001 USMC Retention Survey

e. QOL Programs: Family Dental Care (V74)

Similar to family medical care, family dental care also was highly ranked by both male and female junior enlisted Marines as an influence to stay (Tables 3.5 and 3.6). As shown by Table 3.32, females (39.11 percent) were slightly more likely than males (30.11 percent) to say that family dental care was an influence to stay. Table 3.33 shows that Hispanic (40.80 percent) and white females (39.90 percent) were more likely than black females (31.63 percent) to say that family dental care was an influence to stay. As expected, over 50 percent of married males and females said family dental care was an influence to stay in the Marine Corps (Table 3.34). Finally, CONUS-based junior enlisted Marines were more likely than their OCONUS based peers to say that family dental care was an influence to stay (Table 3.35).

Table 3.32

QOL PROGRAMS

Your Family's Dental Care (V74): Gender

\begin{tabular}{|l|c|c|}
\hline & $\frac{\text { Male }(\mathbf{N}=6777)}{\text { Percent }}$ & $\frac{\text { Female }(\mathbf{N}=\mathbf{7 2 6})}{\text { Percent }}$ \\
\hline Influence to Leave & 12.07 & 9.91 \\
\hline No effect & 57.82 & 50.98 \\
\hline Influence to Stay & 30.11 & 39.11 \\
\hline
\end{tabular}

Source: Author, Computed from FY 2001 USMC Retention Survey 
Table 3.33

Your Family's Dental Care (V74) Cross-Tabulation Percentage:

Race

Male $(\mathrm{N}=6244)$, Female $(\mathrm{N}=654)$

\begin{tabular}{|l|c|c|c|c|c|c|}
\hline & \multicolumn{2}{|c|}{ White } & \multicolumn{2}{c|}{ Black } & \multicolumn{2}{c|}{ Hispanic } \\
\hline $\begin{array}{l}\text { Influence to } \\
\text { Leave }\end{array}$ & 12.30 & 9.97 & 9.57 & 9.18 & 12.21 & 9.60 \\
\hline No Effect & 58.22 & 50.13 & 54.26 & 59.19 & 54.17 & 49.60 \\
\hline $\begin{array}{l}\text { Influence to } \\
\text { Stay }\end{array}$ & 29.48 & 39.90 & 36.17 & 31.63 & 33.62 & 40.80 \\
\hline
\end{tabular}

Source: Author, Computed from FY 2001 USMC Retention Survey

Table 3.34

Your Family's Dental Care (V74) Cross-Tabulation Percentage: Marital Status

Male $(\mathrm{N}=6600)$, Female $(\mathrm{N}=671)$

\begin{tabular}{|l|c|c|c|c|}
\hline & \multicolumn{2}{|c|}{ Single } & \multicolumn{2}{c|}{ Married } \\
\hline Influence to Leave & 6.56 & 6.25 & 26.23 & 16.23 \\
\hline No Effect & 72.98 & 67.25 & 18.85 & 28.42 \\
\hline Influence to Stay & 20.46 & 26.50 & 54.92 & 55.35 \\
\hline
\end{tabular}

Source: Author, Computed from FY 2001 USMC Retention Survey

Table 3.35

Your Family's Dental Care (V73) Cross-Tabulation Percentage: Geographic Location (CONUS and OCONUS) Male $(\mathrm{N}=6669)$, Female $(\mathrm{N}=717)$

\begin{tabular}{|c|c|c|c|c|}
\hline & \multicolumn{2}{|c|}{ CONUS } & \multicolumn{2}{c|}{ OCONUS } \\
\hline Influence to Leave & 12.93 & 11.20 & 7.67 & 3.63 \\
\hline No Effect & 56.06 & 49.43 & 66.90 & 58.19 \\
\hline Influence to Stay & 31.01 & 39.37 & 25.43 & 38.18 \\
\hline
\end{tabular}

Source: Author, Computed from FY 2001 USMC Retention Survey

\section{f. QOL Programs: Voluntary Education}

Voluntary education has been shown by numerous researchers to be a program of great importance to most military personnel. Garcia (1998) found that voluntary education programs were cost effective in retaining personnel compared to similar increases 
in accession and training costs. Kerce (1999) found that 32.4 percent of voluntary education program participants surveyed indicated that the program had a "great impact" on intentions to reenlist. However, the FY 1999 USMC Retention Survey (Kocher and Thomas, 2000) found that education benefits were chosen by male and female first-term enlisted as a reason to leave the Marine Corps.

(1) Quality of education benefits. 'Quality of Education Benefits' was the highest ranked variable for FY 2001 USMC Retention Survey female junior enlisted respondents (mean=4.81, Table 3.6). This variable was also ranked in the 'top ten' for mean value by male junior enlisted Marines (mean=4.25, Table 3.5). The 'opportunity for offduty education' was also a highly ranked variable (mean=4.33, Table 3.6 ) for female junior enlisted respondents.

As shown by Table 3.36 , females (62.68 percent) were more likely than males (46.27 percent) to say that the quality of education benefits are an influence to stay. Black males (56.36 percent, Table 3.37 ) were more likely than Hispanic and white males (49.07 and 44.35 percent, respectively) to say that the quality of education benefits are an influence to stay. Table 3.38 shows that single females (64.35 percent) were more likely than married females (57.62 percent) to say that the quality of education benefits was an influence to stay in the Marine Corps. As depicted by Table 3.39, OCONUS males and females (50.55 and 69.36 percent, respectively) were more likely than CONUS males and females (45.50 and 61.08 percent, respectively) to say that the quality of education benefits are an influence to stay. While this variable was viewed by most respondents as an "influence to stay," a higher percentage of males (26.31 percent, Table 3.36) responded that this variable was an influence to leave than females (16.87 percent, Table 3.36).

Table 3.36

QOL PROGRAMS

Quality of Education Benefits (V85): Gender

\begin{tabular}{|l|c|c|}
\hline & $\frac{\text { Male (N=6786) }}{\text { Percent }}$ & $\frac{\text { Female (N=729) }}{\text { Percent }}$ \\
\hline Influence to Leave & 26.31 & 16.87 \\
\hline No effect & 27.42 & 20.45 \\
\hline Influence to Stay & 46.27 & 62.68 \\
\hline
\end{tabular}

Source: Author, Computed from FY 2001 USMC Retention Survey 
Table 3.37

Quality of Education Benefits (V85) Cross-Tabulation Percentage:

Race

Male $(\mathrm{N}=6251)$, Female $(\mathrm{N}=656)$

\begin{tabular}{|l|c|c|c|c|c|c|}
\hline & \multicolumn{2}{|c|}{ White } & \multicolumn{2}{c|}{ Black } & \multicolumn{2}{c|}{ Hispanic } \\
& M & F & M & F & \multicolumn{1}{c|}{ M } \\
\hline $\begin{array}{l}\text { Influence to } \\
\text { Leave }\end{array}$ & 27.01 & 17.59 & 19.43 & 11.11 & 25.7 & 20.0 \\
\hline No Effect & 28.64 & 21.07 & 24.21 & 20.21 & 25.23 & 20.80 \\
\hline $\begin{array}{l}\text { Influence to } \\
\text { Stay }\end{array}$ & 44.35 & 61.34 & 56.36 & 68.68 & 49.07 & 59.20 \\
\hline
\end{tabular}

Source: Author, Computed from FY 2001 USMC Retention Survey

Table 3.38

Quality of Education Benefits (V85): Cross-Tabulation Percentage Marital Status

Male $(\mathrm{N}=6608)$, Female $(\mathrm{N}=673)$

\begin{tabular}{|l|c|c|c|c|}
\hline & \multicolumn{2}{|c|}{ Single } & \multicolumn{2}{c|}{ Married } \\
\hline Influence to Leave & 27.49 & 16.83 & 23.62 & 17.84 \\
\hline No Effect & 27.46 & 18.82 & 26.67 & 24.54 \\
\hline Influence to Stay & 45.05 & 64.35 & 49.71 & 57.62 \\
\hline
\end{tabular}

Source: Author, Computed from FY 2001 USMC Retention Survey

Table 3.39

Quality of Education Benefits (V85): Cross-Tabulation Percentage Geographic Location (CONUS and OCONUS)

Male $(\mathrm{N}=6677)$, Female $(\mathrm{N}=\mathbf{7 2 0})$

\begin{tabular}{|c|c|c|c|c|}
\hline & \multicolumn{2}{|c|}{ CONUS } & \multicolumn{2}{c|}{ OCONUS } \\
\hline Influence to Leave & 26.75 & 16.91 & 23.57 & 18.01 \\
\hline No Effect & 27.75 & 22.01 & 25.88 & 12.63 \\
\hline Influence to Stay & 45.50 & 61.08 & 50.55 & 69.36 \\
\hline
\end{tabular}

Source: Author, Computed from FY 2001 USMC Retention Survey 
(2) Availability of education benefits (V86). Responses

to the availability of education benefits were similar to responses to the quality of education benefits. As depicted by Tables 3.40 through 3.43, the quality and availability of education benefits is a strong influence for junior enlisted Marines, particularly females, to stay in the Marine Corps. According to Table 3.40, 54.81 percent of females said that the availability of education benefits was an influence to stay. Male junior enlisted Marines were essentially split concerning the availability of education benefits, with about 39 percent (Table 3.40) saying it was an influence to stay and 34 percent (Table 3.40) that it was an influence to leave. According to Table 3.41, black males (51.50 percent) were more likely than white males (36.96 percent) to say that the availability of education benefits was an influence to stay. As depicted by Table 3.42, single females (58.96 percent) were more likely than married females (47.78) to say that availability of education benefits was an influence to stay. Table 3.43 suggests that OCONUS males and females were slightly more likely than OCONUS counterparts to choose availability of education benefits as an influence to stay in the Marine Corps.

Table 3.40

QOL PROGRAMS

Availability of Education Benefits (V86): Gender

\begin{tabular}{|l|c|c|}
\hline & $\frac{\text { Male }(\mathbf{N}=6772)}{\text { Percent }}$ & $\frac{\text { Female }(\mathbf{N}=\mathbf{7 2 8})}{\text { Percent }}$ \\
\hline Influence to Leave & 34.2 & 23.21 \\
\hline No effect & 25.96 & 21.98 \\
\hline Influence to Stay & 39.84 & 54.81 \\
\hline
\end{tabular}

Source: Author, Computed from FY 2001 USMC Retention Survey 
Table 3.41

Availability of Education Benefits (V86) Cross-Tabulation Percentage:

Race

Male $(\mathrm{N}=6237)$, Female $(\mathrm{N}=655)$

\begin{tabular}{|l|c|c|c|c|c|c|}
\hline & \multicolumn{2}{|c|}{ White } & \multicolumn{2}{c|}{ Black } & \multicolumn{2}{c|}{ Hispanic } \\
& M & \multicolumn{1}{c|}{ M } & F & M & F \\
\hline $\begin{array}{l}\text { Influence to } \\
\text { Leave }\end{array}$ & 36.27 & 24.36 & 22.83 & 19.19 & 31.39 & 25.60 \\
\hline No Effect & 26.77 & 25.06 & 25.66 & 15.15 & 24.13 & 18.40 \\
\hline $\begin{array}{l}\text { Influence to } \\
\text { Stay }\end{array}$ & 36.96 & 50.58 & 51.50 & 65.66 & 44.48 & 56.0 \\
\hline
\end{tabular}

Source: Author, Computed from FY 2001 USMC Retention Survey

Table 3.42

Availability of Education Benefits (V86): Cross-Tabulation Percentage Marital Status

Male $(\mathrm{N}=6595)$, Female $(\mathrm{N}=672)$

\begin{tabular}{|l|c|c|c|c|}
\hline & \multicolumn{2}{|c|}{ Single } & \multicolumn{2}{c|}{ Married } \\
\hline Influence to Leave & 34.83 & 23.63 & 32.62 & 22.22 \\
\hline No Effect & 26.21 & 17.41 & 25.00 & 30.0 \\
\hline Influence to Stay & 38.96 & 58.96 & 42.38 & 47.78 \\
\hline
\end{tabular}

Source: Author, Computed from FY 2001 USMC Retention Survey

Table 3.43

Availability of Education Benefits (V86): Cross-Tabulation Percentage

Geographic Location (CONUS and OCONUS)

Male $(\mathrm{N}=6663)$, Female $(\mathrm{N}=720)$

\begin{tabular}{|c|c|c|c|c|}
\hline & \multicolumn{2}{|c|}{ CONUS } & \multicolumn{2}{c|}{ OCONUS } \\
\hline Influence to Leave & 34.6 & 22.3 & 31.4 & 29.0 \\
\hline No Effect & 26.1 & 24.1 & 25.4 & 12.0 \\
\hline Influence to Stay & 39.3 & 53.6 & 43.2 & 59.0 \\
\hline
\end{tabular}

Source: Author, Computed from FY 2001 USMC Retention Survey

a. QOL Program: Military Housing

Military housing consumes the most money of any QOL program, costing DoD nearly \$10 billion annually (Buddin, Gresenz, Hosek, Elliott, Dawson, 1999). Military 
housing has been identified by numerous political and military leaders as a QOL program that has been allowed to deteriorate due to under funding and other resource constraints. As shown by Tables 3.44 through 3.47, junior enlisted Marines were more likely to say that the availability of military housing has no effect upon their reenlistment decision. However, Tables 3.48 through 3.51 suggest that most junior enlisted Marines are dissatisfied with the quality of military housing.

1. Availability of military housing (V64).

Table 3.44

QOL PROGRAMS: Military Housing Availability of Military Housing (V64): Gender

\begin{tabular}{|l|c|c|}
\hline & $\frac{\text { Male (N=6791) }}{\text { Percent }}$ & $\frac{\text { Female (N=734) }}{\text { Percent }}$ \\
\hline Influence to Leave & 35.56 & 36.23 \\
\hline No effect & 49.60 & 51.10 \\
\hline Influence to Stay & 14.84 & 12.67 \\
\hline
\end{tabular}

Source: Author, Computed from FY 2001 USMC Retention Survey

Table 3.45

Availability of Military Housing (V64): Cross-Tabulation Percentage

Race

Male $(\mathrm{N}=6257)$, Female $(\mathrm{N}=660)$

\begin{tabular}{|l|c|c|c|c|c|c|}
\hline & \multicolumn{2}{|c|}{ White } & \multicolumn{2}{c|}{ Black } & \multicolumn{2}{c|}{ Hispanic } \\
& M & F & M & F & M & F \\
\hline $\begin{array}{l}\text { Influence } \\
\text { to Leave }\end{array}$ & 34.98 & 33.41 & 35.81 & 33.33 & 36.94 & 44.09 \\
\hline No Effect & 51.08 & 54.15 & 46.11 & 52.53 & 46.60 & 54.32 \\
\hline $\begin{array}{l}\text { Influence } \\
\text { to Stay }\end{array}$ & 13.94 & 12.44 & 18.08 & 14.14 & 16.46 & 10.23 \\
\hline
\end{tabular}

Source: Author, Computed from FY 2001 USMC Retention Survey 
Table 3.46

Availability of Military Housing (V64): Cross-Tabulation Percentage

Marital Status

Male $(\mathrm{N}=6614)$, Female $(\mathrm{N}=678)$

\begin{tabular}{|l|c|c|c|c|}
\hline & \multicolumn{2}{|c|}{ Single } & \multicolumn{2}{c|}{ Married } \\
\hline Influence to Leave & 34.87 & 36.45 & 37.73 & 36.76 \\
\hline No Effect & 50.70 & 47.55 & 46.43 & 55.52 \\
\hline Influence to Stay & 14.43 & 16.00 & 15.84 & 7.72 \\
\hline
\end{tabular}

Source: Author, Computed from FY 2001 USMC Retention Survey

Table 3.47

Availability of Military Housing (V64): Cross-Tabulation Percentage

Geographic Location (CONUS and CONUS)

Male $(\mathrm{N}=6685)$, Female $(\mathrm{N}=725)$

\begin{tabular}{|c|c|c|c|c|}
\hline & \multicolumn{2}{|c|}{ CONUS } & \multicolumn{2}{c|}{ OCONUS } \\
\hline Influence to Leave & 35.59 & 35.66 & 35.54 & 33.33 \\
\hline No Effect & 49.70 & 53.76 & 49.55 & 43.25 \\
\hline Influence to Stay & 14.71 & 10.58 & 14.91 & 23.42 \\
\hline
\end{tabular}

Source: Author, Computed from FY 2001 USMC Retention Survey

Overall, males and females from all demographic groups, who did not fall into the 'no effect' category, were more likely to say that the availability of military housing was an influence to leave than an influence to stay. A more complete picture of the impact military housing has on the retention intentions of junior enlisted Marines can be determined when the quality of military housing is also examined.

(2) Quality of military housing (V65). Compared with availability of military housing (V65), quality of military housing (V65) was a stronger influence to leave for junior enlisted Marines of all demographic types. As depicted by Table 3.48 , both males (58.05 percent) and females ( 57.90 percent) considered the quality of military housing to be an influence to leave. Further, Table 3.49 states that white males (59.96 percent) were more likely than Hispanic and black males (53.83 and 49.47 percent, respectively) to say that the quality of military housing was an influence to leave. As shown in Table 3.50, single males (60.32 percent) and females (61.48 percent) were more likely than their married peers (51.99 and 53.47 percent, respectively) to say that 
the quality of military housing is an influence to leave. Table 3.51 states that OCONUS males and females were more likely (60.93 and 60.36 percent, respectively) than CONUS counterparts (51.29 and 57.65, respectively) to say that the quality of military housing is an influence to leave.

Since the majority of survey respondents are single and reside in the barracks, the data presented in Tables 3.44 through 3.51 should be considered with respect to the fact that single members are likely to consider the barracks (bachelor enlisted quarters) and married Marines are considering the availability and quality of married enlisted quarters when responding to these questions.

Table 3.48

QOL PROGRAMS: Military Housing Quality of Military Housing (V65): Gender

\begin{tabular}{|l|c|c|}
\hline & $\frac{\text { Male (N=6793) }}{\text { Percent }}$ & $\frac{\text { Female (N=734) }}{\text { Percent }}$ \\
\hline Influence to Leave & 58.05 & 57.90 \\
\hline No effect & 28.51 & 31.89 \\
\hline Influence to Stay & 13.44 & 10.21 \\
\hline
\end{tabular}

Source: Author, Computed from FY 2001 USMC Retention Survey

Table 3.49

Quality of Military Housing (V65): Cross-Tabulation Percentage

Race

Male $(\mathrm{N}=6259)$, Female $(\mathrm{N}=660)$

\begin{tabular}{|l|c|c|c|c|c|c|}
\hline & \multicolumn{2}{|c|}{ White } & \multicolumn{2}{c|}{ Black } & \multicolumn{2}{c|}{ Hispanic } \\
& M & F & M & F & M & F \\
\hline $\begin{array}{l}\text { Influence to } \\
\text { Leave }\end{array}$ & 59.96 & 55.86 & 49.47 & 50.00 & 53.83 & 65.35 \\
\hline No Effect & 27.04 & 33.57 & 35.34 & 38.78 & 32.12 & 25.99 \\
\hline $\begin{array}{l}\text { Influence to } \\
\text { Stay }\end{array}$ & 13.0 & 10.57 & 15.19 & 11.22 & 14.05 & 8.66 \\
\hline
\end{tabular}

Source: Author, Computed from FY 2001 USMC Retention Survey 
Table 3.50

Quality of Military Housing (V65): Cross-Tabulation Percentage

Marital Status

Male $(\mathrm{N}=6615)$, Female $(\mathrm{N}=678)$

\begin{tabular}{|l|c|c|c|c|}
\hline & \multicolumn{2}{|c|}{ Single } & \multicolumn{2}{c|}{ Married } \\
\hline Influence to Leave & 60.32 & 61.48 & 51.99 & 53.47 \\
\hline No Effect & 26.03 & 25.44 & 34.88 & 41.04 \\
\hline Influence to Stay & 13.65 & 13.08 & 13.13 & 5.49 \\
\hline
\end{tabular}

Source: Author, Computed from FY 2001 USMC Retention Survey

Table 3.51

Quality of Military Housing (V65): Cross-Tabulation Percentage Geographic Location (CONUS and OCONUS) Male $(\mathrm{N}=6685)$, Female $(\mathrm{N}=725)$

\begin{tabular}{|c|c|c|c|c|}
\hline & \multicolumn{2}{|c|}{ CONUS } & \multicolumn{2}{c|}{ OCONUS } \\
\hline Influence to Leave & 51.29 & 57.65 & 60.93 & 60.36 \\
\hline No Effect & 35.37 & 32.75 & 25.38 & 26.14 \\
\hline Influence to Stay & 13.34 & 9.60 & 13.69 & 13.50 \\
\hline
\end{tabular}

Source: Author, Computed from FY 2001 USMC Retention Survey

Overall, with the exception of military housing, QOL programs were viewed as influences to stay in the Marine Corps by most junior enlisted Marines. QOL domains will be analyzed in the following sections.

\section{QOL Domains}

\section{a. QOL Domain: Leadership}

1. Your commitment to subordinates (V25). Taking care

of subordinates is viewed by many as the cornerstone of sound leadership. Though most of the Marines included in this analysis are technically not in supervisory positions, all Marines are taught from the first day of boot camp or OCS that the 'senior' Marine, whether a private-first class (E2) or colonel (06), is in charge. In fact, the Marine Corps has a proud history of PFCs that were given 'battlefield promotions' due to combat attrition and served magnificently as squad leaders (normally filled by an E-5, sergeant) and in other tactical leadership positions. All Marines are considered leaders upon receipt of the 'eagle, globe, 
and anchor' (USMC emblem) since they will invariably be responsible for accomplishing a broad range of tasks by leading other Marines. Thus, it is no surprise that 'commitment to subordinates' ranked highly amongst males (Table 3.5, mean=4.71) and females (Table 3.6, mean=4.56).

As shown by Table 3.52, males (48.12 percent) and females (42.93) were somewhat close in saying that their commitment to subordinates was an influence to stay in the Marine Corps. Hispanic males (49.45 percent, Table 3.53) were slightly more likely than white males (48.51 percent, Table 3.53) and black males (41.0 percent, Table 3.53) to say that their commitment to subordinates was an influence to stay in the Marine Corps. White females (44.83 percent) were slightly more likely than Hispanic females (43.75 percent) to say that their commitment to subordinates was an influence to stay. Table 3.54 states that married males (50.25 percent) were more likely than single males (47.23 percent) to say that their commitment to subordinates was an influence to stay. Table 3.55 depicts that OCONUS males and females are more likely than CONUS males and females to say that their commitment to subordinates was an influence to stay.

Table 3.52

QOL DOMAIN: Leadership

Your Commitment to Subordinates (V25): Gender

\begin{tabular}{|l|c|c|}
\hline & $\frac{\text { Male }(\mathbf{N}=6737)}{\text { Percent }}$ & $\frac{\text { Female (N=722) }}{\text { Percent }}$ \\
\hline Influence to Leave & 8.26 & 10.52 \\
\hline No effect & 43.62 & 46.55 \\
\hline Influence to Stay & 48.12 & 42.93 \\
\hline
\end{tabular}

Source: Author, Computed from FY 2001 USMC Retention Survey 
Table 3.53

Commitment to Subordinates (V25): Cross-Tabulation Percentage

Gender by Race

Male $(\mathrm{N}=6203)$, Female $(\mathrm{N}=650)$

\begin{tabular}{|l|c|c|c|c|c|c|}
\hline & \multicolumn{2}{|c|}{ White } & \multicolumn{2}{c|}{ Black } & \multicolumn{2}{c|}{ Hispanic } \\
& M & F & \multicolumn{2}{c|}{ M } & M & F \\
\hline $\begin{array}{l}\text { Influence to } \\
\text { Leave }\end{array}$ & 7.74 & 9.38 & 11.15 & 10.41 & 9.14 & 13.28 \\
\hline No Effect & 43.75 & 45.79 & 47.85 & 50.01 & 41.41 & 42.97 \\
\hline $\begin{array}{l}\text { Influence to } \\
\text { Stay }\end{array}$ & 48.51 & 44.83 & 41.0 & 39.58 & 49.45 & 43.75 \\
\hline
\end{tabular}

Source: Author, Computed from FY 2001 USMC Retention Survey

Table 3.54

Commitment to Subordinates (V25): Cross-Tabulation Percentage

Gender by Marital Status

Male $(\mathrm{N}=6562)$, Female $(\mathrm{N}=667)$

\begin{tabular}{|l|c|c|c|c|}
\hline & \multicolumn{2}{|c|}{ Single } & \multicolumn{2}{c|}{ Married } \\
\hline Influence to Leave & 8.31 & 10.02 & 7.81 & 12.31 \\
\hline No Effect & 44.46 & 47.38 & 41.94 & 47.40 \\
\hline Influence to Stay & 47.23 & 42.60 & 50.25 & 40.29 \\
\hline
\end{tabular}

Source: Author, Computed from FY 2001 USMC Retention Survey

Table 3.55

Commitment to Subordinates (V25): Cross-Tabulation Percentage Geographic Location (CONUS and OCONUS)

Male $(\mathrm{N}=6629)$, Female $(\mathrm{N}=712)$

\begin{tabular}{|c|c|c|c|c|}
\hline & \multicolumn{2}{|c|}{ CONUS } & \multicolumn{2}{c|}{ OCONUS } \\
\hline Influence to Leave & 8.59 & 10.61 & 6.59 & 10.09 \\
\hline No Effect & 44.11 & 47.77 & 41.09 & 40.37 \\
\hline Influence to Stay & 47.30 & 41.62 & 52.32 & 49.54 \\
\hline
\end{tabular}

Source: Author, Computed from FY 2001 USMC Retention Survey 
(2) Trust in Marine leadership (V24). Trust is universally considered a key component of leadership. If a leader has not earned the trust of subordinates, then he or she is not likely to be effective. The majority of males and female junior enlisted Marines responded that trust in Marine leadership was an influence to leave.

Overall, trust in Marine leadership was the lowest performing variable for females (Table 3.6) and second lowest performer (Table 3.5) for males within the leadership domain as an influence to stay.

According to Table 3.56, females (52.8 percent) were more inclined to say that their trust in Marine leadership was a reason to leave the Marine Corps than males (40.6 percent). Table 3.57 shows that Hispanic (35.7 percent) and black (37.8 percent) males were less likely than white males ( 42.4 percent) to say that their trust in Marine leadership was an influence to leave. As shown by Table 3.57, 55.1 percent of black females and 53.8 percent of white females said that trust in Marine leadership was an influence to leave. Females across each marital status category were more likely than male peers to say that Marine leadership was an influence to leave (Table 3.58). Finally, as depicted by Table 3.59, OCONUS-based males and females (39.2 and 54.9 percent, respectively) were more likely than CONUS-based males and females (36.2 and 52.6 percent, respectively) to say that trust in Marine leadership was an influence to leave the Marine Corps.

Table 3.56

QOL Domain: Leadership Trust in Marine Leadership (V24): Gender

\begin{tabular}{|l|c|c|}
\hline & $\frac{\text { Male }(\mathbf{N}=6747)}{\text { Percent }}$ & $\frac{\text { Female (N=723) }}{\text { Percent }}$ \\
\hline Influence to Leave & 40.6 & 52.8 \\
\hline No effect & 28.99 & 23.6 \\
\hline Influence to Stay & 30.41 & 23.6 \\
\hline
\end{tabular}

Source: Author, Computed from FY 2001 USMC Retention Survey 
Table 3.57

Trust in Marine Leadership (V24): Cross-Tabulation Percentage Gender by Race

Male $(\mathrm{N}=6214)$, Female $(\mathrm{N}=650)$

\begin{tabular}{|l|c|c|c|c|c|c|}
\hline & \multicolumn{2}{|c|}{ White } & \multicolumn{2}{c|}{ Black } & \multicolumn{2}{c|}{ Hispanic } \\
& M & F & \multicolumn{1}{c|}{ M } & M & F \\
\hline $\begin{array}{l}\text { Influence to } \\
\text { Leave }\end{array}$ & 42.4 & 53.8 & 37.8 & 55.1 & 35.7 & 50.4 \\
\hline No Effect & 28.5 & 22.60 & 33.1 & 29.60 & 28.40 & 21.60 \\
\hline $\begin{array}{l}\text { Influence to } \\
\text { Stay }\end{array}$ & 29.1 & 23.6 & 29.1 & 15.3 & 35.9 & 28.0 \\
\hline
\end{tabular}

Source: Author, Computed from FY 2001 USMC Retention Survey

Table 3.58

Trust in Marine Leadership (V24): Cross-Tabulation Percentage Gender by Marital Status Male $(\mathrm{N}=6571)$, Female $(\mathrm{N}=669)$

\begin{tabular}{|l|c|c|c|c|}
\hline & \multicolumn{2}{|c|}{ Single } & \multicolumn{2}{c|}{ Married } \\
\hline Influence to Leave & 40.8 & 52.7 & 39.4 & 53.5 \\
\hline No Effect & 28.70 & 22.60 & 30.10 & 26.10 \\
\hline Influence to Stay & 30.5 & 24.7 & 30.5 & 20.4 \\
\hline
\end{tabular}

Source: Author, Computed from FY 2001 USMC Retention Survey

Table 3.59

Trust in Marine Leadership (V24): Cross-Tabulation Percentage Geographic Location (CONUS and OCONUS)

Male $(\mathrm{N}=6638)$, Female $(\mathrm{N}=713)$

\begin{tabular}{|c|c|c|c|c|}
\hline & \multicolumn{2}{|c|}{ CONUS } & \multicolumn{2}{c|}{ OCONUS } \\
\hline Influence to Leave & 36.2 & 52.6 & 39.2 & 54.9 \\
\hline No Effect & 34.1 & 24.40 & 27.50 & 18.10 \\
\hline Influence to Stay & 29.7 & 23.0 & 33.3 & 27.0 \\
\hline
\end{tabular}

Source: Author, Computed from FY 2001 USMC Retention Survey

b. QOL Domain: Career

(1) Job security (V27). Job security has historically been considered a reason to join the military. Unlike civilians, military personnel cannot be 'fired' or layed-off (unless punished under the Uniform Code of Military Justice) before the end of 
the member's service obligation. According to respondents in the 1999 Survey of Active Duty Personnel (DMDC, 2000), approximately 70 percent of soldiers, sailors, airmen, and Marines in paygrades E-1 through E-5 were satisfied with job security. Job security (V27) was the highest ranked variable (mean=4.8, Table 3.5) for males and second highest ranked variable (mean=4.81, Table 3.6) for females that participated in the FY 2001 USMC Retention Survey.

As depicted in tables 3.60 through 3.63, the majority of males and females of all demographic backgrounds responded that job security was an influence to stay. Table 3.60 shows that males (53.39 percent) and females (53.75 percent) were similar in responding that job security was an influence to stay in the Marine Corps. Table 3.61 shows that white (54.18 percent) and Hispanic (53.40 percent) males were more likely than black males (48.55 percent) to say that job security was an influence to stay. White females (54.96 percent) and black females (51.02 percent) were more likely than Hispanic females (48.43 percent) to say that job security was an influence to stay (Table 3.61). Married (59.42 percent) males were more likely than single males (51.05 percent) to say that job security was an influence to stay (Table 3.62). There were no real differences between CONUS and OCONUS respondents (Table 3.63).

Table 3.60

QOL DOMAIN: Career Job Security (V27): Gender

\begin{tabular}{|l|c|c|}
\hline & $\frac{\text { Male (N=6811) }}{\text { Percent }}$ & $\frac{\text { Female (N=733) }}{\text { Percent }}$ \\
\hline Influence to Leave & 10.92 & 13.09 \\
\hline No effect & 35.69 & 33.16 \\
\hline Influence to Stay & 53.39 & 53.75 \\
\hline
\end{tabular}

Source: Author, Computed from FY 2001 USMC Retention Survey 
Table 3.61

Job Security (V27): Cross-Tabulation Percentage

Gender by Race

Male $(\mathrm{N}=6274)$, Female $(\mathrm{N}=659)$

\begin{tabular}{|l|c|c|c|c|c|c|}
\hline & \multicolumn{2}{|c|}{ White } & \multicolumn{2}{c|}{ Black } & \multicolumn{2}{c|}{ Hispanic } \\
& M & \multicolumn{1}{c|}{ M } & M & F \\
\hline $\begin{array}{l}\text { Influence to } \\
\text { Leave }\end{array}$ & 10.48 & 12.93 & 12.30 & 13.26 & 12.10 & 17.18 \\
\hline No Effect & 35.44 & 32.11 & 39.15 & 35.72 & 34.50 & 34.39 \\
\hline $\begin{array}{l}\text { Influence to } \\
\text { Stay }\end{array}$ & 54.18 & 54.96 & 48.55 & 51.02 & 53.40 & 48.43 \\
\hline
\end{tabular}

Source: Author, Computed from FY 2001 USMC Retention Survey

Table 3.62

Job Security (V27): Cross-Tabulation Percentage

Gender by Marital Status

Male $(\mathrm{N}=6634)$, Female $(\mathrm{N}=677)$

\begin{tabular}{|l|c|c|c|c|}
\hline & \multicolumn{2}{|c|}{ Single } & \multicolumn{2}{c|}{ Married } \\
\hline Influence to Leave & 11.31 & 14.56 & 9.87 & 9.92 \\
\hline No Effect & 37.64 & 31.12 & 30.71 & 37.88 \\
\hline Influence to Stay & 51.05 & 54.32 & 59.42 & 52.20 \\
\hline
\end{tabular}

Source: Author, Computed from FY 2001 USMC Retention Survey

Table 3.63

Job Security (V27): Cross-Tabulation Percentage

Geographic Location (CONUS and OCONUS)

Male $(\mathrm{N}=6702)$, Female $(\mathrm{N}=724)$

\begin{tabular}{|c|c|c|c|c|}
\hline & \multicolumn{2}{|c|}{ CONUS } & \multicolumn{2}{c|}{ OCONUS } \\
\hline Influence to Leave & 11.04 & 13.70 & 10.09 & 10.0 \\
\hline No Effect & 35.81 & 32.63 & 35.14 & 37.28 \\
\hline Influence to Stay & 53.15 & 53.67 & 54.77 & 52.72 \\
\hline
\end{tabular}

Source: Author, Computed from FY 2001 USMC Retention Survey

(2) Time away from home (V32). Time away from home (V32)

received the lowest mean score (2.7, Table 3.5) of all survey variables for male junior enlisted Marines and was the second lowest scoring variable (2.87, Table 3.6) for females as an influence to stay. This variable is a component of PERSTEMPO (personnel tempo), 
which has been shown in numerous studies to be a factor in reenlistment decisions. Perstempo, in principle, has many dimensions, such as hours of work per day, days per week, weeks per year, hours on alert, and work per hour. (Hosek and Totten, 1998) Too much or too little deployed time can be an influence to leave the service. According to Hosek and Totten (1998), deployments of less than three months duration increases reenlistment among first-term Marine Corps personnel. However, adding an additional deployment atop the first, such as another three months away from home, reduces the likelihood of reenlistment (Hosek and Totten, 1998). Thus, workload distribution (V60) and time away from home (V32) can provide valuable insights into the effect that PERSTEMPO has upon the reenlistment intentions of junior enlisted Marines.

As depicted by Tables 3.64 through 3.67, about 60 percent of males and females in all demographic categories chose time away from home (V32) as an influence to leave the Marine Corps. Table 3.66 depicts married males and females (68.18 and 65.92 percent, respectively) as more likely than single (60.88 and 55.80 percent, respectively) males and females to say that time away from home was an influence to leave. Table 3.67 shows that CONUS males and females (63.20 and 60.06 percent, respectively) were more likely than OCONUS males and females (59.32 and 52.25 percent, respectively) to say that time away from home was an influence to leave.

Table 3.64

QOL DOMAIN: Career Time Away from Home (V32): Gender

\begin{tabular}{|l|c|c|}
\hline & $\frac{\text { Male }(\mathbf{N}=\mathbf{6 8 0 5})}{\text { Percent }}$ & $\frac{\text { Female }(\mathbf{N}=\mathbf{7 3 1})}{\text { Percent }}$ \\
\hline Influence to Leave & 62.73 & 58.68 \\
\hline No effect & 31.10 & 34.35 \\
\hline Influence to Stay & 6.17 & 6.97 \\
\hline
\end{tabular}

Source: Author, Computed from FY 2001 USMC Retention Survey 
Table 3.65

Time Away from Home (V32): Cross-Tabulation Percentage Gender by Race Male $(\mathrm{N}=6430)$, Female $(\mathrm{N}=657)$

\begin{tabular}{|l|c|c|c|c|c|c|}
\hline & \multicolumn{2}{|c|}{ White } & \multicolumn{2}{c|}{ Black } & \multicolumn{2}{c|}{ Hispanic } \\
& M & F & M & M & F \\
\hline $\begin{array}{l}\text { Influence to } \\
\text { Leave }\end{array}$ & 63.52 & 59.06 & 58.73 & 58.58 & 63.67 & 61.71 \\
\hline No Effect & 30.37 & 33.97 & 33.34 & 36.37 & 30.61 & 32.04 \\
\hline $\begin{array}{l}\text { Influence to } \\
\text { Stay }\end{array}$ & 6.11 & 6.97 & 7.93 & 5.05 & 5.72 & 6.25 \\
\hline
\end{tabular}

Source: Author, Computed from FY 2001 USMC Retention Survey

Table 3.66

Time Away from Home (V32): Cross-Tabulation Percentage Gender by Marital Status Male $(\mathrm{N}=6629)$, Female $(\mathrm{N}=675)$

\begin{tabular}{|l|c|c|c|c|}
\hline & \multicolumn{2}{|c|}{ Single } & \multicolumn{2}{c|}{ Married } \\
& M & F & M & F \\
\hline Influence to Leave & 60.88 & 55.80 & 68.18 & 65.92 \\
\hline No Effect & 33.08 & 37.79 & 25.54 & 26.31 \\
\hline Influence to Stay & 6.04 & 6.41 & 6.28 & 7.77 \\
\hline
\end{tabular}

Source: Author, Computed from FY 2001 USMC Retention Survey

Table 3.67

Time Away from Home (V32): Cross-Tabulation Percentage Geographic Location (CONUS and OCONUS)

Male $(\mathrm{N}=6696)$, Female $(\mathrm{N}=722)$

\begin{tabular}{|c|c|c|c|c|}
\hline & \multicolumn{2}{|c|}{ CONUS } & \multicolumn{2}{c|}{ OCONUS } \\
\hline Influence to Leave & 63.20 & 60.06 & 59.32 & 52.25 \\
\hline No Effect & 30.81 & 33.07 & 33.25 & 39.65 \\
\hline Influence to Stay & 5.99 & 6.87 & 7.43 & 8.10 \\
\hline
\end{tabular}

Source: Author, Computed from FY 2001 USMC Retention Survey 


\section{c. $\quad$ QOL Domain: Current Military Job/Working Conditions}

(1) Job responsibility (V57). Job responsibility was viewed

by male and female junior enlisted Marines with strong opinions as an influence to stay, as depicted in tables 3.68 through 3.71. Table 3.68 shows that males (42.1 percent) were slightly more likely than females (38.2 percent) to say that job responsibility was an influence to stay in the Marine Corps. Table 3.69 shows that white males (43.6 percent) were somewhat more likely than males of other races to say that job responsibility was an influence to stay. Table 3.70 shows slight differences between married and single junior enlisted Marines. Finally, Table 3.71 shows that OCONUS males and females (45.2 and 41.8 percent, respectively) were more likely than CONUS males and females (41.6 and 37.3 percent, respectively) to say that job responsibility was an influence to stay.

Table 3.68

QOL DOMAIN: Career Job Responsibility (V57): Gender

\begin{tabular}{|l|c|c|}
\hline & $\frac{\text { Male }(\mathbf{N}=6780)}{\text { Percent }}$ & $\frac{\text { Female (N=732) }}{\text { Percent }}$ \\
\hline Influence to Leave & 15.8 & 16.8 \\
\hline No effect & 42.1 & 45.0 \\
\hline Influence to Stay & 42.1 & 38.2 \\
\hline
\end{tabular}

Source: Author, Computed from FY 2001 USMC Retention Survey

Table 3.69

Job Responsibility (V57): Cross-Tabulation Percentage

Gender by Race

Male $(\mathrm{N}=6245)$, Female $(\mathrm{N}=658)$

\begin{tabular}{|l|c|c|c|c|c|c|}
\hline & \multicolumn{2}{|c|}{ White } & \multicolumn{2}{c|}{ Black } & \multicolumn{2}{c|}{ Hispanic } \\
\hline Influence to & 16.4 & 18.8 & 14.4 & 19.3 & 13.7 & 11.9 \\
Leave & & & & & & \\
\hline No Effect & 40.0 & 44.4 & 46.10 & 50.10 & 45.8 & 43.7 \\
\hline $\begin{array}{l}\text { Influence to } \\
\text { Stay }\end{array}$ & 43.6 & 36.8 & 39.5 & 30.6 & 40.5 & 44.4 \\
\hline
\end{tabular}

Source: Author, Computed from FY 2001 USMC Retention Survey 
Table 3.70

Job Responsibility (V57): Cross-Tabulation Percentage

Gender by Marital Status

Male $(\mathrm{N}=6604)$, Female $(\mathrm{N}=676)$

\begin{tabular}{|l|c|c|c|c|}
\hline & \multicolumn{2}{|c|}{ Single } & \multicolumn{2}{c|}{ Married } \\
& M & F & M & F \\
\hline Influence to Leave & 16.1 & 17.0 & 15.2 & 19.1 \\
\hline No Effect & 42.3 & 45.70 & 41.80 & 45.70 \\
\hline Influence to Stay & 41.6 & 37.3 & 43.0 & 35.2 \\
\hline
\end{tabular}

Source: Author, Computed from FY 2001 USMC Retention Survey

Table 3.71

Job Responsibility (V57): Cross-Tabulation Percentage Geographic Location (CONUS and OCONUS)

Male $(\mathrm{N}=6671)$, Female $(\mathrm{N}=723)$

\begin{tabular}{|c|c|c|c|c|}
\hline & \multicolumn{2}{|c|}{ CONUS } & \multicolumn{2}{c|}{ OCONUS } \\
& M & F & 15.6 & 15.4 \\
\hline Influence to Leave & 15.7 & 17.1 & 39.20 & 42.8 \\
\hline No Effect & 42.70 & 45.6 & 45.2 & 41.8 \\
\hline
\end{tabular}

Source: Author, Computed from FY 2001 USMC Retention Survey

(2) Workload distribution (V60). As reported by Kocher and

Thomas (2000) and Hall (2001), workload distribution was considered by junior enlisted Marines (E2-E4) as a source of concern. According to Hall (2001), a majority of E2-E4 Marines felt that they had to 'pick up the load' because their unit was understaffed. Since junior enlisted Marines represent the majority of personnel in the Marine Corps and perform the bulk of labor-intensive tasks, this group's perceptions of workload distribution are important.

Overall, workload distribution (V60) was a 'bottom ten' variable for both males (mean=3.17, Table 3.5) and females (mean=3.22, Table 3.6). As illustrated by tables 3.72 through 3.75, workload distribution was an influence to leave for about 50 percent of males and females in all demographic groups. Table 3.72 shows that males (50.07 percent) and females (50.0 percent) were similar in saying that workload distribution was an influence to leave. According to Table 3.73, white males and females (52.62 and 52.3 percent, respectively) were more likely than junior enlisted Marines of other races to 
say that workload distribution was an influence to leave. Table 3.74 shows that married males and females (52.58 and 51.29 percent, respectively) were somewhat more likely than single males and females (49.26 and 49.87 percent, respectively) to say that workload distribution was an influence to leave the Marine Corps. CONUS junior enlisted Marines (Table 3.75) were slightly more likely than OCONUS peers to say that workload distribution was an influence to leave the Marine Corps.

Table 3.72

QOL DOMAIN: Working Conditions

Workload Distribution (V60): Gender

\begin{tabular}{|l|c|c|}
\hline & $\frac{\text { Male (N=6786) }}{\text { Percent }}$ & $\frac{\text { Female (N=730) }}{\text { Percent }}$ \\
\hline Influence to Leave & 50.07 & 50.0 \\
\hline No effect & 36.58 & 35.21 \\
\hline Influence to Stay & 13.35 & 14.79 \\
\hline
\end{tabular}

Source: Author, Computed from FY 2001 USMC Retention Survey

Table 3.73

Workload Distribution (V60): Cross-Tabulation Percentage

Gender by Race

Male $(\mathrm{N}=6250)$, Female $(\mathrm{N}=657)$

\begin{tabular}{|l|c|c|c|c|c|c|}
\hline & \multicolumn{2}{|c|}{ White } & \multicolumn{2}{c|}{ Black } & \multicolumn{2}{c|}{ Hispanic } \\
& M & F & M & F & M & F \\
\hline $\begin{array}{l}\text { Influence to } \\
\text { Leave }\end{array}$ & 52.62 & 52.3 & 36.87 & 38.70 & 47.39 & 54.33 \\
\hline No Effect & 34.77 & 33.82 & 45.05 & 49.06 & 38.81 & 33.17 \\
\hline $\begin{array}{l}\text { Influence to } \\
\text { Stay }\end{array}$ & 12.61 & 13.88 & 18.08 & 12.24 & 13.80 & 12.50 \\
\hline
\end{tabular}

Source: Author, Computed from FY 2001 USMC Retention Survey 
Table 3.74

Workload Distribution (V60): Cross-Tabulation Percentage

Gender by Marital Status

Male $(\mathrm{N}=6609)$, Female $(\mathrm{N}=674)$

\begin{tabular}{|l|c|c|c|c|}
\hline & \multicolumn{2}{|c|}{ Single } & \multicolumn{2}{c|}{ Married } \\
& M & F & M & F \\
\hline Influence to Leave & 49.26 & 49.87 & 52.58 & 51.29 \\
\hline No Effect & 37.25 & 35.49 & 34.38 & 34.69 \\
\hline Influence to Stay & 13.49 & 14.64 & 13.04 & 14.02 \\
\hline
\end{tabular}

Source: Author, Computed from FY 2001 USMC Retention Survey

Table 3.75

Workload Distribution (V60): Cross-Tabulation Percentage Geographic Location (CONUS and OCONUS) Male $(\mathrm{N}=6678)$, Female $(\mathrm{N}=721)$

\begin{tabular}{|c|c|c|c|c|}
\hline & \multicolumn{2}{|c|}{ CONUS } & \multicolumn{2}{c|}{ OCONUS } \\
\hline Influence to Leave & 50.38 & 50.98 & 48.38 & 43.24 \\
\hline No Effect & 36.23 & 34.60 & 38.35 & 39.65 \\
\hline Influence to Stay & 13.39 & 14.42 & 13.27 & 17.11 \\
\hline
\end{tabular}

Source: Author, Computed from FY 2001 USMC Retention Survey

\section{d. QOL Domain: Personal/Family Life}

Based upon the literature review and the author's personal experience, Marines who perceive that pursuing a Marine Corps career detracts from the quality of personal/family life are not likely to serve a career in the Marine Corps. The importance of this domain is substantiated by the considerable investment that DoD and the Marine Corps have made in family support services (v76) and similar programs that target junior enlisted Marines and their family members.

(1) Family influence on career (V63). This variable attempts to measure the impact that family members' influence have on the career decision for the junior enlisted Marine. As depicted in tables 3.76 through 3.79, about 75 percent of junior enlisted Marines said that this variable either had no effect or was an influence to leave the Marine Corps. Table 3.76 shows that males and females (33.18 and 33.74 percent, respectively) provided similar responses, saying that family influence on their career was an 
influence to leave. Table 3.77 shows that Hispanic females (43.31 percent) were more likely than black or white females (32.32 and 31.49 percent, respectively) to say that family influence on their career was an influence to leave the Marine Corps. As shown by table 3.78, married Marines were more likely than single Marines to say that family influence on his/her career was an influence to leave the Marine Corps. Finally, results for CONUS junior enlisted Marines were about the same as more likely than their OCONUS (Table 3.79).

Table 3.76

QOL Domain: Personal/Family Life

Family Influence on Career (V63): Gender

\begin{tabular}{|l|c|c|}
\hline & $\frac{\text { Male (N=6806) }}{\text { Percent }}$ & $\frac{\text { Female (N=735) }}{\text { Percent }}$ \\
\hline Influence to Leave & 33.18 & 33.74 \\
\hline No effect & 43.81 & 44.35 \\
\hline Influence to Stay & 23.01 & 21.90 \\
\hline
\end{tabular}

Source: Author, Computed from FY 2001 USMC Retention Survey

Table 3.77

Family Influence on Career (V63): Cross-Tabulation Percentage

Gender by Race

Male $(\mathrm{N}=6270)$, Female $(\mathrm{N}=661)$

\begin{tabular}{|l|c|c|c|c|c|c|}
\hline & \multicolumn{2}{|c|}{ White } & \multicolumn{2}{c|}{ Black } & \multicolumn{2}{c|}{ Hispanic } \\
\hline $\begin{array}{l}\text { Influence to } \\
\text { Leave }\end{array}$ & 32.64 & 31.49 & 32.39 & 32.32 & 35.89 & 43.31 \\
\hline No Effect & 44.92 & 47.13 & 42.08 & 42.42 & 39.68 & 37.80 \\
\hline $\begin{array}{l}\text { Influence to } \\
\text { Stay }\end{array}$ & 22.44 & 21.38 & 25.53 & 25.25 & 24.43 & 18.90 \\
\hline
\end{tabular}

Source: Author, Computed from FY 2001 USMC Retention Survey 
Table 3.78

Family Influence on Career (V63): Cross-Tabulation Percentage

Gender by Marital Status

Male $(\mathrm{N}=6629)$, Female $(\mathrm{N}=679)$

\begin{tabular}{|l|c|c|c|c|}
\hline & \multicolumn{2}{|c|}{ Single } & \multicolumn{2}{c|}{ Married } \\
\hline Influence to Leave & 26.94 & 26.60 & 49.02 & 43.59 \\
\hline No Effect & 50.19 & 49.26 & 27.00 & 37.36 \\
\hline Influence to Stay & 22.87 & 24.14 & 23.98 & 19.05 \\
\hline
\end{tabular}

Source: Author, Computed from FY 2001 USMC Retention Survey

Table 3.79

Family Influence on Career (V63): Cross-Tabulation Percentage Geographic Location (CONUS and OCONUS)

Male $(\mathrm{N}=6698)$, Female $(\mathrm{N}=726)$

\begin{tabular}{|c|c|c|c|c|}
\hline & \multicolumn{2}{|c|}{ CONUS } & \multicolumn{2}{c|}{ OCONUS } \\
\hline Influence to Leave & 34.1 & 34.9 & 28.9 & 28.83 \\
\hline No Effect & 43.0 & 43.4 & 48.9 & 48.65 \\
\hline Influence to Stay & 22.9 & 21.6 & 22.2 & 22.52 \\
\hline
\end{tabular}

Source: Author, Computed from FY 2001 USMC Retention Survey

(2) Work/Personal time balance (V62). Work/personal time

balance, while included in the personal/family life dimension within the survey, could also be included in the PERSTEMPO dimension that includes 'workload distribution' (V60) and 'time away from home' (V32). As discussed previously, PERSTEMPO, in principle, has many dimensions, such as hours of work per day, days per week, weeks per year, hours on alert, and work per hour (Hosek and Totten, 1999). In the aggregate, when the work 'pendulum' (high PERSTEMPO/OPTEMPO) swings too far, retention efforts are likely to be degraded. According to the FY 2001 USMC Retention Survey, work/personal time balance was the fifth lowest scoring variable (mean=3.02, Table 3.5) for males and fourth lowest scoring variable for females (mean=3.05, Table 3.6) in terms of factors that would influence junior enlisted Marines to stay. These results are reflected in the next four tables.

According to Table 3.80, over 60 percent of male and female junior enlisted Marines perceive the work/personal time balance to be an influence to leave. Table 3.81 shows that Hispanic females (65.35 percent) were more likely than junior enlisted 
Marines of all races and gender to say that work/personal time balance was an influence to leave. Additionally, Table 3.81 depicts that white male and female junior enlisted Marines (62.74 and 64.13 percent, respectively) were more likely than their black male and female peers (54.75 and 54.54 percent, respectively) to say that work/personal time balance was an influence to leave. Married females (67.03 percent) and married males (65.73 percent) were more likely than single junior enlisted Marines to say that work/personal time balance was an influence to leave (Table 3.82). Finally, CONUS-based junior enlisted Marines were only slightly more likely than OCONUS-based peers to say that work/personal time balance was an influence to leave (Table 3.83).

Table 3.80

QOL DOMAIN: Personal/Family Life Work/Personal time balance (V62): Gender

\begin{tabular}{|l|c|c|}
\hline & $\frac{\text { Male (N=6813) }}{\text { Percent }}$ & $\frac{\text { Female (N=735) }}{\text { Percent }}$ \\
\hline Influence to Leave & 61.29 & 62.31 \\
\hline No effect & 21.78 & 19.74 \\
\hline Influence to Stay & 16.93 & 17.95 \\
\hline
\end{tabular}

Source: Author, Computed from FY 2001 USMC Retention Survey

Table 3.81

Work/Personal time balance (V62): Cross-Tabulation Percentage

Gender by Race

Male $(\mathrm{N}=6276)$, Female $(\mathrm{N}=661)$

\begin{tabular}{|l|c|c|c|c|c|c|}
\hline & \multicolumn{2}{|c|}{ White } & \multicolumn{2}{c|}{ Black } & \multicolumn{2}{c|}{ Hispanic } \\
\hline $\begin{array}{l}\text { Influence to } \\
\text { Leave }\end{array}$ & 62.74 & 64.13 & 54.75 & 54.54 & 59.87 & 65.35 \\
\hline No Effect & 20.82 & 19.09 & 24.83 & 29.30 & 23.31 & 18.91 \\
\hline $\begin{array}{l}\text { Influence to } \\
\text { Stay }\end{array}$ & 16.44 & 16.78 & 20.42 & 16.16 & 16.82 & 15.74 \\
\hline
\end{tabular}

Source: Author, Computed from FY 2001 USMC Retention Survey 
Table 3.82

Work/Personal time balance (V62): Cross-Tabulation Percentage

Gender by Marital Status

Male $(\mathrm{N}=6635)$, Female $(\mathrm{N}=679)$

\begin{tabular}{|l|c|c|c|c|}
\hline & \multicolumn{2}{|c|}{ Single } & \multicolumn{2}{c|}{ Married } \\
& M & F & M & F \\
\hline Influence to Leave & 59.78 & 59.35 & 65.73 & 67.03 \\
\hline No Effect & 22.77 & 20.70 & 18.62 & 17.59 \\
\hline Influence to Stay & 17.45 & 19.95 & 15.65 & 15.38 \\
\hline
\end{tabular}

Source: Author, Computed from FY 2001 USMC Retention Survey

Table 3.83

Work/Personal time balance (V62): Cross-Tabulation Percentage Geographic Location (CONUS and OCONUS) Male $(\mathrm{N}=6705)$, Female $(\mathrm{N}=726)$

\begin{tabular}{|c|c|c|c|c|}
\hline & \multicolumn{2}{|c|}{ CONUS } & \multicolumn{2}{c|}{ OCONUS } \\
\hline Influence to Leave & 61.82 & 62.60 & 58.86 & 61.26 \\
\hline No Effect & 21.63 & 20.17 & 22.69 & 17.12 \\
\hline Influence to Stay & 16.55 & 17.23 & 18.45 & 21.62 \\
\hline
\end{tabular}

Source: Author, Computed from FY 2001 USMC Retention Survey

\section{e. QOL Domain: Culture}

The questions from the culture domain range from the administration of regulations (v90, discussed below) to the perception of careerism by SNCOs (E6-E9) and officers (v99). From this domain, interaction between races (v95) and administration of regulations (v90) were at opposite ends of the spectrum.

About 90 percent (Table 3.84) of male and female junior enlisted Marines said that interaction between races (v95) had no effect or was an influence to stay in the Marine Corps. According to Table 3.85, black males and females were more likely (18.94 and 15.15 percent, respectively) than Hispanic (13.11 and 8.66 percent, respectively) and white males and females (11.08 and 8.53 percent, respectively) to say that interaction between races was an influence to leave. Table 3.86 shows that married males and females (29.08 and 26.74 percent, respectively) were slightly less likely than single males and females (29.43 and 31.68 percent, respectively) to say that interaction between races was an influence to stay in the Marine Corps. As depicted by table 3.87, OCONUS Marines were 
slightly more inclined than CONUS peers to say that interaction between races was an influence to stay.

(1) Interaction between races (V95).

Table 3.84

QOL DOMAIN: Interaction Between Races

(V95): Gender

\begin{tabular}{|l|c|c|}
\hline & $\frac{\text { Male (N=6787) }}{\text { Percent }}$ & $\frac{\text { Female (N=733) }}{\text { Percent }}$ \\
\hline Influence to Leave & 12.1 & 9.00 \\
\hline No effect & 58.61 & 61.26 \\
\hline Influence to Stay & 29.29 & 29.74 \\
\hline
\end{tabular}

Source: Author, Computed from FY 2001 USMC Retention Survey

Table 3.85

Interaction Between Races (V95): Cross-Tabulation Percentage

Gender by Race

Male $(\mathrm{N}=6252)$, Female $(\mathrm{N}=660)$

\begin{tabular}{|l|c|c|c|c|c|c|}
\hline & \multicolumn{2}{|c|}{ White } & \multicolumn{2}{c|}{ Black } & \multicolumn{2}{c|}{ Hispanic } \\
\hline $\begin{array}{l}\text { Influence to } \\
\text { Leave }\end{array}$ & 11.08 & 8.53 & 18.94 & 15.15 & 13.11 & 8.66 \\
\hline No Effect & 60.71 & 63.13 & 50.09 & 60.61 & 53.20 & 55.91 \\
\hline $\begin{array}{l}\text { Influence to } \\
\text { Stay }\end{array}$ & 28.21 & 28.34 & 30.97 & 24.24 & 33.69 & 35.43 \\
\hline
\end{tabular}

Source: Author, Computed from FY 2001 USMC Retention Survey

Table 3.86

Interaction Between Races (V95): Cross-Tabulation Percentage

Gender by Marital Status

Male ( $=6610)$, Female $(\mathrm{N}=677)$

\begin{tabular}{|l|c|c|c|c|}
\hline & \multicolumn{2}{|c|}{ Single } & \multicolumn{2}{c|}{ Married } \\
\hline Influence to Leave & 12.04 & 9.16 & 12.10 & 9.16 \\
\hline No Effect & 58.53 & 59.16 & 58.82 & 64.10 \\
\hline Influence to Stay & 29.43 & 31.68 & 29.08 & 26.74 \\
\hline
\end{tabular}

Source: Author, Computed from FY 2001 USMC Retention Survey 
Table 3.87

Interaction Between Races (V95): Cross-Tabulation Percentage Geographic Location (CONUS and OCONUS)

Male $(\mathrm{N}=6679)$, Female $(\mathrm{N}=723)$

\begin{tabular}{|c|c|c|c|c|}
\hline & \multicolumn{2}{|c|}{ CONUS } & \multicolumn{2}{c|}{ OCONUS } \\
\hline Influence to Leave & 12.23 & 9.64 & 11.67 & 6.31 \\
\hline No Effect & 58.80 & 61.27 & 56.94 & 61.26 \\
\hline Influence to Stay & 28.97 & 29.08 & 31.39 & 32.43 \\
\hline
\end{tabular}

Source: Author, Computed from FY 2001 USMC Retention Survey

2. Administration of regulations (V90). Over 40 percent of junior enlisted Marines (Table 3.88) said that the administration of regulations was an influence to leave the Marine Corps. As depicted by Table 3.89, white males (45.02 percent) were more likely than black and Hispanic males females (36.35 and 38.16 percent, respectively) to say that administration of regulations was an influence to leave. Hispanic females (48.82 percent) were more likely than white and black females (43.42 and 41.41 percent, respectively) to say that administration of regulations was an influence to leave. Table 3.90 shows that single males and females (43.86 and 47.28 percent, respectively) are somewhat more likely than married males and females (40.64 and 42.65 percent, respectively) to say that the administration of regulations was an influence to leave the Marine Corps. About 60 percent (Table 3.91) of OCONUS females, compared to about 40 percent of CONUS females, said that administration of regulations was an influence to leave the Marine Corps.

Table 3.88

Administration of Regulations (V90)

Gender

\begin{tabular}{|l|c|c|}
\hline & $\frac{\text { Male (N=6785) }}{\text { Percent }}$ & $\frac{\text { Female (N=732) }}{\text { Percent }}$ \\
\hline Influence to Leave & 42.87 & 45.08 \\
\hline No effect & 43.68 & 41.53 \\
\hline Influence to Stay & 13.44 & 13.39 \\
\hline
\end{tabular}

Source: Author, Computed from FY 2001 USMC Retention Survey 
Table 3.89

Administration of Regulations (V90): Cross-Tabulation Percentage Gender by Race

Male $(\mathrm{N}=6251)$, Female $(\mathrm{N}=659)$

\begin{tabular}{|l|c|c|c|c|c|c|}
\hline & \multicolumn{2}{|c|}{ White } & \multicolumn{2}{c|}{ Black } & \multicolumn{2}{c|}{ Hispanic } \\
& M & F & M & F \\
\hline $\begin{array}{l}\text { Influence to } \\
\text { Leave }\end{array}$ & 45.02 & 43.42 & 36.35 & 41.41 & 38.16 & 48.82 \\
\hline No Effect & 41.96 & 42.49 & 48.58 & 48.48 & 46.92 & 37.80 \\
\hline $\begin{array}{l}\text { Influence to } \\
\text { Stay }\end{array}$ & 13.02 & 14.09 & 15.07 & 10.10 & 14.92 & 13.39 \\
\hline
\end{tabular}

Source: Author, Computed from FY 2001 USMC Retention Survey

Table 3.90

Administration of Regulations (V90): Cross-Tabulation Percentage

Gender by Marital Status

Male $(\mathrm{N}=6608)$, Female $(\mathrm{N}=676)$

\begin{tabular}{|l|c|c|c|c|}
\hline & \multicolumn{2}{|c|}{ Single } & \multicolumn{2}{c|}{ Married } \\
\hline Influence to Leave & 43.86 & 47.28 & 40.64 & 42.65 \\
\hline No Effect & 43.35 & 36.88 & 44.11 & 47.06 \\
\hline Influence to Stay & 12.79 & 15.84 & 15.25 & 10.29 \\
\hline
\end{tabular}

Source: Author, Computed from FY 2001 USMC Retention Survey

Table 3.91

Administration of Regulations (V90): Cross-Tabulation Percentage Geographic Location (CONUS and OCONUS)

Male $(\mathrm{N}=6676)$, Female $(\mathrm{N}=722)$

\begin{tabular}{|c|c|c|c|c|}
\hline & \multicolumn{2}{|c|}{ CONUS } & \multicolumn{2}{c|}{ OCONUS } \\
\hline Influence to Leave & 42.01 & 42.23 & 47.96 & 59.46 \\
\hline No Effect & 44.62 & 43.21 & 38.15 & 33.33 \\
\hline Influence to Stay & 13.37 & 14.57 & 13.89 & 7.21 \\
\hline
\end{tabular}

Source: Author, Computed from FY 2001 USMC Retention Survey

\section{f. QOL Domain: USMC Values}

The domain of USMC Values captures the opinions of junior enlisted Marines from survey questions 100 through 103 (Appendix A). The survey scale for these questions asks respondents to use a five-point Likert scale (agree/disagree). Two questions 
were chosen from this dimension for further analysis: "What the Marine Corps stands for is important to me" (v100) and "I would be very happy to spend the rest of my career in the Marine Corps "(v103). What junior enlisted Marines said in response to these questions provides an interesting contrast of opinions. Junior enlisted Marines overwhelmingly agree that what the Marine Corps stands for is important. Conversely, Marines overwhelmingly disagreed that they would be very happy to spend the rest of their career in the Marine Corps.

(1) What the Marine Corps stands for is important to me (V100). As shown by Table 3.92, over 70 percent of of males and females agreed "what the Marine Corps stands for is important to me." Table 3.93 shows that black males and females (68.56 and 59.38 percent, respectively) were less likely than peers of other races to agree that "what the Marine Corps stands for is important to me." Married females (68.28 percent, Table 3.94) were less likely than other peers to agree. Finally, Table 3.95 shows that there are no strong differences between CONUS and OCONUS junior enlisted Marines.

Table 3.92

What the Marine Corps Stands for is Important to me (V100): Gender

\begin{tabular}{|l|c|c|}
\hline & $\frac{\text { Male }(\mathbf{N}=6685)}{\text { Percent }}$ & $\frac{\text { Female }(\mathbf{N}=723)}{\text { Percent }}$ \\
\hline Disagree & 8.51 & 10.10 \\
\hline Neutral & 13.06 & 17.57 \\
\hline Agree & 78.43 & 72.34 \\
\hline
\end{tabular}

Source: Author, Computed from FY 2001 USMC Retention Survey 
Table 3.93

What the Marine Corps stands for is important to me (V100):

Cross-Tabulation Percentage

Gender by Race

Male $(\mathrm{N}=6157)$, Female $(\mathrm{N}=651)$

\begin{tabular}{|l|c|c|c|c|c|c|}
\hline & \multicolumn{2}{|c|}{ White } & \multicolumn{2}{c|}{ Black } & \multicolumn{2}{c|}{ Hispanic } \\
& M & F & M & M & F \\
\hline Disagree & 8.14 & 7.71 & 13.16 & 14.58 & 8.61 & 14.17 \\
& & & & & & \\
\hline Neutral & 11.44 & 15.19 & 18.28 & 26.04 & 16.23 & 20.47 \\
& & & & & & \\
\hline Agree & 80.42 & 77.10 & 68.56 & 59.38 & 75.17 & 65.35 \\
\hline
\end{tabular}

Source: Author, Computed from FY 2001 USMC Retention Survey

Table 3.94

What the Marine Corps stands for is important to me (V100):

Cross-Tabulation Percentage

Gender by Marital Status

Male $(\mathrm{N}=6510)$, Female $(\mathrm{N}=667)$

\begin{tabular}{|l|c|c|c|c|}
\hline & \multicolumn{2}{|c|}{ Single } & \multicolumn{2}{c|}{ Married } \\
\hline Disagree & M & F & M & F \\
\hline Neutral & 8.34 & 8.52 & 8.90 & 12.69 \\
\hline Agree & 12.86 & 17.29 & 13.58 & 19.03 \\
\hline
\end{tabular}

Source: Author, Computed from FY 2001 USMC Retention Survey

Table 3.95

What the Marine Corps Stands for is important to me (V100):

Cross-Tabulation Percentage

Geographic Location (CONUS and OCONUS)

Male $(\mathrm{N}=6581)$, Female $(\mathrm{N}=713)$

\begin{tabular}{|c|c|c|c|c|}
\hline & \multicolumn{2}{|c|}{ CONUS } & \multicolumn{2}{c|}{ OCONUS } \\
\hline Disagree & 8.68 & 10.60 & 7.83 & 8.26 \\
\hline Neutral & 13.38 & 16.89 & 11.46 & 21.10 \\
\hline Agree & 77.94 & 72.52 & 80.71 & 70.64 \\
\hline
\end{tabular}

Source: Author, Computed from FY 2001 USMC Retention Survey 
(2) I would be happy to spend the rest of my career in the Marine Corps (V103). As depicted by Table 3.96, over 60 percent of male and female junior enlisted Marines disagreed with the statement "I would be happy to spend the rest of my career in the Marine Corps." Table 3.97 shows that white and black females (64.39 and 72.41 percent, respectively) were more likely than their peers to disagree. Married females (67.68 percent) were more likely than married males (55.98 percent) to disagree (Table 3.98). According to Table 3.99, CONUS junior enlisted Marines were more likely than OCONUS peers to disagree.

Table 3.96

I would be happy to spend the rest of my career in the Marine Corps (V103):

Gender

\begin{tabular}{|l|c|c|}
\hline & $\frac{\text { Male }(\mathbf{N}=6252)}{\text { Percent }}$ & $\frac{\text { Female (N=667) }}{\text { Percent }}$ \\
\hline Disagree & 60.78 & 64.02 \\
\hline Neutral & 20.84 & 18.29 \\
\hline Agree & 18.38 & 17.69 \\
\hline
\end{tabular}

Source: Author, Computed from FY 2001 USMC Retention Survey

Table 3.97

I would be happy to spend the rest of my career in the Marine Corps (V103):

Cross-Tabulation Percentage

Gender by Race

Male $(\mathrm{N}=5758)$, Female $(\mathrm{N}=600)$

\begin{tabular}{|l|c|c|c|c|c|c|}
\hline & \multicolumn{2}{|c|}{ White } & \multicolumn{2}{c|}{ Black } & \multicolumn{2}{c|}{ Hispanic } \\
\hline Disagree & 61.81 & 64.39 & 58.30 & 72.41 & 58.81 & 60.68 \\
& & & & & & \\
\hline Neutral & 20.40 & 18.69 & 23.72 & 16.09 & 19.29 & 19.66 \\
& & & & & & \\
\hline Agree & 17.79 & 16.92 & 17.98 & 11.49 & 21.90 & 19.66 \\
\hline
\end{tabular}

Source: Author, Computed from FY 2001 USMC Retention Survey 
Table 3.98

I would be happy to spend the rest of my career in the Marine Corps (V103):

Cross-Tabulation Percentage

Gender by Marital Status

Male $(\mathrm{N}=6092)$, Female $(\mathrm{N}=615)$

\begin{tabular}{|l|c|c|c|c|}
\hline & \multicolumn{2}{|c|}{ Single } & \multicolumn{2}{c|}{ Married } \\
\hline Disagree & 62.77 & 62.43 & 55.98 & 67.68 \\
\hline Neutral & 20.84 & 20.72 & 21.05 & 14.23 \\
\hline Agree & 16.39 & 16.85 & 22.97 & 17.79 \\
\hline
\end{tabular}

Source: Author, Computed from FY 2001 USMC Retention Survey

Table 3.99

I would be happy to spend the rest of my career in the Marine Corps(V103):

Cross-Tabulation Percentage

Geographic Location (CONUS and OCONUS)

Male $(\mathrm{N}=6148)$, Female $(\mathrm{N}=657)$

\begin{tabular}{|c|c|c|c|c|}
\hline & \multicolumn{2}{|c|}{ CONUS } & \multicolumn{2}{c|}{ OCONUS } \\
\hline Disagree & 61.51 & 66.25 & 57.80 & 53.0 \\
\hline Neutral & 20.61 & 16.88 & 22.02 & 24.0 \\
\hline Agree & 17.88 & 16.88 & 20.18 & 23.0 \\
\hline
\end{tabular}

Source: Author, Computed from FY 2001 USMC Retention Survey

g. QOL Domain: USMC Sense of Community

The USMC Sense of Community dimension draws upon the research of Van Laar (1999) discussed in the literature review of this thesis. According to Van Laar (1999), sense of community is derived from three interlocking sources: an attachment to people, developed through social interactions and supportive relationships; an attachment to the workgroup, fostered through involvement in similar tasks; and an attachment to an organization, created as an individual identifies with the values of an organization. Thus, survey questions 104 through 106 are hypothesized to measure this relationship between the junior enlisted Marine and his/her sense of community.

(1) I do not feel emotionally attached to the Marine Corps (V105). As depicted by tables 3.100 thorough 3.103, junior enlisted Marines were 'split' between agreement and disagreement with the statement "I do not feel emotionally attached to the Marine Corps." According to Table 3.101, black males (46.62 percent) and 
females (52.58 percent) were more likely than members of other races to agree. Table 3.102 shows that married females (47.19 percent) were more likely to agree than their single peers. Finally, Table 3.103 shows that CONUS-based junior enlisted Marines were slightly more likely than OCONUS-based junior enlisted Marines to agree.

Table 3.100

I do not feel emotionally attached to the Marine Corps (V105): Gender

\begin{tabular}{|l|c|c|}
\hline & $\frac{\text { Male }(\mathbf{N}=6644)}{\text { Percent }}$ & $\frac{\text { Female (N=719) }}{\text { Percent }}$ \\
\hline Disagree & 40.62 & 38.94 \\
\hline Neutral & 19.82 & 19.33 \\
\hline Agree & 39.55 & 41.72 \\
\hline
\end{tabular}

Source: Author, Computed from FY 2001 USMC Retention Survey

Table 3.101

I do not feel emotionally attached to the Marine Corps (V105):

Cross-Tabulation Percentage

Gender by Race

Male $(\mathrm{N}=6118)$, Female $(\mathrm{N}=648)$

\begin{tabular}{|l|c|c|c|c|c|c|}
\hline & \multicolumn{2}{|c|}{ White } & \multicolumn{2}{c|}{ Black } & \multicolumn{2}{c|}{ Hispanic } \\
& M & F & M & F & M & F \\
\hline Disagree & 41.68 & 39.58 & 33.64 & 25.77 & 41.24 & 41.94 \\
& & & & & & \\
\hline Neutral & 19.06 & 18.97 & 19.74 & 21.65 & 22.73 & 22.58 \\
& & & & & & \\
\hline Agree & 39.26 & 41.45 & 46.62 & 52.58 & 36.03 & 35.48 \\
\hline
\end{tabular}

Source: Author, Computed from FY 2001 USMC Retention Survey 
Table 3.102

I do not feel emotionally attached to the Marine Corps (V105):

Cross-Tabulation Percentage

Gender by Marital Status

Male $(\mathrm{N}=6464)$, Female $(\mathrm{N}=665)$

\begin{tabular}{|l|c|c|c|c|}
\hline & \multicolumn{2}{|c|}{ Single } & \multicolumn{2}{c|}{ Married } \\
\hline Disagree & 40.52 & 40.70 & 41.14 & 34.08 \\
\hline Neutral & 20.14 & 20.85 & 19.10 & 18.73 \\
\hline Agree & 39.34 & 38.44 & 39.76 & 47.19 \\
\hline
\end{tabular}

Source: Author, Computed from FY 2001 USMC Retention Survey

Table 3.103

I do not feel emotionally attached to the Marine Corps (V105):

Cross-Tabulation Percentage

Geographic Location (CONUS and OCONUS)

Male $(\mathrm{N}=6539)$, Female $(\mathrm{N}=709)$

\begin{tabular}{|c|c|c|c|c|}
\hline & \multicolumn{2}{|c|}{ CONUS } & \multicolumn{2}{c|}{ OCONUS } \\
\hline Disagree & 39.15 & 38.00 & 48.26 & 44.95 \\
\hline Neutral & 20.38 & 20.0 & 16.37 & 15.60 \\
\hline Agree & 40.47 & 42.0 & 35.37 & 39.45 \\
\hline
\end{tabular}

Source: Author, Computed from FY 2001 USMC Retention Survey

(2) I do not feel a strong sense of belonging to the Marine Corps

(V106). As depicted by Tables 3.104 through 3.107, males were more likely than females to disagree with the statement 'I do not feel a strong sense of belonging to the Marine Corps' (v106). Table 3.104 shows that males (47.71 percent) disagreed with the statement more than females (41.63 percent). According to Table 3.105, black females (43.01 percent) were more likely to agree than disagree. Hispanic males and females (51.11 and 47.54 percent, respectively) were more likely than males and females of other races to disagree. Table 3.106 shows that married females (43.77 percent) were more likely to agree than single junior enlisted Marines (male and female). Finally, Table 3.107 shows that OCONUS males (52.63 percent) and females (49.06 percent) were more likely than CONUS males (46.82 percent) and females (40.50 percent) to disagree. 
Table 3.104

QOL DOMAIN: I do not feel a strong sense of belonging to the Marine Corps (V106): Gender

\begin{tabular}{|l|c|c|}
\hline & $\frac{\text { Male }(\mathbf{N}=\mathbf{6 6 2 5})}{\text { Percent }}$ & $\frac{\text { Female }(\mathbf{N}=\mathbf{7 1 1})}{\text { Percent }}$ \\
\hline Disagree & 47.71 & 41.63 \\
\hline Neutral & 22.79 & 20.25 \\
\hline Agree & 29.49 & 38.12 \\
\hline
\end{tabular}

Source: Author, Computed from FY 2001 USMC Retention Survey

Table 3.105

I do not feel a strong sense of belonging to the Marine Corps (V106):

Cross-Tabulation Percentage

Gender by Race

Male $(\mathrm{N}=6105)$, Female $(\mathrm{N}=643)$

\begin{tabular}{|l|c|c|c|c|c|c|}
\hline & \multicolumn{2}{|c|}{ White } & \multicolumn{2}{c|}{ Black } & \multicolumn{2}{c|}{ Hispanic } \\
& M & F & M & F & M & F \\
\hline Disagree & 47.96 & 40.65 & 41.83 & 33.33 & 51.11 & 47.54 \\
& & & & & & \\
\hline Neutral & 22.41 & 21.73 & 23.67 & 23.66 & 22.95 & 17.21 \\
& & & & & & \\
\hline Agree & 29.63 & 37.62 & 34.50 & 43.01 & 25.94 & 35.25 \\
\hline
\end{tabular}

Source: Author, Computed from FY 2001 USMC Retention Survey

Table 3.106

I do not feel a strong sense of belonging to the Marine Corps (V106):

Cross-Tabulation Percentage

Gender by Marital Status

Male $(\mathrm{N}=6452)$, Female $(\mathrm{N}=660)$

\begin{tabular}{|l|c|c|c|c|}
\hline & \multicolumn{2}{|c|}{ Single } & \multicolumn{2}{c|}{ Married } \\
\hline Disagree & M & F & M & F \\
\hline Neutral & 47.42 & 43.80 & 49.05 & 37.36 \\
\hline Agree & 22.94 & 22.53 & 22.54 & 18.87 \\
\hline
\end{tabular}

Source: Author, Computed from FY 2001 USMC Retention Survey 
Table 3.107

I do not feel a strong sense of belonging to the Marine Corps (V106):

Cross-Tabulation Percentage

Geographic Location (CONUS and OCONUS)

Male $(\mathrm{N}=6519)$, Female $(\mathrm{N}=701)$

\begin{tabular}{|c|c|c|c|c|}
\hline & \multicolumn{2}{|c|}{ CONUS } & \multicolumn{2}{c|}{ OCONUS } \\
\hline Disagree & 46.82 & 40.50 & 52.63 & 49.06 \\
\hline Neutral & 23.29 & 20.67 & 19.98 & 16.98 \\
\hline Agree & 29.89 & 38.82 & 27.39 & 33.96 \\
\hline
\end{tabular}

Source: Author, Computed from FY 2001 USMC Retention Survey

\section{h. QOL Domain: Education/Training}

Based upon the responses of junior enlisted Marines, education appears to be an important influence upon the decision to stay or leave the Marine Corps. The education/training domain provides more evidence of the importance education and training potentially has on the career decision of junior enlisted Marines. As indicated by tables

3.108 through 3.111, male and female junior enlisted Marines from all categories strongly agreed with the statement "I want more education/training so that I can get out and get a better job" (v111). Males and females from all demographic categories (Tables 3.1123.115) were slightly more likely to agree than disagree with the statement 'more education opportunities would encourage me to re-enlist or remain in the service' (v114). When reviewing the data provided in Tables 3.108 through 3.115, it is important to note that this dimension received a coefficient-alpha score of .529 (Table 3.2). As discussed earlier in this chapter, coefficient-alpha scores of less than .70 suggest that the data may not be a good measure of the QOL domain of education and training. 
(1) I want more education/training so that I can get out and get a better job (V111).

Table 3.108

QOL DOMAIN: Education/Training

I want more education/training so that I can get out and get a better job

(V111): Gender

\begin{tabular}{|l|c|c|}
\hline & $\frac{\text { Male }(\mathbf{N}=\mathbf{6 6 4 6})}{\text { Percent }}$ & $\frac{\text { Female (N=717) }}{\text { Percent }}$ \\
\hline Disagree & 7.49 & 8.65 \\
\hline Neutral & 17.69 & 19.11 \\
\hline Agree & 74.81 & 72.25 \\
\hline
\end{tabular}

Source: Author, Computed from FY 2001 USMC Retention Survey

Table 3.109

I want more education/training so that I can get out and get a better job (V111):

Cross-Tabulation Percentage

Gender by Race

Male $(\mathrm{N}=6120)$, Female $(\mathrm{N}=646)$

\begin{tabular}{|l|c|c|c|c|c|c|}
\hline & \multicolumn{2}{|c|}{ White } & \multicolumn{2}{c|}{ Black } & \multicolumn{2}{c|}{ Hispanic } \\
& M & F & M & M & F \\
\hline Disagree & 7.49 & 8.55 & 9.62 & 3.06 & 6.50 & 12.60 \\
& & & & & & \\
\hline Neutral & 19.31 & 19.71 & 11.43 & 16.33 & 16.10 & 19.69 \\
& & & & & & \\
\hline Agree & 73.21 & 71.73 & 78.95 & 80.61 & 77.40 & 67.72 \\
& & & & & & \\
\hline
\end{tabular}

Source: FY 2001 USMC Retention Survey

Table 3.110

I want more education/training so that I can get out and get a better job (V111):

Cross-Tabulation Percentage

Gender by Marital Status

Male $(\mathrm{N}=6471)$, Female $(\mathrm{N}=663)$

\begin{tabular}{|l|c|c|c|c|}
\hline & \multicolumn{2}{|c|}{ Single } & \multicolumn{2}{c|}{ Married } \\
\hline Disagree & 7.02 & 8.44 & 8.11 & 9.62 \\
\hline Neutral & 17.54 & 17.37 & 18.34 & 20.38 \\
\hline Agree & 75.44 & 74.19 & 73.55 & 70.00 \\
\hline
\end{tabular}

Source: Author, Computed from FY 2001 USMC Retention Survey 
Table 3.111

I want to get more education/training so that I can get out and get a better job (V111):

Cross-Tabulation Percentage

Geographic Location (CONUS and OCONUS)

Male $(\mathrm{N}=6540)$, Female $(\mathrm{N}=708)$

\begin{tabular}{|c|c|c|c|c|}
\hline & \multicolumn{2}{|c|}{ CONUS } & \multicolumn{2}{c|}{ OCONUS } \\
\hline Disagree & 7.52 & 8.19 & 7.42 & 10.91 \\
\hline Neutral & 17.57 & 19.73 & 18.33 & 16.36 \\
\hline Agree & 74.91 & 72.07 & 74.25 & 72.73 \\
\hline
\end{tabular}

Source: Author, Computed from FY 2001 USMC Retention Survey

(2) More education opportunities would encourage me to reenlist or remain in the service (V114).

Table 3.112

QOL DOMAIN: Education/Training

More education opportunities would encourage me to reenlist or remain in the service (V114): Gender

\begin{tabular}{|l|c|c|}
\hline & $\frac{\text { Male (N=6494) }}{\text { Percent }}$ & $\frac{\text { Female (N=693) }}{\text { Percent }}$ \\
\hline Disagree & 33.57 & 34.78 \\
\hline Neutral & 23.59 & 24.82 \\
\hline Agree & 42.84 & 40.40 \\
\hline
\end{tabular}

Source: Author, Computed from FY 2001 USMC Retention Survey

Table 3.113

More education opportunities would encourage me to reenlist or remain in the service (V114): Cross-Tabulation Percentage

Gender by Race

Male $(\mathbf{N}=5975)$, Female $(\mathrm{N}=624)$

\begin{tabular}{|l|c|c|c|c|c|c|}
\hline & \multicolumn{2}{|c|}{ White } & \multicolumn{2}{c|}{ Black } & \multicolumn{2}{c|}{ Hispanic } \\
\hline Disagree & 35.70 & 36.61 & 35.28 & 35.05 & 26.29 & 34.17 \\
& & & & & & \\
\hline Neutral & 24.37 & 27.76 & 19.25 & 17.53 & 21.91 & 24.17 \\
& & & & & & \\
\hline Agree & 39.93 & 35.63 & 45.47 & 47.42 & 51.80 & 41.67 \\
\hline
\end{tabular}

Source: Author, Computed from FY 2001 USMC Retention Survey 
Table 3.114

More education opportunities would encourage me to reenlist or remain in the service (V114): Cross-Tabulation Percentage

Gender by Marital Status

Male $(\mathrm{N}=6324)$, Female $(\mathrm{N}=641)$

\begin{tabular}{|l|c|c|c|c|}
\hline & \multicolumn{2}{|c|}{ Single } & \multicolumn{2}{c|}{ Married } \\
\hline Disagree & 34.28 & 32.37 & 31.49 & 41.0 \\
\hline Neutral & 23.65 & 24.21 & 23.62 & 22.99 \\
\hline Agree & 42.07 & 43.42 & 44.90 & 36.02 \\
\hline
\end{tabular}

Source: Author, Computed from FY 2001 USMC Retention Survey

Table 3.115

More education opportunities would encourage me to reenlist or remain in the service

(V114): Cross-Tabulation Percentage

Geographic Location (CONUS and OCONUS)

Male $(\mathrm{N}=6392)$, Female $(\mathrm{N}=683)$

\begin{tabular}{|c|c|c|c|c|}
\hline & \multicolumn{2}{|c|}{ CONUS } & \multicolumn{2}{c|}{ OCONUS } \\
\hline Dissatisfied & 34.35 & 35.88 & 30.09 & 28.30 \\
\hline Neutral & 23.52 & 25.48 & 24.25 & 22.64 \\
\hline Satisfied & 42.12 & 38.65 & 45.67 & 49.06 \\
\hline
\end{tabular}

Source: Author, Computed from FY 2001 USMC Retention Survey

i. QOL Domain: Satisfaction with USMC

Survey questions 117 through 128 ask respondents to state how satisfied or dissatisfied they are with eleven broad dimensions. Of these dimensions, nine are applicable to the conceptual model presented in this thesis. To gain more insight into these domains, variables that represent domains where junior enlisted Marines are either satisfied (Primary MOS, v119) or dissatisfied (Family Life, v123) were chosen for further analysis.

(1) Primary MOS assignment (V119). As depicted by Tables

3.116 through 3.119, most junior enlisted Marines indicated that they were satisfied with their primary MOS (military occupational specialty), v119. According to Table 3.116, male junior enlisted Marines (54.06 percent) were more likely than females (46.25 percent) to say that they were satisfied with their primary MOS assignment. As shown in Table 3.117, black and Hispanic females (41.24 and 35.16 percent, respectively) were less likely than males and peers of other races to say that they were satisfied with their primary MOS 
assignment. Table 3.118 shows that males were more likely than females of all marital status to say that they were satisfied. Finally, Table 3.119 shows no strong differences between CONUS and OCONUS junior enlisted Marines.

Table 3.116

QOL DOMAIN: Satisfaction with USMC

Primary MOS Assignment

(V119): Gender

\begin{tabular}{|l|c|c|}
\hline & $\frac{\text { Male (N=6793) }}{\text { Percent }}$ & $\frac{\text { Female (N=733) }}{\text { Percent }}$ \\
\hline Dissatisfied & 27.60 & 34.65 \\
\hline Neutral & 18.34 & 19.10 \\
\hline Satisfied & 54.06 & 46.25 \\
\hline
\end{tabular}

Source: Author, Computed from FY 2001 USMC Retention Survey

Table 3.117

Primary MOS Assignment (V119): Cross-Tabulation Percentage

Gender by Race

Male $(\mathrm{N}=6254)$, Female $(\mathrm{N}=660)$

\begin{tabular}{|l|c|c|c|c|c|c|}
\hline & \multicolumn{2}{|c|}{ White } & \multicolumn{2}{c|}{ Black } & \multicolumn{2}{c|}{ Hispanic } \\
& M & F & M & \multicolumn{2}{|c|}{ M } & F \\
\hline Dissatisfied & 27.65 & 33.79 & 26.68 & 36.08 & 26.49 & 37.50 \\
& & & & & & \\
\hline Neutral & 17.12 & 16.55 & 20.32 & 22.68 & 22.58 & 27.34 \\
& & & & & & \\
\hline Satisfied & 55.23 & 49.66 & 53.00 & 41.24 & 50.92 & 35.16 \\
& & & & & & \\
\hline
\end{tabular}

Source: Author, Computed from FY 2001 USMC Retention Survey 
Table 3.118

Primary MOS Assignment (V119): Cross-Tabulation Percentage

Gender by Marital Status

Male $(\mathrm{N}=6616)$, Female $(\mathrm{N}=677)$

\begin{tabular}{|l|c|c|c|c|}
\hline & \multicolumn{2}{|c|}{ Single } & \multicolumn{2}{c|}{ Married } \\
\hline Dissatisfied & 27.41 & 34.16 & 27.94 & 36.26 \\
\hline Neutral & 18.63 & 17.33 & 17.76 & 21.25 \\
\hline Satisfied & 53.96 & 48.51 & 54.30 & 42.49 \\
\hline
\end{tabular}

Source: Author, Computed from FY 2001 USMC Retention Survey

Table 3.119

Primary MOS Assignment (V119): Cross-Tabulation Percentage Geographic Location (CONUS and OCONUS) Male $(\mathrm{N}=6685)$, Female $(\mathrm{N}=723)$

\begin{tabular}{|l|c|c|c|c|}
\hline & \multicolumn{2}{|c|}{ CONUS } & \multicolumn{2}{c|}{ OCONUS } \\
& M & F & 28.27 & 34.23 \\
\hline Dissatisfied & 27.50 & 34.97 & 17.13 & 17.12 \\
\hline Neutral & 18.56 & 19.44 & 54.60 & 48.65 \\
\hline
\end{tabular}

Source: Author, Computed from FY 2001 USMC Retention Survey

(2) Your family life while in the Marine Corps (V123). Table

3.120 depicts that over 40 percent of male and female junior enlisted Marines are dissatisfied with their family life while in the Marine Corps. As shown in Table 3.121, males of all races were more likely than females to say they were dissatisfied. Table 3.122 shows that married males and females were less likely than single junior enlisted Marines to have strong opinions about their family life in the Marine Corps; about fifty percent of married males and females were dissatisfied. Married males and females were also more likely than single Marines to say they were satisfied with family life in the Marine Corps (29.67 and 34.07 percent, respectively). CONUS males and females were slightly more likely (48.13 and 43.07, respectively) than OCONUS peers (44.59 and 41.82 percent, respectively) to say they were dissatisfied. 
Table 3.120

QOL DOMAIN: SATISFACTION WITH USMC

Your Family Life while in the Marine Corps

(V123): Gender

\begin{tabular}{|l|c|c|}
\hline & $\frac{\text { Male }(\mathbf{N}=6797)}{\text { Percent }}$ & $\frac{\text { Female }(\mathbf{N}=\mathbf{7 3 3})}{\text { Percent }}$ \\
\hline Dissatisfied & 47.54 & 42.70 \\
\hline Neutral & 35.31 & 33.29 \\
\hline Satisfied & 17.15 & 24.01 \\
\hline
\end{tabular}

Source: Author, Computed from FY 2001 USMC Retention Survey

Table 3.121

Your Family Life while in the Marine Corps (V123): Cross-Tabulation Percentage

Gender by Race

Male $(\mathrm{N}=6260)$, Female $(\mathrm{N}=660)$

\begin{tabular}{|l|c|c|c|c|c|c|}
\hline & \multicolumn{2}{|c|}{ White } & \multicolumn{2}{c|}{ Black } & \multicolumn{2}{c|}{ Hispanic } \\
\hline Dissatisfied & 49.19 & 44.14 & 41.17 & 39.80 & 45.19 & 42.52 \\
& & & & & & \\
\hline Neutral & 34.75 & 33.33 & 36.22 & 30.61 & 35.46 & 37.80 \\
\hline Satisfied & 16.06 & 22.53 & 22.61 & 29.59 & 19.35 & 19.69 \\
& & & & & & \\
\hline
\end{tabular}

Source: Author, Computed from FY 2001 USMC Retention Survey

Table 3.122

Your Family Life while in the Marine Corps (V123): Cross-Tabulation Percentage

Gender by Marital Status

Male $(\mathrm{N}=6620)$, Female $(\mathrm{N}=677)$

\begin{tabular}{|l|c|c|c|c|}
\hline & \multicolumn{2}{|c|}{ Single } & \multicolumn{2}{c|}{ Married } \\
& M & F & M & F \\
\hline Dissatisfied & 44.99 & 38.12 & 52.89 & 48.72 \\
\hline Neutral & 42.34 & 43.81 & 17.44 & 17.22 \\
\hline Satisfied & 12.67 & 18.07 & 29.67 & 34.07 \\
\hline
\end{tabular}

Source: Author, Computed from FY 2001 USMC Retention Survey 
Table 3.123

Your Family Life while in the Marine Corps (V123): Cross-Tabulation Percentage Geographic Location (CONUS and OCONUS)

Male $(\mathrm{N}=6689)$, Female $(\mathrm{N}=723)$

\begin{tabular}{|l|c|c|c|c|}
\hline & \multicolumn{2}{|c|}{ CONUS } & \multicolumn{2}{c|}{ OCONUS } \\
& M & F & M \\
\hline Dissatisfied & 48.13 & 43.07 & 44.59 & 41.82 \\
\hline Neutral & 33.92 & 31.97 & 42.09 & 39.09 \\
\hline Satisfied & 17.96 & 24.96 & 13.32 & 19.09 \\
\hline
\end{tabular}

Source: Author, Computed from FY 2001 USMC Retention Survey

While the cross-tabulations presented in this section provide valuable insights into the effect that QOL programs and QOL-related domains have upon junior enlisted Marines, further analysis is needed before conclusions and recommendations can be made. A final retention model that captures the retention decision for junior enlisted Marines as a function of theoretically relevant explanatory variables is provided in the next section. The final retention model will be analyzed further in Chapter IV of this thesis. 
THIS PAGE INTENTIONALLY LEFT BLANK. 


\section{MODEL SPECIFICATION AND RESULTS}

\section{A. FINAL RETENTION MODEL}

Based upon the theoretical underpinnings of the preliminary conceptual model for retention and the preliminary analysis presented in Chapter III, the following explanatory (independent) variables were chosen for further analysis.

\section{Retention=f(Demographic characteristics, QOL-programs and domains, Civilian employment opportunities)}

Table 4.1

Final Explanatory Variables

\begin{tabular}{|l|l|l|}
\hline DEMOGRAPHIC & $\begin{array}{l}\text { QOL PROGRAMS } \\
\text { AND DOMAINS }\end{array}$ & $\begin{array}{l}\text { CIVILIAN } \\
\text { EMPLOYMENT } \\
\text { OPPORTUNITIES }\end{array}$ \\
\hline $\begin{array}{l}\text { Paygrade, Race, } \\
\text { Marital Status, }\end{array}$ & $\begin{array}{l}\text { QOL Programs } \\
\text { MWR, Family Services, } \\
\text { Day Care, military } \\
\text { housing, medical benefits, } \\
\text { educational benefits }\end{array}$ & $\begin{array}{l}\text { Other employment } \\
\text { opportunities }\end{array}$ \\
\hline $\begin{array}{l}\text { QOL Domains } \\
\text { Leadership, USMC career, } \\
\text { MOS assignment, working } \\
\text { conditions, personal life, } \\
\text { family life, USMC culture, } \\
\text { Sense of Community }\end{array}$ & \\
\hline
\end{tabular}

Source: Author, Computed from FY 2001 USMC Retention Survey

A binary dependent variable, with responses coded either as "stay" or "leave," was originally specified for both male and female models. However, due to the relatively small number of useable female observations $(\mathrm{N}=464)$, those who responded "uncertain" to the stay-leave question were retained in the sample and an ordered dependent variable was created to explain the reenlistment intentions of junior enlisted female Marines. The ordered dependent variable has three values, "leave," "undecided," and "stay," increasing the number of female observations to 644. Both variables are described in detail in the following sections.

\section{Dependent Variable: Junior Enlisted Male Sample}

The dependent variable "REINTENT" is comprised of combinations of variable v116 for survey question 116, "Please describe your career intentions." For question 116, there are seven possible responses. For each survey response, the author has provided three 
mutually exclusive categories: STAY (Marine intends to reenlist), LEAVE (Marine intends to leave at EAOS), and DELETE (responses are deleted). Thus, the seven survey responses to survey question 116 were categorized as follows:

1. I intend to stay in the Marine Corps until I retire. (STAY)

2. I do not intend to retire/stay 20 years, but I do intend to reenlist. (STAY)

3. I intend to leave the Marine Corps as soon as my obligation is complete. (LEAVE)

4. I am undecided about my future with the Marine Corps. (DELETE)

5. I want to stay in the Marine Corps but don't think I will be allowed to stay. (DELETE)

6. I will probably leave the Marine Corps, but I would stay if I could change my job assignment. (LEAVE)

7. I will probably leave the Marine Corps, but I would stay if I could change my MOS. (LEAVE)

Based upon the literature review and the author's experience, survey responses coded as STAY indicate that the respondent is likely to reenlist in the Marine Corps. Conversely, LEAVE responses suggest that it is likely that the Marine will separate from the Marine Corps when his/her current obligation is completed. Responses 4 and 5 to question 116 were deleted since it is likely that Marines who provided this response do not have an opinion regarding reenlistment intentions or have disciplinary/administrative problems that would preclude reenlistment. Finally, responses 6 and 7 to question 116 were coded as "LEAVE" since respondents state that they will "probably leave."

\section{Dependent Variable: Female Junior Enlisted Marine Sample}

The dependent variable for the female sample uses three values: 1=LEAVE, $2=\mathrm{UNDECIDED}$, and $3=\mathrm{STAY}$. The following methodology was used to create the ordered dependent variable:

1. I intend to stay in the Marine Corps until I retire. (STAY)

2. I do not intend to retire/stay 20 years, but I do intend to re-enlist. (STAY)

3. I intend to leave the Marine Corps as soon as my obligation is complete. (LEAVE)

4. I am undecided about my future with the Marine Corps. (UNDECIDED)

5. I want to stay in the Marine Corps but don't think I will be allowed to stay. (DELETE)

6. I will probably leave the Marine Corps, but I would stay if I could change my job assignment. (LEAVE)

7. I will probably leave the Marine Corps, but I would stay if I could change my MOS. (LEAVE) 


\section{B. MODEL SPECIFICATION}

Question 116 of the FY 2001 USMC Retention Survey (Appendix A), asks junior enlisted Marines to provide their intentions regarding retention. As discussed earlier in this chapter, these questions were used to develop a dichotomous, binary dependent variable for the junior enlisted male Marine sample $(0=\mathrm{LEAVE}, 1=\mathrm{STAY})$ and an ordered dependent variable ( $1=$ LEAVE, $2=\mathrm{UNDECIDED}, 3=\mathrm{STAY}$ ) for junior enlisted female Marines. Both models are estimated using maximum likelihood techniques.

Binary responses (stay or leave) and ordered responses (stay, undecided, and leave) and their relationship with a set of explanatory variables can be further studied using logistic regression analysis (SAS, 2000). The linear logistic model has the form:

$$
\operatorname{logit}(\mathrm{p})=\log (\mathrm{p} / 1-\mathrm{p})=\alpha+\beta^{\prime} \mathrm{x}
$$

where $\alpha$ is the intercept parameter and $\beta$ is the vector of slope parameters (SAS, 2000). As discussed in Studenmund (2001), the coefficients created by the binary logit model, represent the impact of a one-unit increase in the independent (explanatory) variable, holding the other explanatory variables constant, on the log of the odds of a given choice, not on the probability itself. For ordinal response models, the SAS PROC LOGISTIC procedure fits a common slopes cumulative model, which is a parallel lines regression model based on the cumulative probabilities of the response categories (e.g., stay, undecided, and leave) rather than on their individual probabilities (SAS, 2000).

In the binary logit model, the estimated effect of the coefficient on reenlistment intention can be converted to a marginal effect, which is defined as the change in the probability of intending to reenlist given a 1-unit change in the explanatory variable. Changes in the explanatory variables are evaluated from a "base-case" junior enlisted Marine. The basecase refers to a junior enlisted Marine with certain characteristics, providing a baseline to measure unit changes in each explanatory variable. From the marginal effect, the percentage effect can be readily obtained, providing the percentage change in the probability of intending to reenlist. Together, marginal effects and percentage effects can be used to evaluate the impact of each explanatory variable in the conceptual model on the reenlistment intentions of junior enlisted Marines with base case characteristics.

Similarly, the ordered logit model provides the same set of explanatory variable coefficients as described for the binary logit model, but has two slopes that provide the 
predicted probabilities of the female junior enlisted Marine with base case characteristics intending to stay (Level 1) in the Marine Corps and the probability of the base case female staying or being undecided (Level 2). To calculate the probability of intending to leave, the probability of the junior female enlisted Marine staying or being undecided (Level 2) is subtracted from 1. Once the probabilities of each outcome have been calculated, the marginal effect and percentage change of each explanatory variable on each ordinal outcome can be determined (Kocher and Mar, 2001).

\section{EXPLANATORY VARIABLE SELECTION}

According to Studenmund (2001), the single most important determinant of a variable's relevance as a prediction of retention is its theoretical justification. Thus, explanatory variables were chosen primarily because they were well grounded in previous research.

Demographic explanatory variables were selected from survey questions 1 through 17. QOL program, QOL domain and civilian employment opportunity variables were selected from survey questions 18 through 131 (Appendix A). Due to the fact that survey questions 18 through 99 were coded based upon the perceived 'influence to stay or leave' the Marine Corps, these variables are endogenous or simultaneously determined. For example, respondents to survey question 77 (MWR program availability) chose it as being an 'influence to leave', 'no effect' (undecided) or 'influence to stay' in the Marine Corps on a seven-point Likert scale. In this context, the dependent variable (STAY, UNDECIDED, or LEAVE) is related to the independent variable (MWR programs) in addition to the effect other independent variables have on the dependent variable. To minimize this effect, a QOL index was created. The index is set equal to 1 for responses of 'influence to stay' for MWR (v77), Day Care (v75), and Family Service Center (v76) and set equal to 0 for all other responses. A similar index for Military Housing (quality/availability) was also created.

Survey questions 117 through 128 use 'satisfaction/dissatisfaction' on a five-point Likert scale. Since questions from this group represent QOL domains that fit the conceptual model, appropriate independent variables are chosen from this section. Finally, a dichotomous independent variable (CIVDIV) was created from survey question 130, "Do you believe that it would be easy to find employment that compensates as well as the 
Marines"? (Appendix A). If a junior enlisted Marine responded 'yes', CIVDIV was coded as equal to 1 . Responses of 'no' or 'don't know' were coded as equal to 0 .

As illustrated in Table 4.1 of this thesis, the following explanatory variables (with variable name in parenthesis) were chosen for inclusion in the logit model.

\section{Demographic Variables}

a. Paygrade (V8).

Paygrade is a continuous variable created from responses to survey question 8. Since the purpose of this thesis is to study junior enlisted Marines in paygrades E2 through E4, Marines in paygrades E1 or E5 and above were deleted. As Marines rise through the military grade hierarchy, they are likely to reveal characteristics that suggest the Marine Corps will be a good employment match for the individual. Additionally, the average Corporal (E4, 3 years TIS) makes $\$ 360$ more per month than a Private First-Class (E2) (DFAS, 2002). Thus, the expected effect of this variable is that a one-grade increase in paygrade will increase the likelihood that the junior enlisted Marine will intend to stay, ceteris paribus. The base case junior enlisted Marine is a Lance Corporal (paygrade E3).

\section{b. Race/Ethnic Group (BLACK).}

The variable BLACK (African-American) was created from survey question 5, "Are you: white, Black/African-American, Asian/Pacific Islander, Native American/Aleut/Eskimo, Other?" The variable BLACK is dichotomous, and was coded as BLACK $=1$, all others $=0$. The Marine Corps is expected to be a better career choice for African-American's due to improved opportunities for advancement compared to civilian alternatives. Therefore, African-American junior enlisted Marines with base case characteristics are expected to have a higher probability of intending to reenlist than nonAfrican-American junior enlisted Marines, ceteris paribus. The base case for junior enlisted Marines is non-African-American.

\section{c. Marital Status (MARRIED).}

The variable MARRIED was created from responses to survey question 6. The variable MARRIED is a dichotomous variable created by coding all respondents to survey question 2 as either married (1) or not married (0). Since the military provides relatively stable employment, it is expected that married junior enlisted Marines are more 
likely to intend to reenlist than single junior enlisted Marines, ceteris paribus. The base case for junior enlisted Marines is single, no dependents.

\section{d. Dependent Children (CHILDREN).}

The variable CHILDREN is dichotomous, and was created from responses to survey question 7, "Do you have any dependents?" Responses of 'dependent child(ren) living with me' and 'dependent children not living with me' were coded as 1 , all other responses were coded as 0 . As discussed above, the base case for junior enlisted Marines was single, with no family members (spouse or dependent children).

While only 15 percent of junior enlisted males and 20 percent of junior enlisted female Marines had dependent children, it is expected that junior enlisted Marines with children are more likely to intend to reenlist than junior enlisted Marines without children, ceteris paribus. As discussed in the section above, the stability of military employment and relatively generous benefits, including family service centers and day care, are expected to make the Marine Corps a better choice for junior enlisted Marines with children than civilian alternatives.

\section{QOL Programs}

\section{a. Quality of Life (QOL) Programs (QOL_PRGM).}

As discussed throughout this thesis, QOL programs are hypothesized to have a positive impact upon the reenlistment intentions of junior enlisted Marines. Kerce (1995) and other researchers have found that QOL programs are positively linked to retention. The QOL Program variable is an index that measures the availability of MWR Programs (V77), Family Service Centers (V76), and Day Care Centers (V75) on the retention intentions of junior enlisted Marines. For junior enlisted Marines who said that any one of these factors was an influence to stay in the Marine Corps, QOL_PRGM is coded as a 1. Marines who said that all of these factors had no effect, or were an influence to leave, are coded as 0 . As discussed earlier in this thesis, since most junior enlisted Marines are single males, Family Service Centers (FSC) and Day Care Centers are not likely to have a strong impact upon reenlistment intentions. However, the fact that these programs exist and provide evidence that the Marine Corps is concerned about the welfare of Marines and family members can contribute to positive perceptions of these programs by both users and non-users. MWR programs (V77) represent broad QOL programs such as commissaries, exchanges, fitness 
centers, golf courses, and the like. As discussed earlier in this thesis, Koopman and Goldhaber (1997) found that MWR and FSC had a positive impact upon retention. Thus, the effect of the variable QOL_PRGM is expected to increase the likelihood of intending to stay in the Marine Corps, ceteris paribus.

\section{b. Military Housing (MILHOUSE).}

The variable MILHOUSE was created as an index (similar to QOL_PRGM) of Military Housing Availability (V64) and Quality of Military Housing (V65). Junior enlisted Marines who said that either of these variables were an influence to stay in the Marine Corps were coded as 1; junior enlisted Marines who said either of these variables had no effect or were an influence to leave were coded as 0 . The effect of a one-unit increase in MILHOUSE is expected to increase the likelihood of intending to stay in the Marine Corps, ceteris paribus.

\section{c. Medical Benefits (V126).}

Satisfaction with medical benefits (V126) measures the level of dissatisfaction/satisfaction respondents reported with medical benefits. As discussed earlier in this thesis, responses were measured using a five-point Likert scale, with responses ranging from highly dissatisfied (0) to highly satisfied (5). The FY 1999 USMC Retention Survey (Kocher and Thomas, 2000) identified medical benefits as being a reason to stay for first term enlisted men and women. Thus, the expected effect of a one-unit increase in satisfaction with medical benefits (v126) is an increase in the likelihood of intending to stay in the Marine Corps, ceteris paribus.

\section{d. Educational Benefits (V127).}

Satisfaction with educational benefits (V127) measures the level of dissatisfaction/satisfaction respondents reported with education benefits while in the Marine Corps. Responses were measured using a five-point Likert scale, with responses ranging from highly dissatisfied (0) to highly satisfied (5). As discussed in Chapter III of this thesis, Garcia (1998) found that voluntary education programs have a positive impact upon retention. Thus, it is expected that for every one-unit increase in satisfaction with educational benefits (V127), the likelihood of intending to stay in the Marine Corps will increase, ceteris paribus. 


\section{QOL Domains}

\section{a. Leadership (V117).}

Satisfaction with leadership (V117) measures the level of dissatisfaction/satisfaction respondents reported with leadership in the Marine Corps. Responses were measured using a five-point Likert scale, with responses ranging from highly dissatisfied (0) to highly satisfied (5). Based upon the author's experience, it is hypothesized that junior enlisted Marines who are satisfied with USMC leadership are more likely to remain in the Marine Corps. Thus, the expected effect of leadership (V117) is that for every one-unit increase in satisfaction, the likelihood of intending to stay in the Marine Corps will increase, ceteris paribus.

\section{b. Marine Corps Career (V118).}

Satisfaction with your Marine Corps career (V118) measures the level of dissatisfaction/satisfaction respondents reported with their Marine Corps career. Responses were measured using a five-point Likert scale, with responses ranging from highly dissatisfied (0) to highly satisfied (5). As discussed in Chapter II, numerous studies find support (Kocher and Thomas, 1994 and Finn, 1988) for the positive impact that career and job satisfaction have on reenlistment behavior. Thus, the expected effect of a one-unit increase in satisfaction with the junior enlisted Marines career is an increase in the likelihood of intending to stay in the Marine Corps, ceteris paribus.

\section{c. Primary MOS Assignment (V119).}

Satisfaction with the primary MOS assignment (V119) measures the level of dissatisfaction/satisfaction respondents reported with their primary MOS assignment (Survey question 119, Appendix B). Responses were measured using a five-point Likert scale, with responses ranging from highly dissatisfied (0) to highly satisfied (5). Similar to variable V118 (satisfaction with your Marine Corps career), this variable is a more specific measure of how junior enlisted Marines feel about their military occupation specialty (MOS), or job assignment. While efforts are made to accommodate individual desires, such as 'guaranteed job' enlistment contracts, a mismatch may result between the needs of the Marine Corps and the MOS assignment preferred by the junior enlisted Marine. Thus, a one-unit increase in satisfaction with a junior enlisted Marine's primary MOS assignment 
(V119) is hypothesized to increase the likelihood of intending to stay in the Marine Corps, ceteris paribus.

\section{d. Current Duty Station (V120).}

Satisfaction with your current duty station (V120) is derived from survey question 120 ("Your current duty station"). This variable (V120) measures the level of dissatisfaction/satisfaction respondents reported with the junior enlisted Marines' current duty station. Responses were measured using a five-point Likert scale, with responses ranging from highly dissatisfied (0) to highly satisfied (5).

Ideally, duty station assignments are based upon a match between the preferences of the Marine Corps and the Marine. However, many junior enlisted Marines (similar to most junior officers) may not have adequate experience or guidance from leaders to influence their current duty station assignment. The expected effect of a one-unit increase in satisfaction with the junior enlisted Marine's current duty station (V120) is hypothesized to increase the likelihood of intending to stay in the Marine Corps, ceteris paribus.

\section{e. Working Conditions (V121).}

Satisfaction with working conditions is derived from survey question 121 ("Your working conditions in the Marine Corps"). Satisfaction with working conditions (V121) measures the level of dissatisfaction/satisfaction respondents reported with their working conditions in the Marine Corps. Responses were measured using a five-point Likert scale, with responses ranging from highly dissatisfied (0) to highly satisfied (5). The expected effect of this variable is that for every one-unit increase in satisfaction, the likelihood of intending to stay in the Marine Corps will increase, ceteris paribus.

\section{f. Personal Life (V122).}

Satisfaction with personal life (V122) is derived from survey question 122 ("Your personal life in the Marine Corps"). This variable (V122) measures the level of dissatisfaction/satisfaction respondents reported in their personal life in the Marine Corps. Responses were measured using a five-point Likert scale, with responses ranging from highly dissatisfied (0) to highly satisfied (5). The expected effect of this variable is that every one-unit increase in satisfaction, the likelihood of intending to stay in the Marine Corps will increase, ceteris paribus. 


\section{g. Family Life (V123).}

Satisfaction with family life (V123) is derived from survey question 123 ("Your family life in the Marine Corps"). This variable (V123) measures the level of dissatisfaction/satisfaction respondents reported in their personal life in the Marine Corps. Responses were measured using a five-point Likert scale, with responses ranging from highly dissatisfied (0) to highly satisfied (5). The expected effect of this variable is that every one-unit increase in satisfaction, the likelihood of intending to stay in the Marine Corps will increase, ceteris paribus.

\section{i. USMC Culture (V128).}

Satisfaction with the culture of the Marine Corps (V128) is derived from survey question 128 ("The culture of the Marine Corps"). This variable (V128) measures the level of dissatisfaction/satisfaction respondents reported with the culture of the Marine Corps. Responses were measured using a five-point Likert scale, with responses ranging from highly dissatisfied (0) to highly satisfied (5). The expected effect of this variable is that every one-unit increase in satisfaction, the likelihood of intending to stay in the Marine Corps will increase, ceteris paribus.

\section{j. $\quad$ Sense of Community (NO_BELONG).}

The variable NO_BELONG was derived from survey question 106 ("I do not feel a strong sense of belonging to the Marine Corps."). As discussed in Chapter II of this thesis, Van Laar (1999) defined "sense of community" as consisting of two elements: an emotional connection among members and identification with the community--the sense of belonging to a group. Table 2.2 of this thesis provides factors that are believed to increase "sense of community." NO_BELONG is a dichotomous variable: Junior enlisted Marines who agreed/strongly agreed with survey question 106 were coded as 1; otherwise, NO_BELONG is coded as 0 . The expected effect of this variable is that junior enlisted Marine responses coded as 1 are likely to intend to leave the Marine Corps.

\section{Civilian Employment Opportunities}

a. Easy to find employment that compensates as well as the Marines? (CIVDIV)

The variable CIVDIV was derived from survey question 130 ("Do you believe that it would be easy to find employment that compensates (pay and benefits) as 
well as the Marines?"). This variable is dichotomous; a response of 'yes' to survey question 130 was coded as 1 , otherwise, CIVDIV was coded as 0 . As discussed in Chapter II, previous research (Table 2.1) has established that military members who believe they can probably find a good civilian job are likely to pursue employment opportunities beyond the military. Accordingly, survey question 130 could be interpreted as a proxy for assessing the likelihood that a junior enlisted Marine will actively pursue civilian employment. The expected effect of this variable is that junior enlisted Marine responses coded as 1 (yes) are likely to intend to leave the Marine Corps.

Table 4.2 provides a summary of the explanatory variables and the hypothesized sign of each variable.

Table 4.2.

Explanatory Variables and Expected Signs

\begin{tabular}{|c|c|c|}
\hline Variable Name & Variable Type & Expected Sign \\
\hline Demographic & & \\
\hline Paygrade & Continuous & + \\
\hline White & Dichotomous & Base Case- \\
\hline Black & Dichotomous & + \\
\hline Single & Dichotomous & Base Case \\
\hline Children & Dichotomous & + \\
\hline QOL Programs & & + \\
\hline QOL_PRGM & Dichotomous & + \\
\hline MILHOUSE & Dichotomous & + \\
\hline Medical Benefits (V126) & Continuous & + \\
\hline Education Benefits (V127) & Continuous & - \\
\hline QOL Domains & \multicolumn{2}{|c|}{} \\
\hline NO_BELONG & Dichotomous & + \\
\hline CIVDIV & Dichotomous & + \\
\hline Leadership (V117) & Continuous & + \\
\hline USMC Career (V118) & Continuous & + \\
\hline Primary MOS (V119) & Continuous & + \\
\hline Current Duty Station (V120) & Continuous & + \\
\hline Working Conditions (V121) & Continuous & + \\
\hline Personal Life (V122) & Continuous & + \\
\hline Family Life (V123) & Continuous & + \\
\hline USMC Culture (V128) & Continuous & + \\
\hline Sample Sizes: Males =4,240; Females=464 & + \\
\hline Source: Author Coding of Variables in FY 2000 USMC Retention Survey \\
\hline
\end{tabular}




\section{RESULTS}

\section{Junior Enlisted Male Data Set}

The estimated logistic regression model for the junior enlisted male data set had a Likelihood ratio Chi-Square score of 1090.38 with 18 degrees of freedom, which was significant at the one percent level. Based upon this test, the null hypothesis that the explanatory variables are equal to zero (no explanatory power) can be rejected. Variance inflation factors (VIF) were calculated for each explanatory variable, and were within acceptable levels (VIF <2.05). As shown by Table 4.3, 15 of the 18 explanatory variables were statistically significant. With the exception of Current Duty Station (V120), signs were in the expected direction. Leadership (V117) was slightly above the .10 level of significance. With the emphasis that the Marine Corps places on leadership, the fact that this variable was not significant is surprising.

Table 4.3

Male Junior Enlisted Marines Reenlistment Intention Logit Model $(\mathrm{N}=4226)$

\begin{tabular}{|c|c|c|c|}
\hline Variable & Coefficient & Standard Error & Pr>Chi Sq \\
\hline Pay grade (V8) & $.2679 * * *$ & .0968 & .0057 \\
\hline QOL PRGM & $.5377 * * *$ & .1057 & $<.0001$ \\
\hline Black & $.5376 * * *$ & .1598 & .0008 \\
\hline Married & $.2656 * *$ & .1284 & .0386 \\
\hline Children & $.4647 * * *$ & .1518 & .0022 \\
\hline NO_BELONG & $-1.0920 * * *$ & .1538 & $<.0001$ \\
\hline CIVDIV & $-.6753 * * *$ & .1035 & $<.0001$ \\
\hline MILHOUSE & $.5177 * * *$ & .1151 & $<.0001$ \\
\hline Leadership (V117) & .0860 & .0544 & .1137 \\
\hline USMC Career (V118) & $.3272 * * *$ & .0630 & $<.0001$ \\
\hline Primary MOS (V119) & $.1218 * * *$ & .0471 & .0097 \\
\hline Current Duty Station (V120) & $-.1292 * * *$ & .0433 & .0029 \\
\hline Working Conditions (V121) & .0737 & .0586 & .2084 \\
\hline Personal Life (V122) & $.2410 * * *$ & .0581 & $<.0001$ \\
\hline Family Life (V123) & $.2835 * * *$ & .0613 & $<.0001$ \\
\hline Medical Benefits (V126) & $.1194 * *$ & .0583 & .0404 \\
\hline Education Benefits (V127) & .0693 & .05 & .1656 \\
\hline USMC Culture (V128) & $.3185 * * *$ & .0603 & $<.0001$ \\
\hline Goodness of Fit & Chi-Square & DF & Pr $>$ ChiSq \\
\hline Likelihood Ratio & 1090.36 & 18 & $<.0001$ \\
\hline
\end{tabular}

\footnotetext{
* $\quad$ Significant at 10 percent level
} 
** $\quad$ Significant at 5 percent level

*** $\quad$ Significant at 1 percent level

Source: Author, Computed from FY 2001 USMC Retention Survey

\section{Female Junior Enlisted Marine Data Set}

The logit model for the junior enlisted female data set had Likelihood Ratio ChiSquare score of 202.91 with 18 degrees of freedom and was significant at the one percent level. Variance inflation factors (VIF) were calculated for each explanatory variable, and were within acceptable levels (VIF <2.15). As shown by Table 4.4, eight of the 18 explanatory variables were significant. The variables MARRIED, Leadership (V117), Current Duty Station (V120), Family Life (V123), and Education Benefits (V127) did not have the expected sign. Furthermore, the fact that Education Benefits (V127) was not significant is surprising.

\section{Table 4.4}

Female Junior Enlisted Marine Reenlistment Intention Logit Model $(\mathrm{N}=640)$

\begin{tabular}{|c|c|c|c|}
\hline Variable & Coefficient & Standard Error & Pr $>$ Chi Sq \\
\hline Paygrade (V8) & .1438 & .1711 & .4006 \\
\hline QOL PRGM & .2381 & .1876 & .2044 \\
\hline Black & $.5739 * *$ & .2474 & .0204 \\
\hline Married & -.0780 & .1955 & .6899 \\
\hline Children & .2725 & .2280 & .2319 \\
\hline NO_BELONG & $-1.0647 * * *$ & .2166 & $<.0001$ \\
\hline CIVDIV & $-.4996 * * *$ & .1762 & .0046 \\
\hline MILHOUSE & $.6930 * * *$ & .2250 & .0021 \\
\hline Leadership (V117) & -.1117 & .0939 & .2345 \\
\hline USMC Career (V118) & $.3756^{* * *}$ & .1108 & .0007 \\
\hline Primary MOS (V119) & .0480 & .0824 & .5602 \\
\hline Current Duty Station (V120) & $-.1584 * *$ & .0762 & .0377 \\
\hline Working Conditions (V121 & $.2935 * * *$ & .0979 & .0027 \\
\hline Personal Life (V122) & .0984 & .1005 & .3277 \\
\hline Family Life (V123) & -.0230 & .1044 & .8256 \\
\hline Medical Benefits (V126) & .0852 & .0902 & .3447 \\
\hline Education Benefits (V127) & -.0382 & .0972 & .6943 \\
\hline USMC Culture (V128) & $.3156 * * *$ & .1126 & .0050 \\
\hline Goodness of Fit & Chi-Square & DF & Pr $>$ Chi Sq \\
\hline Likelihood Ratio & 202.91 & 18 & $<.0001$ \\
\hline
\end{tabular}

* $\quad$ Significant at 10 percent level 
** $\quad$ Significant at 5 percent level

*** $\quad$ Significant at 1 percent level

Source: Author, Computed from FY 2001 USMC Retention Survey

For both basic models, variables BLACK, NO_BELONG, CIVDIV, MILHOUSE, USMC Career (V118), Current Duty Station (V120), and USMC Culture (V128) were statistically significant. All had expected signs with the exception of Current Duty Station (V120).

\section{E. MARGINAL EFFECTS AND PERCENTAGE EFFECTS OF RETENTION FACTORS}

\section{Male Junior Enlisted Marine Data Set}

Marginal effects of the explanatory variables measure the impact of a one-unit change in each variable on the retention probability, holding all other variables constant. As shown in Table 4.5, the marginal effect for the variable Paygrade of .028 implies that, for two otherwise identical Marines, the probability of intending to reenlist is 2.8 percentage points higher for the Marine with the higher paygrade (e.g.. E4) compared to the Marine with the lower paygrade (e.g., E-3). Since the 'base case' junior enlisted male has a paygrade of E3 (Lance Corporal), an E4 (Corporal) with the same base case characteristics is 26.15 percent more likely to intend to reenlist (shown in column 2). Table 4.5 provides the marginal (percentage point) effect and percentage change effect of each variable on the reenlistment intention probability.

Table 4.5

Marginal Effects and Percentage Effects of Statistically Significant Variables on Male Reenlistment Intentions(N=4226)

\begin{tabular}{|l|c|c|}
\hline \multicolumn{1}{|c|}{ Variable } & Marginal Effect & \% Effect \\
\hline Paygrade (V8) & .028 & 26.15 \\
\hline QOL_PRGM & .063 & 58.62 \\
\hline Black & .063 & 58.53 \\
\hline Married & .028 & 26.62 \\
\hline Children & .053 & 49.16 \\
\hline NO_BELONG & -.068 & 63.91 \\
\hline CIVDIV & -.050 & -46.38 \\
\hline MILHOUSE & .061 & 56.58 \\
\hline USMC Career (V118) & .036 & 33.39 \\
\hline Primary MOS (V119) & .012 & 11.13 \\
\hline
\end{tabular}




\begin{tabular}{|l|c|c|}
\hline Current Duty Station (V120) & -.012 & -11.20 \\
\hline Personal Life (V122) & .025 & 23.19 \\
\hline Family Life (V123) & .030 & 27.82 \\
\hline Medical Benefits (V126) & .011 & 10.20 \\
\hline USMC Culture (V128) & .034 & 31.53 \\
\hline
\end{tabular}

Note: Base Case Reenlistment Intention Probability: 10.78\%

Source: Author, Computed from Table 4.3

\section{Female Enlisted Marine Data Set}

As discussed earlier in the chapter, an ordered dependent variable was used to analyze the reenlistment intentions of female junior enlisted Marines. The ordered dependent value measures female junior enlisted Marines intentions to either stay or leave, or to be undecided. Table 4.6 shows the probability of a base case junior enlisted female choosing one of these mutually exclusive outcomes. For example, a female junior enlisted Marine with base-case characteristics who agreed or strongly agreed $(=1)$ with survey question 106 ("I do not feel a strong sense of belonging to the Marine Corps") is -6.1 percentage points, or 63.18 percent, less likely to stay in the Marine Corps. Furthermore, the model estimates that this same Marine is -15.9 percentage points, or 49.0 percent, less likely than the base case Marine to be undecided about whether to stay or leave the Marine Corps. Finally, the model estimates that this same Marine is 22.1 percentage points, or 38.27 percent, more likely than the base case Marine to intend to leave the Marine Corps.

Table 4.6

Marginal and Percentage Effects

Statistically Significant Variables on Female Retention Intentions ( $\mathbf{N}=640)$ (Base Case Probability in Parenthesis)

\begin{tabular}{|l|c|c|c|c|c|c|}
\hline \multirow{2}{*}{ Variable } & \multicolumn{2}{|c|}{ STAY (.0967) } & \multicolumn{2}{c|}{ UNDECIDED (.3257) } & \multicolumn{2}{c|}{ LEAVE (.5775) } \\
\cline { 2 - 7 } & $\begin{array}{l}\text { Marginal } \\
\text { Percentage }\end{array}$ & $\begin{array}{l}\text { Effects } \\
\text { Effects }\end{array}$ & $\begin{array}{l}\text { Marginal } \\
\text { Percentage }\end{array}$ & $\begin{array}{l}\text { Effects } \\
\text { Effects }\end{array}$ & $\begin{array}{l}\text { Marginal } \\
\text { Percentage }\end{array}$ & $\begin{array}{l}\text { Effects } \\
\text { Effects }\end{array}$ \\
\hline BLACK & .062 & 65.09 & .079 & 24.42 & -.142 & -24.68 \\
\hline NO_BELONG & -.061 & -63.18 & -.159 & -49.0 & .221 & 38.27 \\
\hline CIVDIV & -.035 & -36.93 & -.079 & -24.33 & .115 & 19.91 \\
\hline MILHOUSE & .079 & 82.32 & .091 & 28.21 & -.171 & -29.70 \\
\hline $\begin{array}{l}\text { USMC Career } \\
\text { (V118) }\end{array}$ & .038 & 39.35 & .054 & 16.70 & -.092 & -16.01 \\
\hline $\begin{array}{l}\text { Current Duty } \\
\text { Station } \\
\text { (V120) }\end{array}$ & -.013 & -13.47 & -.025 & -7.69 & .038 & 6.59 \\
\hline
\end{tabular}




\begin{tabular}{|l|c|c|c|c|c|c|}
\hline $\begin{array}{l}\text { Working } \\
\text { Conditions } \\
\text { (V121) }\end{array}$ & .028 & 29.74 & .044 & 13.51 & -.072 & -12.60 \\
\hline $\begin{array}{l}\text { USMC Culture } \\
(\mathrm{V} 128)\end{array}$ & .031 & 32.32 & .047 & 14.43 & -.078 & -13.55 \\
\hline
\end{tabular}

Source: Author, Computed from Table 4.4

\section{F. BASIC RETENTION MODEL WITH INTERACTIONS}

In order to further explore the impact that additional, potentially important explanatory variables may have on the reenlistment intentions of junior enlisted male and female Marines, several extensions to the basic retention models were estimated. First, theoretically important interaction terms were created. An interaction term is an independent (explanatory) variable in a regression equation that is the multiple of two or more independent variables. Such interaction terms are used when the change in the dependent variable with respect to one independent variable depends on the level of another independent variable. Secondly, a variable for the Infantry (male model only) MOS assignment was added to the basic retention model. This MOS accounts for over 20 percent of male junior enlisted Marines. Table 4.7 summarizes the additional model specifications analyzed:

Table 4.7

Additional Logit Model Specifications

\begin{tabular}{|c|c|c|c|}
\hline Variable Name & Variable Components & $\frac{\text { Expected }}{\text { Direction }}$ & Results \\
\hline NO_BELBLACK & NO_BELONG*BLACK & Negative & $\begin{array}{c}\text { Significant for } \\
\text { females (see Tables } \\
4.8 \text { and 4.9); } \\
\text { insignificant for } \\
\text { males (see Table } \\
\text { C.1). }\end{array}$ \\
\hline MARRIEDED & MARRIED*SATISFACTION & Positive & $\begin{array}{c}\text { Significant for males } \\
\text { (see Tables 4.10 and } \\
\end{array}$ \\
& WITH EDUCATION & & $\begin{array}{c}\text { 4.11); insignificant } \\
\text { for females (see } \\
\text { Table C.2). }\end{array}$ \\
\hline MARRIEDQOL & MARRIED * QOL_PRGM & Positive & $\begin{array}{c}\text { Not significant for } \\
\text { males or females. }\end{array}$ \\
& & & $\begin{array}{c}\text { See Tables C.3 and } \\
\text { C.4. for more } \\
\text { information. }\end{array}$ \\
\hline MARRIEDFSC & MARRIED*FAMSVC & Positive & Not significant for \\
\hline
\end{tabular}




\begin{tabular}{|c|c|c|c|}
\hline & & & $\begin{array}{c}\text { males or females. } \\
\text { See Tables C.5. and } \\
\text { C.6. for more } \\
\text { information. }\end{array}$ \\
\hline MARRIEDMWR & MARRIED*MWR & Positive & $\begin{array}{c}\text { Not significant for } \\
\text { males or females. } \\
\text { See Tables C.7 and } \\
\text { C.8. for more } \\
\text { information. }\end{array}$ \\
\hline DEPDAYCARE & CHILDREN*DAYCARE & Positive & $\begin{array}{c}\text { Not significant for } \\
\text { males or females. } \\
\text { See Table C.9. and } \\
\text { C.10. for more } \\
\text { information. }\end{array}$ \\
\hline INFANTRY & $\begin{array}{c}\text { Junior enlisted Marines (male } \\
\text { only) with primary MOS of } \\
\text { 03XX (Infantry), Survey } \\
\text { question 11. }\end{array}$ & Negative & $\begin{array}{c}\text { Not significant (male } \\
\text { only). See Table } \\
\text { C.11. }\end{array}$ \\
& & & \\
\hline
\end{tabular}

\section{NO_BELBLACK (Interaction of NO_BELONG and BLACK)}

Based upon the theoretical foundations of both variables, it was expected that NO_BELONG ("Does not feel a strong sense of belonging to USMC") interacted with BLACK (African-American Marines) would show that African-American Marines who do not feel a strong sense of belonging to the USMC would be more likely to intend to leave the Marine Corps than the average Marine. This variable is dichotomous, with possible values of 0 or 1 depending upon the Marine's race and a positive response to survey question 106. As shown by Table 3.105 (Chapter III), African-American males and females were more likely than white Marines to say that they "do not feel a strong sense of belonging to the USMC." As depicted by Table C.1 (Appendix C), NO_BELBLACK was in the expected direction (negative) for African-American males but was not statistically significant. However, as shown in Table 4.8, NO_BELBLACK was statistically significant for African-American females (.0341) but was not in the expected direction (positive). 
Table 4.8

Reenlistment Intention Logit Model with NO_BELBLACK Variable(N=640, Female Junior Enlisted Marine)

\begin{tabular}{|l|c|c|c|}
\hline \multicolumn{1}{|c|}{ Variable } & Coefficient & Standard Error & Pr>Chi Sq \\
\hline NO_BELBLACK & $1.0819^{* *}$ & .5239 & .0389 \\
\hline Paygrade (V8) & .1464 & .1716 & .3937 \\
\hline QOL_PRGM & .2505 & .1884 & .1836 \\
\hline Black & .2448 & .2935 & .4042 \\
\hline Married & -.1003 & .1959 & .6089 \\
\hline Children & .2498 & .2286 & .2744 \\
\hline NO_BELONG & $-1.262^{* * *}$ & .2415 & $<.0001$ \\
\hline CIVDIV & $-.5160^{* * *}$ & .1768 & .0035 \\
\hline MILHOUSE & $.6565^{* * *}$ & .2258 & .0036 \\
\hline Leadership (V117) & -.1328 & .0947 & .1610 \\
\hline USMC Career (V118) & $.3734^{* * *}$ & .1113 & .0008 \\
\hline Primary MOS (V119) & .0508 & .0826 & .5386 \\
\hline Current Duty Station (V120) & $-.1487^{*}$ & .0767 & .0525 \\
\hline Working Conditions (V121) & $.2921^{* * *}$ & .0986 & .0030 \\
\hline Personal Life (V122) & .1026 & .1011 & .3101 \\
\hline Family Life (V123) & -.0342 & .1050 & .7450 \\
\hline Medical Benefits (V126) & .0827 & .0906 & .3613 \\
\hline Education Benefits (V127) & -.0262 & .0977 & .7886 \\
\hline USMC Culture (V128) & $.3260^{* * *}$ & .1134 & .0040 \\
\hline \multicolumn{1}{|c|}{ Goodness of Fit } & Chi-Square & DF & Pr>ChiSq \\
\hline Likelihood Ratio & 207.03 & 19 & $<.0001$ \\
\hline \multicolumn{2}{|c|}{ Sigificant }
\end{tabular}

* $\quad$ Significant at 10 percent level

** $\quad$ Significant at 5 percent level

*** Significant at 1 percent level

Table 4.9 provides marginal and percentage effects for the female junior enlisted Marine reenlistment intention logit model with the NO_BELBLACK variable. 
Table 4.9

Reenlistment Intention Logit Model

with NO_BELBLACK Marginal and Percentage Effects

for Statistically Significant Variables (N=640, Female Junior Enlisted Marine)

(Base Case Probability in Parenthesis)

\begin{tabular}{|l|c|c|c|c|c|c|}
\hline \multirow{2}{*}{ Variable } & \multicolumn{2}{|c|}{ STAY (.1022) } & \multicolumn{2}{c|}{$\begin{array}{c}\text { UNDECIDED } \\
\text { (.3364) }\end{array}$} & \multicolumn{2}{c|}{ LEAVE (.5613) } \\
\cline { 2 - 7 } & $\begin{array}{c}\text { Marginal } \\
\text { Effects }\end{array}$ & $\begin{array}{c}\text { Percentage } \\
\text { Effects }\end{array}$ & $\begin{array}{l}\text { Marginal } \\
\text { Effects }\end{array}$ & $\begin{array}{c}\text { Percentage } \\
\text { Effects }\end{array}$ & $\begin{array}{l}\text { Marginal } \\
\text { Effects }\end{array}$ & $\begin{array}{c}\text { Percentage } \\
\text { Effects }\end{array}$ \\
\hline NO_BELBLACK & 14.92 & 145.98 & 10.95 & 32.56 & -25.88 & -46.10 \\
\hline NO_BELONG & -7.10 & -69.45 & -18.65 & -55.44 & 25.75 & 45.88 \\
\hline CIVDIV & -3.85 & -37.74 & -8.19 & -24.36 & 12.05 & 21.47 \\
\hline MILHOUSE & 7.77 & 76.0 & 8.45 & 25.13 & -16.23 & -28.91 \\
\hline $\begin{array}{l}\text { USMC Career } \\
\text { (V118) }\end{array}$ & 3.96 & 38.77 & 5.32 & 15.83 & -9.29 & -16.55 \\
\hline $\begin{array}{l}\text { Current Duty } \\
\text { Station } \\
\text { (V120) }\end{array}$ & -1.28 & -12.57 & -2.33 & -6.94 & 3.62 & 6.45 \\
\hline $\begin{array}{l}\text { Working } \\
\begin{array}{l}\text { Conditions } \\
\text { (V121) }\end{array}\end{array}$ & 3.00 & 29.42 & 4.26 & 12.66 & -7.27 & -12.95 \\
\hline $\begin{array}{l}\text { USMC Culture } \\
\text { (V128) }\end{array}$ & 3.40 & 33.29 & 4.71 & 14.01 & -8.11 & -14.46 \\
\hline
\end{tabular}

* $\quad$ Significant at 10 percent

** $\quad$ Significant at 5 percent level

*** $\quad$ Significant at 1 percent level

2. MARRIEDED (Interaction of MARRIED and Satisfaction with Education Benefits)

Based upon the theoretical foundations of both variables, it was expected that MARRIEDED would have a positive impact upon the reenlistment intentions of junior enlisted Marines. As discussed in Table 3.10, satisfaction with education benefits (survey question 127, Appendix B) received the highest mean score from female junior enlisted Marines and was ranked six of 10 variables by male junior enlisted Marines (Table 3.9). Furthermore, according to Table 3.38, about 50 percent of married junior enlisted Marines said that the quality of education benefits was an influence to stay in the Marine Corps. Thus, the variable MARRIEDED was created to estimate the differential impact that the 
interaction of MARRIED and "Satisfaction with Education Benefits" would have on the reenlistment intentions of junior enlisted Marines.

As shown in Table 4.10, MARRIEDED is significant but is not in the expected direction. Table 4.11 shows that MARRIEDED reduces the likelihood of junior enlisted males with base case characteristics intending to reenlist by 1.55 percentage points, or 14.7 percent. It is also of note that variable V127, Satisfaction with Education Benefits, is statistically significant when MARRIEDED is added to the basic regression model. The basic regression model plus MARRIED was not statistically significant for junior enlisted females (see Appendix C). Table C.2 (Appendix C) provides logit regression results for female junior enlisted Marines.

Table 4.10

\section{Reenlistment Intention Logit Model with MARRIEDED} ( $N=4240$, Male Junior Enlisted Marines)

\begin{tabular}{|c|c|c|c|}
\hline Variable & Coefficient & Standard Error & Pr>Chi Sq \\
\hline MARRIEDED & $-.1731 *$ & .0969 & .0741 \\
\hline Paygrade (V8) & $.2703^{* * *}$ & .0968 & .0053 \\
\hline QOL PRGM & $.5462 * * *$ & .1058 & $<.0001$ \\
\hline Black & $.5408 * * *$ & .1600 & .0007 \\
\hline Married & $.8584 * *$ & .3546 & .0155 \\
\hline Children & $.4466^{* * *}$ & .1515 & .0032 \\
\hline NO_BELONG & $-1.090 * * *$ & .1537 & $<.0001$ \\
\hline CIVDIV & $-.6694 * * *$ & .1036 & $<.0001$ \\
\hline MILHOUSE & $.5138 * * *$ & .1151 & $<.0001$ \\
\hline Leadership (V117) & $.0907^{*}$ & .0545 & .0962 \\
\hline USMC Career (V118) & $.3244 * * *$ & .0631 & $<.0001$ \\
\hline Primary MOS (V119) & $.1224 * * *$ & .0471 & .0094 \\
\hline Current Duty Station (V120) & $-.1258 * * *$ & .0434 & .0037 \\
\hline Working Conditions (V121) & .0712 & .0586 & .2242 \\
\hline Personal Life (V122) & $.2380 * * *$ & .0582 & $<.0001$ \\
\hline Family Life (V123) & $.2873 * * *$ & .0614 & $<.0001$ \\
\hline Medical Benefits (V126) & $.1184 * *$ & .0583 & .0423 \\
\hline Education Benefits (V127) & $.1221 * *$ & .0587 & .0375 \\
\hline USMC Culture (V128) & $.3165 * * *$ & .0603 & $<.0001$ \\
\hline Goodness of Fit & Chi-Square & DF & Pr $>$ ChiSq \\
\hline Likelihood Ratio & 1093.52 & 19 & $<.0001$ \\
\hline
\end{tabular}

* $\quad$ Significant at 10 percent

** $\quad$ Significant at 5 percent level

*** $\quad$ Significant at 1 percent level 
Table 4.11

\section{Reenlistment Intention Logit Model with Marginal Effects and Percentage Effects \\ MARRIEDED \\ (N=4240, Male Junior Enlisted Marines)}

Base Case Reenlistment Intention Probability: 10.51 Percent

\begin{tabular}{|l|c|c|}
\hline \multicolumn{1}{|c|}{ Variable } & Marginal Effect & \% Change \\
\hline MARRIEDED & -.015 & -14.74 \\
\hline Paygrade (V8) & 2.79 & 26.50 \\
\hline QOL_PRGM & 6.30 & 59.90 \\
\hline Black & 6.23 & 59.27 \\
\hline Married & 11.13 & 105.89 \\
\hline Children & 4.95 & 47.09 \\
\hline NO_BELONG & -6.73 & -64.03 \\
\hline CIVDIV & -4.86 & -46.24 \\
\hline MILHOUSE & 5.85 & 55.66 \\
\hline USMC Leadership (V117) & .85 & 8.08 \\
\hline USMC Career (V118) & 3.42 & 32.54 \\
\hline Primary MOS (V119) & 1.17 & 11.13 \\
\hline Current Duty Station (V120) & -1.16 & -11.03 \\
\hline Personal Life (V122) & 2.42 & 23.02 \\
\hline Family Life (V123) & 2.98 & 28.35 \\
\hline Medical Benefits (V126) & 1.13 & 10.75 \\
\hline Education Benefits (V127) & 1.17 & 11.13 \\
\hline USMC Culture (V128) & 3.33 & 31.68 \\
\hline
\end{tabular}

\section{MARRIEDQOL (Interaction of MARRIED and QOL_PRGM).}

Based upon the theoretical foundations of both variables discussed earlier, it was expected that MARRIEDQOL would have a positive impact upon the reenlistment intentions of junior enlisted Marines. As shown in this thesis, MARRIED and QOL_PRGM were individually significant for junior enlisted male Marines (Table 4.3). Thus, it was expected that the interaction of these variables would result in a significant, positive effect on reenlistment intentions of junior enlisted Marines. However, MARRIEDQOL was not significant for male or female logit models (Tables C.3 and C.4, Appendix C).

\section{MARRIEDFSC (Interaction of MARRIED and FAMSVC).}

Based upon the theoretical foundations of both variables discussed earlier, it was expected that MARRIEDFSC would have a positive impact upon the reenlistment intentions of junior enlisted Marines. As shown above, MARRIED was significant for males (Tables 
4.3). The variable FAMSVC (Availability of Family Services) is a binary, dichotomous variable coded as 1 if the junior enlisted Marine said the availability of Family Support Services (v76) was an influence to stay in the Marine Corps. All other responses were coded as 0 . Thus, it was expected that the interaction of these variables would result in a significant, positive effect on reenlistment intentions of junior enlisted Marines. However, as shown by Tables C.5 and C.6, MARRIEDFSC was not significant for male or female logit models.

\section{MARRIEDMWR (Interaction of MARRIED and MWR).}

Based upon the theoretical foundations of both variables, it was expected that MARRIEDMWR would have a positive impact upon the reenlistment intentions of junior enlisted Marines. As shown above, MARRIED was significant for males (Table 4.3). MWR (MWR Program Availability) is a binary, dichotomous variable coded as 1 if the junior enlisted Marine said MWR program availability was an influence to stay in the Marine Corps. All other responses were coded as 0 . Thus, it was expected that the interaction of these variables would result in a significant, positive effect on reenlistment intentions of junior enlisted Marines. However, as shown by Tables C.7 and C.8, MARRIEDMWR was not significant for male or female logit models.

\section{DEPDAYCARE (Interaction of CHILDREN and DAYCARE).}

Based upon the theoretical foundations of both variables, it was expected that DEPDAYCARE would have a positive impact upon the reenlistment intentions of junior enlisted Marines. As shown above, CHILDREN was significant for males (Table 4.3). DAYCARE (Availability of Day Care) is a binary, dichotomous variable coded as 1 if the junior enlisted Marine said the availability of Day Care was an influence to stay in the Marine Corps. All other responses were coded as 0 . Thus, it was expected that the interaction of these variables would result in a significant, positive effect on reenlistment intentions of junior enlisted Marines. However, as shown by Tables C.9 and C.10, DEPDAYCARE was not significant for male or female logit models.

\section{INFANTRY.}

Approximately 20 percent of junior enlisted male Marines who responded to the FY 2001 USMC Retention Survey are assigned the infantry (03XX) primary MOS. Since lateral moves from other MOS into infantry generally do not occur, these junior enlisted 
Marines will eventually be the Squad Leaders (Sergeant, E5) and Platoon Sergeants (Staff Sergeant, E6) of the future. It can be said that without infantry, there is no Marine Corps. Thus, the retention of these Marines is essential to the future of the Marine Corps.

INFANTRY is a binary, dichotomous variable coded as 1 if the junior enlisted Marine said he (current policy allows only male Marines to be assigned the 03XX MOS) was assigned the primary MOS of 03XX. All other responses were coded as 0 . Due to the arduous physical and mental demands of life in infantry units, it was expected that INFANTRY junior enlisted Marines were more likely to leave the Marine Corps than nonINFANTRY junior enlisted Marines, ceteris paribus. However, as shown by Table C.11, INFANTRY was not significant. 
THIS PAGE INTENTIONALLY LEFT BLANK 


\section{SUMMARY, CONCLUSIONS AND RECOMMENDATIONS}

This thesis investigates the impact of United States Marine Corps Quality of Life (QOL) programs and QOL domains on the retention intentions of junior enlisted Marines. The data used for this thesis were drawn from the FY 2001 United States Marine Corps Retention Survey. Restrictions imposed on the data were: Marine Corps enlisted members, paygrades E-2 to E-4; with active duty base dates during calendar year 1998 and 1999, with a current age between 18 and 31 . From these data, bivariate crosstabulation analysis was conducted and a multivariate logit regression model was estimated to determine the impact that certain QOL programs and QOL domains have on the reenlistment intentions of junior enlisted Marines. Based upon the research presented in Chapters III and IV, the primary research questions introduced in Chapter I and listed below have been answered.

1. What impact do specific QOL programs and QOL domains have on the reenlistment intentions of junior Marines?

2. What QOL programs and QOL-related domains (e.g., work conditions, job satisfaction) are important to junior enlisted Marines?

3. Are there differences in QOL programs and related QOL domains between different geographic locations (CONUS and OCONUS)?

There are several limitations to this thesis. First, as discussed in Chapter III, the response rate for the FY 2001 USMC Retention Survey was only about 30 percent. As suggested by Edwards, et al., (1997), demographic characteristics of survey respondents were compared with the demographics of the junior enlisted Marine population (Table 3.1). According to Table 3.1, survey respondents were demographically similar to the actual population of junior enlisted Marines, except that males and blacks are slightly under-represented in the survey and females and married E- $2 \mathrm{~s}$ are slightly over-represented. Regardless, the fact that almost 70 percent of Marines of all grades chose not to participate in the FY 2001 survey suggests that non-response bias is likely to affect the results. Second, the conceptual model presented in this thesis uses reenlistment intentions instead of actual reenlistment behavior as the dependent variable. As discussed in Chapter III of this thesis, reenlistment intentions are an accurate predictor of actual reenlistment behavior if three conditions are met: 
1. There must be correspondence between the measure of intention and the measure of behavior as to the target, action, time, and context.

2. Intentions change over time. The longer the time interval, the less accurate is the prediction of behavior from intention. In other words, the closer to the decision point, the more accurate is the intention as a predictor of behavior.

3. Aggregate intentions are used. Aggregate intentions are much more stable than individual intentions over time, because incidents--like injuries, illness, pregnancy, money losses, etc.,---are likely to balance out at the aggregate level. Predictions of behavior from intentions at the aggregate level are therefore often remarkably accurate. (Aizen and Fishbein, 1980).

Due to privacy concerns, the survey database with social security numbers could not be obtained for this thesis. Social security numbers are useful in matching respondent data with actual personal data from data warehouses such as the Defense Manpower Data Center (DMDC) or files from manpower planners at HQMC. Therefore, the survey data were restricted by using active duty base date (ADBD) and other self-reported data. The fact that $\mathrm{ADBD}$ and other self-reported data, such as paygrade, primary MOS, and other information could not be verified may weaken the reliability of the results provided in this thesis. Finally, the small sample size for non-white females $(\mathrm{N}<300)$ reduces the reliability of the findings discussed in this analysis for this group. Male and female Asian and Native American observations for the bivariate analysis discussed in Chapter III were deleted due to the low number of observations.

\section{A. SUMMARY}

Male and female junior enlisted Marines who said that they do not feel a sense of belonging to the Marine Corps are more likely to intend to leave the Marine Corps than other junior enlisted Marines. Van Laar (1999) defines sense of community as consisting of two elements: social support--an emotional connection among members--and identification with the community--the sense of belonging to a group. Programs such as Marine Corps Family Team Building (MCFTB) and the 'Single Marine' program are hypothesized to increase sense of community by strengthening the "attachment to other people, the workgroup, and the organization" (Van Laar, 1999). According to Van Laar (1999), the perception of leadership supportiveness also is an important component of 
social support. When junior enlisted Marines were asked about their trust in Marine leadership, over 40 percent of male and 50 percent of female junior enlisted Marines said it was an influence to leave the Marine Corps. This thesis also found further evidence that the emotional connection to the Marine Corps amongst junior enlisted Marines is fragile-- about 40 percent said they did not feel emotionally attached to the Marine Corps. Additionally, over 40 percent of junior enlisted Marines said they were dissatisfied with their family life in the Marine Corps. Thus, the sense of community QOL domain is a rich source of information concerning the morale (or 'espirit de corps') and reenlistment intentions of junior enlisted Marines.

What junior enlisted Marines said about USMC culture and values is closely related to the sense of community QOL domain. Junior enlisted Marines who were more satisfied with USMC Culture were more likely to intend to reenlist. Over 70 percent of junior enlisted Marines agreed that 'what the Marine Corps stands for is important to me.' This result is understandable from a common-sense perspective.

The appeal of the Marine Corps is also understandable. As discussed earlier in this thesis, the majority (about 60 percent) of the current USMC active duty population consists of junior enlisted Marines in paygrade E2-E4. Accordingly, the trends that affect society are likely to affect these Marines. Wilcox (2001) discussed the trends that shape the current generation of junior enlisted Marines, known as 'Millenials' (born after 1981). As illustrated earlier in this thesis, the average age of junior enlisted Marines is just over 21 years (born after 1980). Thus, many junior enlisted Marines studied in this thesis are likely to belong to the Millenial group. Wilcox (2001) found that, to Millenials, "the greatest appeal of the Marine Corps, and the one that makes the service unique, is 'SelfImprovement' and 'Challenge/Best'." Additionally, Wilcox (2001) found that the "widest appeal for the Marine Corps lies in the idea of being the best or toughest." Thus, these attributes are likely to summarize what USMC culture and values mean to many junior enlisted Marines. One needs only to look at the latest USMC ads in print or on television to be reminded of the self-improvement, challenge, and toughness that is attributed to the Marine Corps. Compared to the other services and civilian organizations, the Marine Corps culture and values clearly stand out. 
This thesis also shows that junior enlisted Marines who believe that they can easily find civilian employment that compensates as well as the Marine Corps are more likely to leave the Marine Corps than the average Marine. According to Ehrenberg and Smith (2000), workers (e.g., junior enlisted Marines) will have a higher probability of quitting (e.g., leave at EAOS) when it is relatively easy for them to obtain a better job quickly.

This thesis provides evidence that the availability and quality of military housing are important factors in the reenlistment intentions of junior enlisted Marines. According to Ed Rogers, Marine Corps Base Camp Pendleton, California facilities manager, the base has a $\$ 137$ million backlog for military construction projects--an amount he describes as "terribly underestimated." (Himmelspach, 2001) The situation at Camp Pendleton exemplifies what senior leaders acknowledge as one of the most serious problems facing the Marine Corps. The Sergeant Major of the Marine Corps, Sergeant Major Alford McMichael, in testimony to the House military construction (MILCON) subcommittee said "I continue to meet with the spouses and children of Marines in family housing that should have been demolished 20 years ago but remain standing because we have no other choice." (Maze, 2002) As reported in this thesis, junior enlisted Marines who said that the availability or quality of military housing were influences to stay in the Marine Corps are more likely to intend to reenlist. Thus, this thesis provides additional information for leaders to justify continued improvement of military housing and increased investment in MILCON.

This thesis also shows that junior enlisted Marines who are satisfied with their careers are more likely to intend to reenlist in the Marine Corps. This finding corroborates numerous other studies that have found similar evidence for civilian and military people. As discussed earlier in this thesis, 'USMC Career' is a broad QOL dimension. Though not highly correlated with other variables used in this analysis, USMC Career is hypothesized to represent the junior enlisted Marine's satisfaction with his/her current and future career prospects. It is unlikely that a junior enlisted Marine would say that he/she was satisfied/highly satisfied career unless this individual believed that current and future career prospects were good. 
As shown in Chapter IV of this thesis, junior enlisted Marines who were satisfied with his/her current duty station were more likely to leave the Marine Corps. This result is contrary to the author's a priori expectations. However, this result can be explained by using some of the tenants of human capital theory (Ehrenberg and Smith, 2001) discussed earlier. It makes economic and common sense that Marines who are satisfied with their current duty station may want to 'homestead', and remain in the area permanently. This decision may be based upon a combination of economic and personal factors that, while beyond the scope of this thesis, are worthy of further research.

\section{B. CONCLUSIONS}

As shown in Chapters III and IV of this thesis, QOL programs and QOL domains have an impact on the reenlistment intentions of junior enlisted Marines. Junior enlisted Marines who said that the availability of MWR, daycare, or Family Service Center (FSC) availability was an influence to stay in the Marine Corps were more likely to intend to reenlist. The availability and quality of voluntary education benefits were also an influence to stay in the Marine Corps for most junior enlisted Marines. On the other hand, the quality of military housing was viewed by most junior enlisted Marines as an influence to leave the Marine Corps. Marines who said that the quality or availability of military housing was an influence to stay were more likely to intend to reenlist in the Marine Corps.

Of the QOL domains that were found in this thesis to be statistically significant, a sense of community was the most intriguing. It makes common-sense that Marines who do not feel emotionally attached or a sense of belonging to the Marine Corps are more likely to intend to leave. Given the emphasis that the Marine Corps places on espirit de corps and programs like Single Marine and Family Team Building, it is surprising that many junior enlisted Marines said that they do not feel attached to the Marine Corps. It is not surprising that Marines who do not feel a sense of belonging to the Marine Corps are not likely to intend to reenlist.

Finally, OCONUS and CONUS junior enlisted Marines were largely similar in their responses. Some differences were found in QOL programs such as MWR program availability, military housing, and the availability and quality of education benefits. However, these differences were not large enough to conclude that there are potentially 
significant differences between how QOL programs and QOL domains are perceived by OCONUS and CONUS junior enlisted Marines.

\section{RECOMMENDATIONS}

As discussed earlier in this thesis, QOL has many definitions. While most academically accepted versions incorporate subjective and/or objective QOL measures, former Sergeant Major of the Marine Corps Lewis G. Lee declared that QOL is "coming home alive" (Fuentes, 1999). Though this statement on the surface appears to be contrary to what many policy-makers and senior military leaders have said about QOL, I believe that it captures the primary responsibility of military leadership: prepare our soldiers, sailors, airmen, and Marines so that they are successful on the battlefield and can safely return home.

With 'coming home alive' as the basis for defining military QOL, the primary focus of policy-makers should be to continue pursuing the training and materiel that will enable our forces to be successful on the battlefield ('readiness'). QOL programs and domains should be viewed as contributing to the desired outcome of readiness by the positive impact they may have on retention. The Marine Corps can improve the impact that QOL programs and QOL domains have on these desired outcomes by implementing the following recommendations.

\section{Increase Participation by Junior Enlisted Marines and Family Members in the Marine Corps Family Team Building and Single Marine Programs.}

The theoretical and statistical importance of 'sense of belonging' to the Marine Corps and Marine Corps culture shown in this thesis provides additional justification for programs such as Marine Corps Family Team Building and the Single Marine Program. Both programs provide opportunities for building positive social relationships and skills that help the Marine and family members to thrive in the dynamic Marine Corps culture. Leaders should continue to emphasize use of these programs by junior enlisted Marines and their family members. Additionally, the upcoming FY 2002 USMC QOL Study should analyze the impact that these specific programs have on the reenlistment behavior of junior enlisted Marines. 


\section{Continue to improve the Quality and Availability of Military Housing for Junior Enlisted Marines.}

As shown in this thesis, most junior enlisted Marines said the quality of military housing was a reason to leave the Marine Corps. By continuing to focus on repairing and replacing unsatisfactory military housing, the Marine Corps should improve the likelihood of junior enlisted Marines intending to reenlist. The FY 2003 MILCON budget for Marine family housing is 20 percent, higher than FY 2002 (Jowers, 2002). The increased spending is part of the Marine Corps goal to fix or replace dilapidated family housing by 2005 (Jowers, 2002). Furthermore, privatization efforts promise to improve the availability and quality of military housing. These efforts should continue.

\section{Use Probability Samples for Future Surveys.}

As discussed throughout this thesis, the FY 2001 USMC Retention Survey was intended to be completed by all active duty Marines (less Marines in transit between duty stations and initial training). According to HQMC representatives, 150,000 surveys were mailed, resulting in approximately 40,000 usable observations (America, 2001). While conducting a census survey has many potential benefits, including increasing "face validity" and suggesting the senior leadership cares enough about employees (e.g., Marines) to ask for their input, it can also be logistically and financially impossible (Edwards, et al., 1997). Probability sampling, on the other hand, enables the organization

to focus resources more efficiently, resulting in a better response rate than the census survey. As the famous pollster George Gallup noted, "an accurate blood test requires only a few drops of blood". (Edwards, et al., 1997). Thus, accurate generalizations can be made from data drawn from a representative sample (Henry, 1990).

\section{Results of this Thesis should be used by FY 2002 USMC QOL Study Team.}

This thesis will be forwarded to the FY 2002 USMC QOL Study team (HQMC, MRE) upon its completion. This thesis will provide the QOL Study team with relevant data about the impact of QOL programs and QOL domains on the reenlistment intentions of junior enlisted Marines (Chapter IV) and a summary of what demographic subsets of respondents said about QOL programs and QOL domains (Chapter III). These data can 
provide the QOL Study team with a baseline from which to gauge changes in the opinions and reenlistment propensity of junior enlisted Marines.

\section{Use Conceptual Model with Actual Retention Data.}

As shown by this thesis, the conceptual model for reenlistment intentions of junior enlisted Marines has provided useful data. Future research should be conducted using FY 2001 USMC Retention Survey data (with respondent social security number) and a USMC enlisted master file (available from HQMC/MPP) to determine how well the model predicts junior enlisted Marines retention decision. If this recommendation is implemented, the true usefulness of the predictive capability of the regression equations used in this thesis will be better understood. 
APPENDIX A: FY 2001 USMC RETENTION SURVEY

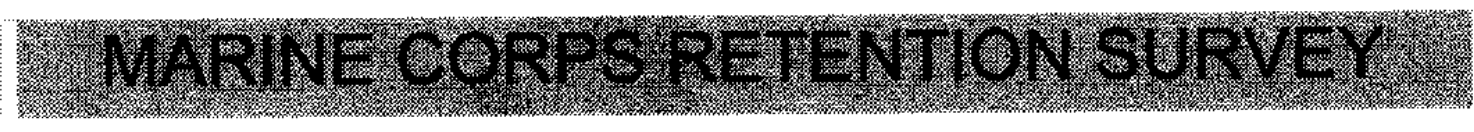

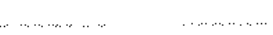

This survey concerns how you feel about different aspects of your career as a Marine and your life in generat. Because all people don't feel the same way about being a Marine, there is no right or wrong answer.

The survey is being mailed to every Marine in the Corps. Please note that this survey is not anonymous. This survey was designed by the Navy Personnel Research, Studies, and Technology Department. Your completed stervey will be mailed directly back to them. They will then analyze the information you provide and present summary results to the Headquarters USMC. Your Information is strictly confidential. That is, no one will see your individual responses. We are interested in your opinions. Your answers will help us understand retention in the Marire Corps.

\section{PRIVACY ACT STATEMENT}

Public Law 93-579. called the Privacy Act of 1974, requires that you be informed of the purpose of this survey and of the uses to be made of the information collected. The Navy Personnel Research, Studies, and Technology Department may collect the information requested in this survey under the authority of Title 5, U.S. Code 301

The information collected in this survey will be used to evaluate existing and proposed policies, procedures, and programs in the Marine Corps. The data will be analyzed and maintained by the Navy Personnel Research, Studies, and Technology Department.

Providing information is completely voluntary. All responses will be held in confidence. The information you provide will be considered only when statistically combined with the responses of others, and will not be identified with any single individual The intormation will not became part of your permartent record and will not affect your career in any way. Failure to respond to any question will not result in any penalties except the lack of your opinions in the survey results.

If you have any questions, please call
Dr. Michael White, D\$N $882-4659$ or (901) $874-4659$
Navy Personnel Research, Studies, and Technology Department
Milington, Tennessee $38055+1300$

MARKING INSTRUCTIONS

- Use a No. 2 PENCIL ONLY.

- DO NOT USE ink, ballpoint or felt tip perts.

- Erase cleanly and completely any changes your make.

- Make black marks that fill the circle.

- When applicable, write the numbers in the boxes at the top of the block

- Do not make stray marks on the form.

- Do not fold, tear, or mutilate this form.

\section{EXAMPLES}

1. What is your gender?

Male

\footnotetext{
- Female
}

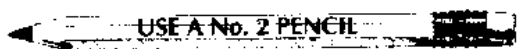

INCORRECT: $\because X \bigcirc$

CORRECT: 


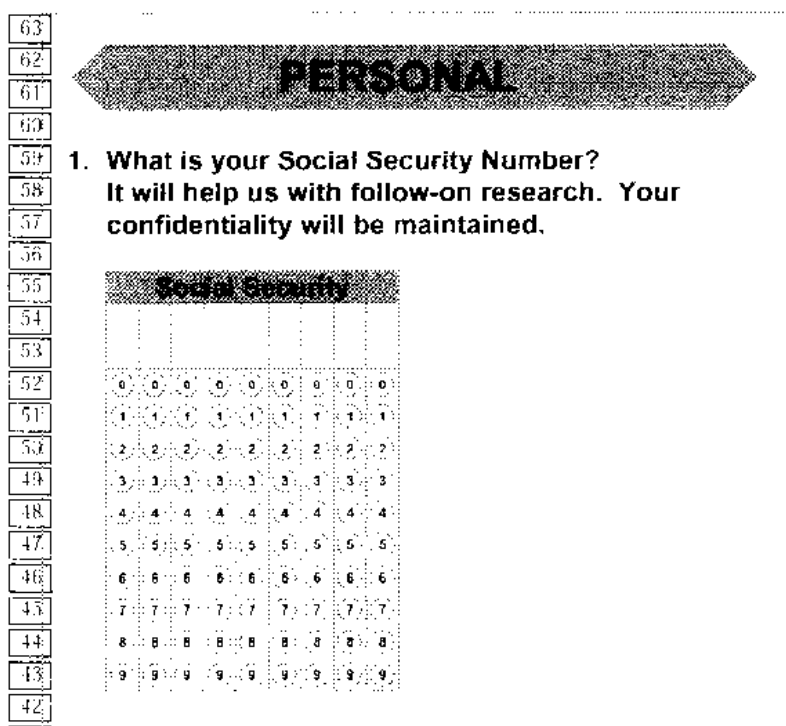

2. What is your gender?

\section{Malé}

Female

3. What is your age?

$$
\begin{aligned}
& \text { Years } \\
& \text { - } 0 \\
& \because 1 \quad 1 \\
& \text { :2:2 } \\
& \text { : } 3 \\
& \text { :4 } 4 \\
& \begin{array}{lll}
: 5 & 5 \\
\hline
\end{array} \\
& \because 6 \\
& 7 \\
& \text { - }
\end{aligned}
$$

4. Are you of Spanish/Hispanic descent?

$$
\text { Yes }
$$

No

5. Are you:

White

Black/African-American

Asian/Pacific Islander

Native American/Aleut/Eskimo

Other

\begin{tabular}{|c|c|c|}
\hline E-1 & $\therefore \quad W-1$ & 0.1 \\
\hline$E-2$ & $W-2$ & $\mathrm{O}-2$ \\
\hline$E-3$ & $w-3$ & $0-3$ \\
\hline$E-4$ & $W-4$ & $0-4$ \\
\hline E-5 & $W-5$ & $0-5$ \\
\hline$E-6$ & & Q-6 \\
\hline E-7 & $0-1 E$ & 0-7 or above \\
\hline E-8 & $\mathrm{O}-2 \mathrm{E}$ & \\
\hline & O-3E & \\
\hline
\end{tabular}

\section{What is your marital status?}

Never been married

Married

Married but separated

Divorced

Widowed
7. Do you have any dependents? (Mark ALL that apply.)

$$
\begin{aligned}
& \text { No, i have no dependents } \\
& \text { Spouse (non-military) } \\
& \text { Dependent child(ren) living with me } \\
& \text { Dependent child(ren) not living with me } \\
& \text { Legal ward(s) living with me } \\
& \text { Dependent parent(s) or other relative(s) } \\
& \text { Spouse (military) }
\end{aligned}
$$

8. What is your paygrade?

9. What is the date of rank for your current paygrade?

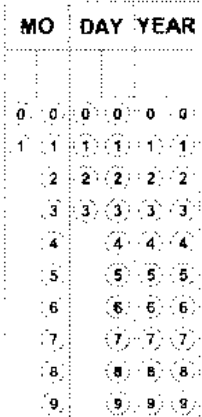

10. What is your active duty base date (the first day you were on active duty)?

$$
\text { MO DAY YEAR }
$$

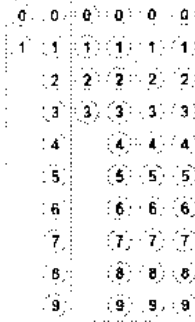


11. What are your primary MOS and billet/duty MOSs?

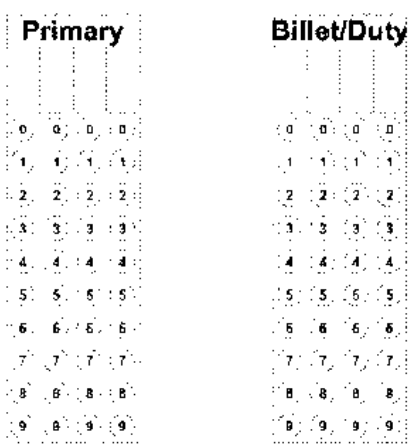

12. Where are you stationed?

CONUS, currently deployed CONUS, currently not deployed Overseas, currently deployed

Overseas, currently not deployed

13. Are you a geographic bachelor?

Yes (If YES answer the following question) No (If NO, skip to question 15)

14. Are you a geographic bachetor because of: (Mark ALL that apply.)

Your spouse's job

Your children's school

Cost of living at this location

Moving costs for family

Personal preferences of self or spouse

Other (specify)
15. How many months have you been deployed in the last 12 months?

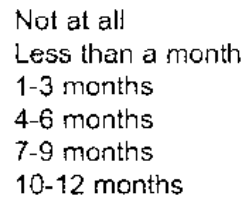

Not at all

Less than a month

1-3 months

$4-6$ months

$7-9$ months

$10-12$ months

16. Have you worked at a civilian job during the last month?

Yes (go to question 17 )

No (go to question 18)

17. Why did you take this job? (Mark ALL that apply.)

I just enjoy this lype of work

My current military salary does not pay my bills

I want to save/invest the money from my second job

I just want to eam some extra money (buy nicer car, clothes, etc.)

I have to pay off an oid debt or correct past financial mistakes

I am obtaining experience for when I get out of the Marine Corps

Using the scale below, please indicate whether the following factors have influenced your decision to stay, to leave, or had no effect on your Marine career intentions.

18. The quality of leadership at the senior officer loval

19. The quality of leadership at the junior officer level

20. The quality of leadership at the warrant officer level

21. The quality of leadership at the SNCO level

22. The quality of leadership at the NCO level

23. The quality of leadership of your immediate supervisor

24. Your trust in Marine leadership

25. Your commitment to your subordinates

26. The quality of senior civilian leadership (e.g., SECNAV) of the military

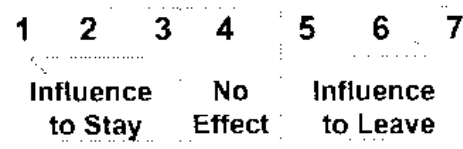




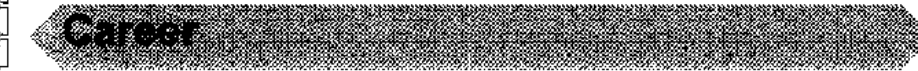

Using the scale below, please indicate whether the following factors have influenced your decision to stay, to leave, or had no effect on your Marine career intentions.

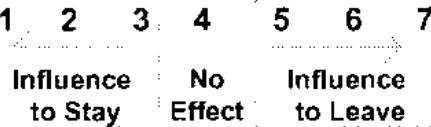

27. Your job security

28. Your opportunity for promotion

29. Your opportunity for professional development

30. Quality of training you have received in your MOS

31. Quality of training you have received in general Mifitary Skills

32. The amount of time you are away from home

33. The control you have over your job assignments

34. Your assignment to leadership positions

35. Your choice of duty stations

36. Your skilts relative to the job's demands

37. Your training relative to the job's demands

38. Career guidance you get from superiors

39. Your opportunities for technical training

40. Your opportunities for off-duty education

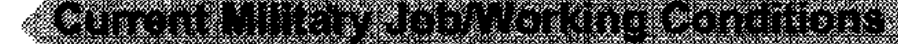

Using the scale below, please indicate whether the following factors have influenced your decision to stay, to leave, or had no effect on your Marine career intentions.

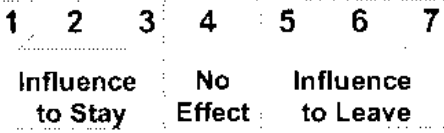

41. Your morale

42. The safety conditions in your unit

43. Your unit's morale

44. The discipline in your unit

45. The number of hours you work on your military job

46. Competence of your co-workers

47. Respect from your immediate superiors

48. Level of recognition for your accomplishments

49. Manning levels in your unit

50. Your unit's deployments

51. Technical competence of your inmediate supervisors

52. Your current job assignment

53. Availability of materiass required to do your job

54. Availability of equipment required to do your job

55. Availability of the tools to do your job

56. Authority necessary to do your job

57. Level of responsibility associated with your job

58. Sense of accomplishment from doing your job

59. Red tape associated with doing your job

60. Fair distribution of the workload across people in your unit

61. Your ability to transfer to another duty station/job 


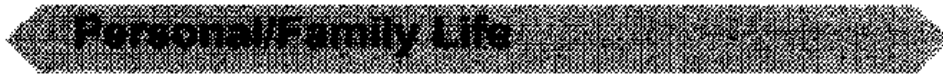

Using the scale below, please indicate whether the following factors have influenced your decision to stay, to leave, or had no effect on your Marine career intentions.

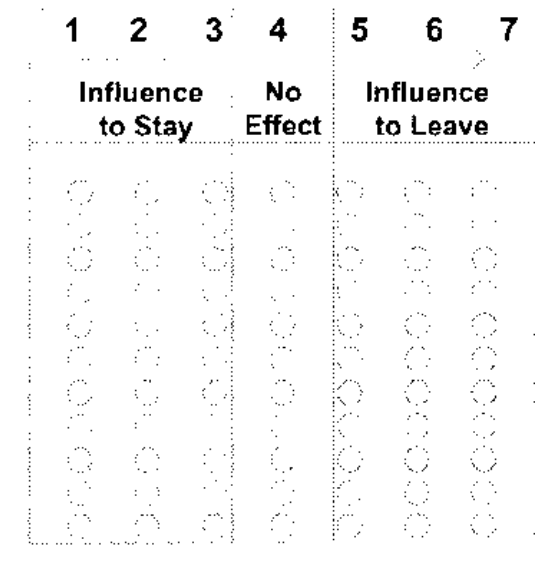

62. Balance between work and personal time

63. Your family's influence on your Marine Corps career

64. Availability of military quarters

65. Quality of military quarters

66. Location of off-base housing

67. Cost of off-base housing

68. Living conditions during deployment

69. Frequency of moves

70. The impact of moves on your family

71. Distance from your duty station to your home of record

72. Impact of your military service on youf spouse's career

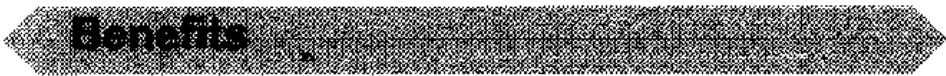

Using the scale below, please indicate whether the following factors have influenced your decision to stay, to leave, or had no effect on your Marine career intentions.

73. Your family's medical care

74. Your family's dental care

75. Availability of daycare

76. Availability of family support services

77. MWR programs available to you

78. Your current pay

79. Your future pay (pay raises from promotions, otc.)

80. Your current retirement benefits

81. Quality of your medical care

82. Availability of your medical benefits (appointments, specialists, waiting lists, etc.)

83. Your dental benefits

84. Your medical benefits

85. Quality of education benefits

86. Availability of your education benefits

87. Your special pay

88. Your opportunity for special pay in the future

89. The current system of boruses

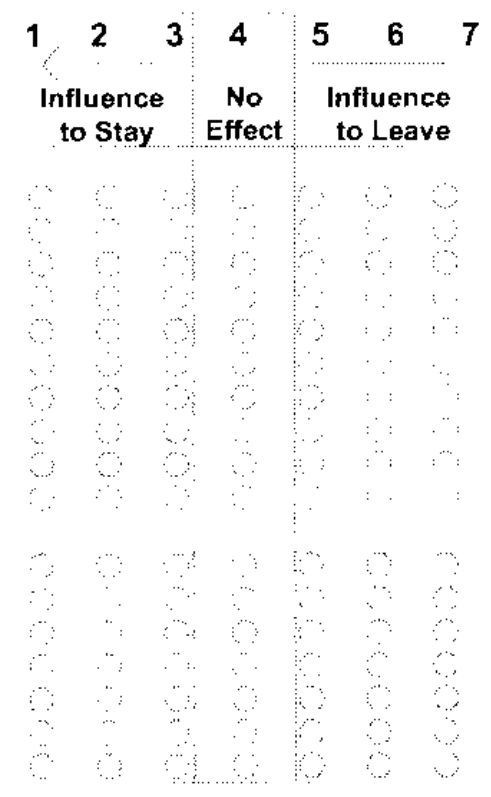




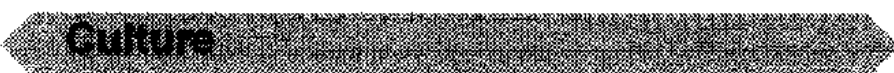

Using the scale below, please indicate whether the following factors have influenced your decision to stay, to leave, or had no effect on your Marine career intentions.

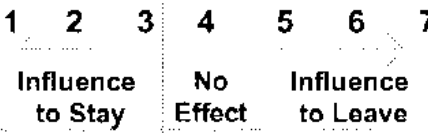

90. Administration of regulations

91. Administration of discipline

92. Fairness of physical fitness standards

93. Fairness of weight standards

94. Administration of moral standards

95. Interaction between races

96. Interaction between sexes

97. Interaction between officers and enlisted

98. Zero-defect philosoplyy

99. Careerism by SNCO's and officers

Please indicate the extent to which you AGREE or DISAGREE with the following items using the scale below. Please note that some of the items are positively worded and some are negatively worded.

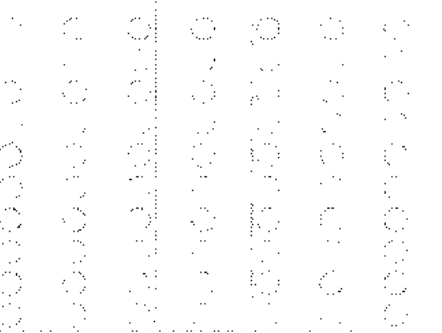

100. What the Marine Corps stands for is important to me.

101. My attachment to the Marine Corps is primarily based on the similarity of my values to Marine Corps values.

102. Overall, I'm proud that I joined the Marine Corps.

103. I would be very happy to spend the rest of my career in the Marine Corps.

104. I do not feel "part of the family" in the Marine Corps.

105. I do not feel emotionally attached to the Marine Corps.

106. I do not feel a strong sense of belonging to the Marine Corps.

107. Too much of my life would be disrupted if I decided I wanted to leave the Marine Corps now

108. It would be too costly for me to leave the Marine Corps right now.

109. I feel that I have too few options to consider leaving the Marine Corps now.

110. I believo that being a Marine is an obligation/duty to my country.

111. I want more education/training so that I can get out and get a better job.

112. I want more education/training because it makes me a better Marine/person.

113. More technical education/training would encourage me to seek civilian job opportunities.

114. More education opportunities would encourage me to re-enlist or remain in the service.

115. I intend to get out of the Marine Corps so that I can get better technical training/education. 
116. Please describe your career intentions. (Please choose ONE option only.)

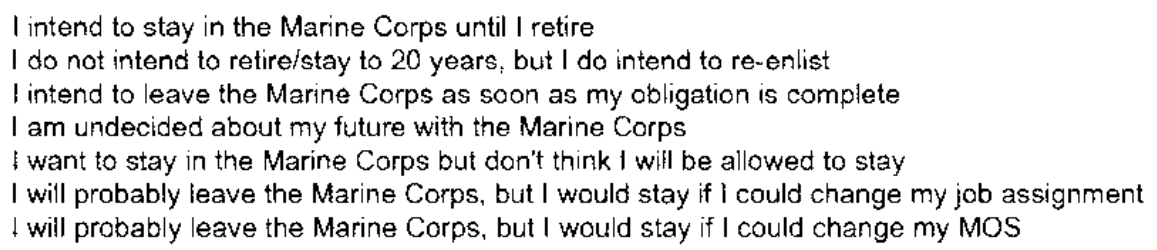

Please indicate how SATISFIED or DISSATISFIED you are with the following aspects of Marine Crops life using the scale below.

\footnotetext{
117. Leadership in the Marine Corps

118. Your Marine Corps career

119. Your primary MOS assignment

120. Your current duty station

121. Your working conditions in the Marine Corps

122. Your personal life while in the Marine Corps

123. Your family life while in the Marine Corps

124. Your current pay in the Marine Corps

125. Your retirement benefits in the Marine Corps

126. Your medical benefits while in the Marine Corps

127. Your educational benefits while in the Marine Corps

128. The culture of the Marine corps
}

Highly Dissatisfied
Dissatisfied
Neither Satisfied nor Dissatisfied
Satisfied
Hlghly Satisfied

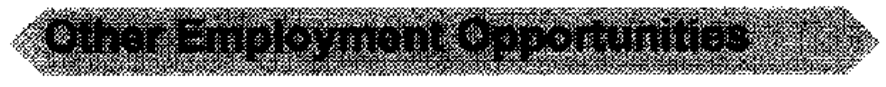

129. Do you believe that the Marine Corps is your best eurrent job choice?

130. Do you believe that it would be easy to find employment that compensates (pay and benefits) as well as the Marines?

131. Do vou believe that it would be easy for you to adjust to life as a civilian? 
132. What can be done to encourage you to remain in the Marine corps until retirement?

\title{
Thank you for your time and effort!
}

\author{
If you have any questions, please call: \\ Dr. Michael White \\ (901) 874-4659 or DSN 882-4659 \\ or email: michael.white@persnet.navy.mil
}

Please complete the survey as soon as possible, and return in the enclosed envelope to:

COMMANDING OFFICER

Survey Operations Center (SOC)

Navy Personnel Research, Studies,

and Technology (PERS-14)

5720 Integrity Drive

Millington, TN $38055-1400$ 


\section{APPENDIX B. PRELIMINARY VARIABLES IN DESCENDING ORDER; MALE AND FEMALE JUNIOR ENLISTED MARINES}

Appendix B, Tables B.1 and B.2 provide means and standard deviations for all preliminary continuous variables. All continuous variables are measured using a Likert scale. A value of 1 indicates that the variable is an "influence to leave", a value of 4 means the variable has "no effect" upon the decision to leave or stay, and a value of 7 indicates an "influence to stay" in the Marine Corps. Variables noted with an asterisk are measured using a Likert scale with values that range from 1 to 5 . A value of 1 means that a respondent "strongly disagrees", a value of 3 means the respondent "neither agrees or disagrees," and a value of 5 indicates that a respondent "strongly agrees." Variables noted with two asterisks are measured using a Likert scale with values that range from 1 to 5 . A value of 1 means that a respondent is "highly dissatisfied", a value of 3 indicates that the respondent is "neither satisfied or dissatisfied," and a value of 5 indicates that a respondent is "highly satisfied."

Table B.1.

Mean Distribution of Continuous Variables Junior Enlisted Males ( $\mathbf{N = 6 8 3 4})$

\begin{tabular}{|l|c|c|}
\hline \multicolumn{1}{|c|}{ Variable (Name) } & Mean & Std Deviation \\
\hline \multicolumn{1}{|c|}{ QOL PROGRAPHIC } & & \\
\hline AGE & 21.36 & 2.07 \\
\hline Influence to stay: MWR Programs (V77) & 4.28 & 1.17 \\
\hline Family Service Centers & & \\
\hline Influence to stay: Availability of Family Services (V76) & 4.21 & .97 \\
\hline Day Care Centers & & \\
\hline Influence to stay: Availability of Day Care (V75) & 3.99 & .95 \\
\hline Family Housing & & \\
\hline Influence to stay: Availability of Military Housing (V64) & 3.5 & 1.43 \\
\hline Influence to stay: Quality of Military Housing (V65) & 2.95 & 1.61 \\
\hline Medical Care & & \\
\hline Influence to stay: Family Medical Care (V73) & 4.39 & 1.37 \\
\hline
\end{tabular}




\begin{tabular}{|c|c|c|}
\hline Influence to stay: Family Dental Care (V74) & 4.31 & 1.34 \\
\hline $\begin{array}{l}\text { Satisfaction: Your Medical Benefits while in the Marine } \\
\text { Corps (V126)** }\end{array}$ & 3.45 & 1.11 \\
\hline \multicolumn{3}{|l|}{ Voluntary Education } \\
\hline Influence to stay: Quality of Educational Benefits (V85) & 4.24 & 1.7 \\
\hline Influence to stay: Availability of Education Benefits (V86) & 3.95 & 1.76 \\
\hline Influence to stay: Opportunity for Off-Duty Education (V40) & 3.67 & 1.95 \\
\hline $\begin{array}{l}\text { Agree: I want more education/training so that I can get out } \\
\text { and get a better job (V111)* }\end{array}$ & 4.11 & 1.04 \\
\hline $\begin{array}{l}\text { Agree: I want more education/training because it makes me a } \\
\text { better Marine/person (V112)* }\end{array}$ & 4.10 & 1.02 \\
\hline $\begin{array}{l}\text { Agree: More technical education/training would encourage } \\
\text { me to seek civilian job opportunities (V113)* }\end{array}$ & 3.70 & 1.14 \\
\hline $\begin{array}{l}\text { Agree: More education opportunities would encourage me to } \\
\text { re-enlist or remain in the service (V114)* }\end{array}$ & 3.11 & 1.40 \\
\hline $\begin{array}{l}\text { Agree: I intend to get out of the Marine Corps so that I can } \\
\text { get better technical training/education (V115) }\end{array}$ & 3.71 & 1.20 \\
\hline Satisfaction: Education Benefits (V127)** & 3.09 & 1.21 \\
\hline \multicolumn{3}{|l|}{ QOL DOMAIN } \\
\hline \multicolumn{3}{|l|}{ Military Career } \\
\hline Influence to stay: Job Security (V27) & 4.8 & 1.48 \\
\hline Influence to stay: Promotion Opportunity (V28) & 3.93 & 1.74 \\
\hline $\begin{array}{l}\text { Influence to stay: Professional Development Opportunity } \\
\text { (V29) }\end{array}$ & 4.14 & 1.65 \\
\hline Influence to stay: Control over Job Assignments (V33) & 3.22 & 1.58 \\
\hline Influence to stay: Assignment to Leadership Positions (V34) & 4.18 & 1.48 \\
\hline Influence to stay: Choice of Duty Stations (V35) & 3.51 & 1.85 \\
\hline Satisfaction: Your Marine Corps Career (V118)** & 3.17 & 1.14 \\
\hline Satisfaction: Your primary MOS (V119)** & 3.32 & 1.27 \\
\hline Satisfaction: Your Current Duty Station (V120)** & 3.13 & 1.34 \\
\hline \multicolumn{3}{|l|}{ Work Conditions/Leadership } \\
\hline Influence to stay: Senior Officer Leadership (V18) & 4.05 & 1.44 \\
\hline Influence to stay: Junior Officer Leadership (V19) & 3.95 & 1.37 \\
\hline Influence to stay: Warrant Officer Leadership (V20) & 4.25 & 1.23 \\
\hline Influence to stay: SNCO Leadership (V21) & 4.02 & 1.73 \\
\hline
\end{tabular}




\begin{tabular}{|l|c|c|}
\hline Influence to stay: NCO Leadership (V22) & 3.70 & 1.66 \\
\hline Influence to stay: Immediate Supervisor Leadership (V23) & 4.19 & 1.68 \\
\hline Influence to stay: Trust in Marine Leadership (V24) & 3.72 & 1.62 \\
\hline Influence to stay: Commitment to Subordinates (V25) & 4.71 & 1.35 \\
\hline Influence to stay: Senior Civilian Leadership (V26) & 3.90 & .96 \\
\hline Influence to stay: Morale (V41) & 3.67 & 1.95 \\
\hline Influence to stay: Career Guidance from Superiors (V38) & 3.78 & 1.52 \\
\hline Influence to stay: Time Away from Home (V32) & 2.70 & 1.47 \\
\hline Influence to stay: Safety in your Unit (V42) & 4.16 & 1.2 \\
\hline Influence to stay: Unit Morale (V43) & 3.15 & 1.57 \\
\hline Influence to stay: Discipline in Unit (V44) & 3.45 & 1.46 \\
\hline Influence to stay: Military Job Hours Worked (V45) & 3.14 & 1.60 \\
\hline Influence to stay: Competence of Co-Workers (V46) & 3.51 & 1.47 \\
\hline Influence to stay: Respect from Superiors (V47) & 3.76 & 1.71 \\
\hline Influence to stay: Recognition of Accomplishments (V48) & 3.21 & 1.67 \\
\hline Influence to stay: Manning levels in Unit (V49) & 3.58 & 1.18 \\
\hline Influence to stay: Unit Deployments (V50) & 3.61 & 1.53 \\
\hline Influence to stay: Current Job (V52) & 3.92 & 1.66 \\
\hline Influence to stay: Technical Competence of Supervisor (V51) & 3.99 & 1.41 \\
\hline Influence to stay: Material Availability (V53) & 3.48 & 1.48 \\
\hline Influence to stay: Equipment Availability (V54) & 3.51 & 1.47 \\
\hline Influence to stay: Tool Availability (V55) & 3.62 & 1.43 \\
\hline Influence to stay: Authority to do Job (V56) & 3.80 & 1.39 \\
\hline Influence to stay: Job Responsibility (V57) & 4.41 & 1.42 \\
\hline Influence to stay: Sense of Job Accomplishment (V58) & 4.26 & 1.73 \\
\hline Influence to stay: Red Tape at Job (V59) & 3.29 & 1.32 \\
\hline Influence to stay: Workload Distribution (V60) & 3.17 & 1.49 \\
\hline $\begin{array}{l}\text { Influence to stay: Ability to transfer to New Duty Station/Job } \\
\text { (V61) }\end{array}$ & 3.01 & 1.71 \\
\hline Satisfaction: Leadership (V117)** & 2.91 & 1.12 \\
\hline Satisfaction: Working Conditions (V121)** & \\
\hline
\end{tabular}




\begin{tabular}{|c|c|c|}
\hline Personal/Family Life & & \\
\hline Influence to stay: Work/Personal Time Balance (V62) & 3.02 & 1.59 \\
\hline Influence to stay: Family Influence on Career (V63) & 3.70 & 1.59 \\
\hline $\begin{array}{l}\text { Influence to stay: Living Conditions During Deployment } \\
\text { (V68) }\end{array}$ & 3.43 & 1.22 \\
\hline Influence to stay: Frequency of Moves (V69) & 3.43 & 1.16 \\
\hline Influence to stay: Impact of Moves on Family (V70) & 3.39 & 1.13 \\
\hline $\begin{array}{l}\text { Influence to stay: Distance from Duty Station to Home of } \\
\text { Record (V71) }\end{array}$ & 2.88 & 1.55 \\
\hline $\begin{array}{l}\text { Influence to stay: Impact of Military Service on Spouses } \\
\text { Career (V72) }\end{array}$ & 3.51 & 1.10 \\
\hline Influence to stay: Location of Off-Base Housing (V66) & 3.76 & 1.10 \\
\hline Influence to stay: Cost of Off-Base Housing (V67) & 3.46 & 1.21 \\
\hline Satisfaction: Personal Life in the Marine Corps (V122)** & 2.57 & 1.21 \\
\hline Satisfaction:Family Life While in the Marine Corps (V123)** & 2.49 & 1.08 \\
\hline USMC Culture & & \\
\hline Influence to stay: Administration of Regulations (V90) & 3.39 & 1.34 \\
\hline Influence to stay: Administration of Discipline (V91) & 3.44 & 1.40 \\
\hline Influence to stay: Fairness of PT Standards (V92) & 4.05 & 1.54 \\
\hline Influence to stay: Fairness of Weight Standards (V93) & 3.99 & 1.48 \\
\hline Influence to stay: Administration of Moral Standards (V94) & 3.67 & 1.44 \\
\hline Influence to stay: Interaction between the Races (V95) & 4.27 & 1.29 \\
\hline Influence to stay: Interaction between the Sexes (V96) & 3.72 & 1.38 \\
\hline $\begin{array}{l}\text { Influence to stay: Interaction between Officers and Enlisted } \\
\text { (V97) }\end{array}$ & 3.62 & 1.37 \\
\hline Influence to stay: Zero Defect Mentality (V98) & 3.70 & 1.22 \\
\hline Influence to stay: Careerism by SNCO/Officers (V99) & 3.67 & 1.34 \\
\hline Satisfaction: Culture of the Marine Corps (V128)** & 3.17 & 1.10 \\
\hline Sense of Community & & \\
\hline $\begin{array}{l}\text { Agree: What Marine Corps Stands for is important to me } \\
\text { (V100)* }\end{array}$ & 4.06 & 1.04 \\
\hline $\begin{array}{l}\text { Agree: Attachment to Marine Corps is based on similar value } \\
\text { system (V101)* }\end{array}$ & 3.45 & 1.17 \\
\hline Agree: Proud that I joined the Marine Corps (V102)* & 4.05 & 1.12 \\
\hline
\end{tabular}




\begin{tabular}{|l|c|c|}
\hline $\begin{array}{l}\text { Agree: Be happy to spend the rest of career in Marine Corps } \\
\text { (V103)* }\end{array}$ & 2.24 & 1.32 \\
\hline Agree: Do not feel part of Marine Corps Family (V104)* & 2.78 & 1.25 \\
\hline Agree: Do not feel attached to the Marine Corps (V105)* & 2.99 & 1.34 \\
\hline $\begin{array}{l}\text { Agree: Do not feel strong sense of belonging to Marine Corps } \\
\text { (V106)* }\end{array}$ & 2.74 & 1.27 \\
\hline
\end{tabular}

Source: Author, Computed from FY 2001 USMC Retention Survey

Table B.2

Mean Distribution of Continuous Variables Junior Enlisted Females ( $\mathbf{N}=\mathbf{7 3 6}$ )

\begin{tabular}{|l|c|c|}
\hline \multicolumn{1}{|c|}{ Variable (Name) } & Mean & Std Deviation \\
\hline DEMOGRAPHIC & & \\
\hline QGE & 21.32 & 2.21 \\
\hline Influence to stay: MWR Programs (V77) & & \\
\hline Family Service Centers & 4.38 & 1.06 \\
\hline Influence to stay: Availability of Family Services (V76) & 4.30 & 1.04 \\
\hline Day Care Centers & & \\
\hline Influence to stay: Availability of Day Care (V75) & 3.85 & 1.25 \\
\hline Family Housing & & \\
\hline Influence to stay: Availability of Military Housing (V64) & 3.43 & 1.40 \\
\hline Influence to stay: Quality of Military Housing (V65) & 2.85 & 1.50 \\
\hline Medical Care & & \\
\hline Influence to stay: Family Medical Care (V73) & 4.56 & 1.52 \\
\hline Influence to stay: Family Dental Care (V74) & 4.58 & 1.43 \\
\hline $\begin{array}{l}\text { Satisfaction: Medical Benefits while in the Marine Corps } \\
\text { (V126** }\end{array}$ & 3.49 & 1.19 \\
\hline Voluntary Education & & \\
\hline Influence to stay: Quality of Educational Benefits (V85) & 4.81 & 1.62 \\
\hline Influence to stay: Availability of Education Benefits (V86) & 4.56 & 1.70 \\
\hline Influence to stay: Opportunity for Off-Duty Education (V40) & 4.33 & 1.96 \\
\hline
\end{tabular}




\begin{tabular}{|c|c|c|}
\hline $\begin{array}{l}\text { Agree: I want more education/training so that I can get out } \\
\text { and get a better job (V111)* }\end{array}$ & 4.05 & 1.07 \\
\hline $\begin{array}{l}\text { Agree: I want more education/training because it makes me a } \\
\text { better Marine/person (V112)* }\end{array}$ & 4.04 & 1.01 \\
\hline $\begin{array}{l}\text { Agree: More technical education/training would encourage } \\
\text { me to seek civilian job opportunities (V113)* }\end{array}$ & 3.71 & 1.10 \\
\hline $\begin{array}{l}\text { Agree: More education opportunities would encourage me to } \\
\text { re-enlist or remain in the service (V114)* }\end{array}$ & 3.05 & 1.41 \\
\hline $\begin{array}{l}\text { Agree: I intend to get out of the Marine Corps so that I can } \\
\text { get better technical training/education (V115)* }\end{array}$ & 3.58 & 1.25 \\
\hline Satisfaction: Education Benefits (V127)** & 3.50 & 1.12 \\
\hline \multicolumn{3}{|l|}{ QOL DOMAIN } \\
\hline \multicolumn{3}{|l|}{ Military Career } \\
\hline Influence to stay: Job Security (V27) & 4.81 & 1.54 \\
\hline Influence to stay: Promotion Opportunity (V28) & 3.83 & 1.78 \\
\hline $\begin{array}{l}\text { Influence to stay: Professional Development Opportunity } \\
\text { (V29) }\end{array}$ & 4.10 & 1.64 \\
\hline Influence to stay: Control over Job Assignments (V33) & 3.16 & 1.60 \\
\hline Influence to stay: Assignment to Leadership Positions (V34) & 3.97 & 1.53 \\
\hline Influence to stay: Choice of Duty Stations (V35) & 3.57 & 1.81 \\
\hline Satisfaction: Your Marine Corps Career (V118)** & 3.05 & 1.15 \\
\hline Satisfaction: Your primary MOS Assignment (V119)** & 3.08 & 1.31 \\
\hline Satisfaction: Current Duty Station (V120)** & 3.26 & 1.33 \\
\hline \multicolumn{3}{|l|}{ Work Conditions/Leadership } \\
\hline Influence to stay: Senior Officer Leadership (V18) & 4.04 & 1.46 \\
\hline Influence to stay: Junior Officer Leadership (V19) & 3.86 & 1.36 \\
\hline Influence to stay: Warrant Officer Leadership (V20) & 4.29 & 1.29 \\
\hline Influence to stay: SNCO Leadership (V21) & 3.76 & 1.78 \\
\hline Influence to stay: NCO Leadership (V22) & 3.44 & 1.63 \\
\hline Influence to stay: Immediate Supervisor Leadership (V23) & 4.08 & 1.74 \\
\hline Influence to stay: Trust in Marine Leadership (V24) & 3.34 & 1.65 \\
\hline Influence to stay: Commitment to Subordinates (V25) & 4.56 & 1.36 \\
\hline Influence to stay: Senior Civilian Leadership (V26) & 3.96 & .88 \\
\hline Influence to stay: Morale (V41) & 3.48 & 1.81 \\
\hline
\end{tabular}




\begin{tabular}{|l|l|l|}
\hline Influence to stay: Career Guidance from Superiors (V38) & 3.71 & 1.57 \\
\hline Influence to stay: Time Away from Home (V32) & 2.87 & 1.45 \\
\hline Influence to stay: Safety in your Unit (V42) & 4.14 & 1.14 \\
\hline Influence to stay: Unit Morale (V43) & 3.05 & 1.56 \\
\hline Influence to stay: Discipline in Unit (V44) & 3.22 & 1.45 \\
\hline Influence to stay: Military Job Hours Worked (V45) & 3.37 & 1.59 \\
\hline Influence to stay: Competence of Co-Workers (V46) & 3.42 & 1.51 \\
\hline Influence to stay: Respect from Superiors (V47) & 3.62 & 1.74 \\
\hline Influence to stay: Recognition of Accomplishments (V48) & 3.15 & 1.76 \\
\hline Influence to stay: Manning levels in Unit (V49) & 3.62 & 1.19 \\
\hline Influence to stay: Unit Deployments (V50) & 3.69 & 1.34 \\
\hline Influence to stay: Current Job (V52) & 3.76 & 1.69 \\
\hline Influence to stay: Technical Competence of Supervisor (V51) & 3.90 & 1.38 \\
\hline Influence to stay: Material Availability (V53) & 3.83 & 1.32 \\
\hline Influence to stay: Equipment Availability (V54) & 3.83 & 1.29 \\
\hline Influence to stay: Tool Availability (V55) & 3.89 & 1.23 \\
\hline Influence to stay: Authority to do Job (V56) & 3.89 & 1.32 \\
\hline Influence to stay: Job Responsibility (V57) & 4.31 & 1.33 \\
\hline Influence to stay: Sense of Job Accomplishment (V58) & 4.16 & 1.77 \\
\hline Influence to stay: Red Tape at Job (V59) & 3.60 & 1.18 \\
\hline Influence to stay: Workload Distribution (V60) & 3.22 & 1.55 \\
\hline $\begin{array}{l}\text { Influence to stay: Ability to transfer to New Duty Station/Job } \\
\text { (V61) }\end{array}$ & 3.20 & 1.68 \\
\hline Satisfaction: Leadership (V117)** & 2.69 & 1.09 \\
\hline Satisfaction: Working Conditions (V121)** & 3.00 & 1.14 \\
\hline Personal/Family Life & 3.47 & 1.14 \\
\hline Influence to stay: Work/Personal Time Balance (V62) & 3.05 & 1.62 \\
\hline Influence to stay: Family Influence on Career (V63) & 3.65 & 1.60 \\
\hline $\begin{array}{l}\text { Influence to stay: Living Conditions During Deployment } \\
\text { (V68) }\end{array}$ & 3.61 & 1.04 \\
\hline Influence to stay: Frequency of Moves (V69) & & \\
\hline
\end{tabular}




\begin{tabular}{|c|c|c|}
\hline Influence to stay: Impact of Moves on Family (V70) & 3.42 & 1.14 \\
\hline $\begin{array}{l}\text { Influence to stay: Distance from Duty Station to Home of } \\
\text { Record (V71) }\end{array}$ & 3.05 & 1.55 \\
\hline $\begin{array}{l}\text { Influence to stay: Impact of Military Service on Spouses } \\
\text { Career (V72) }\end{array}$ & 3.56 & 1.15 \\
\hline Influence to stay: Location of Off-Base Housing (V66) & 3.76 & 1.23 \\
\hline Influence to stay: Cost of Off-Base Housing (V67) & 3.32 & 1.40 \\
\hline Satisfaction: Personal Life in the Marine Corps (V122)** & 2.80 & 1.26 \\
\hline Satisfaction: Family Life While in the Marine Corps(V123)** & 2.68 & 1.16 \\
\hline \multicolumn{3}{|l|}{ USMC Culture } \\
\hline Influence to stay: Administration of Regulations (V90) & 3.36 & 1.35 \\
\hline Influence to stay: Administration of Discipline (V91) & 3.40 & 1.41 \\
\hline Influence to stay: Fairness of PT Standards (V92) & 3.77 & 1.60 \\
\hline Influence to stay: Fairness of Weight Standards (V93) & 3.57 & 1.62 \\
\hline Influence to stay: Administration of Moral Standards (V94) & 3.62 & 1.49 \\
\hline Influence to stay: Interaction between the Races (V95) & 4.32 & 1.23 \\
\hline Influence to stay: Interaction between the Sexes (V96) & 3.62 & 1.23 \\
\hline $\begin{array}{l}\text { Influence to stay: Interaction between Officers and Enlisted } \\
\text { (V97) }\end{array}$ & 3.61 & 1.34 \\
\hline Influence to stay: Zero Defect Mentality (V98) & 3.77 & 1.09 \\
\hline Influence to stay: Careerism by SNCO/Officers (V99) & 3.73 & 1.18 \\
\hline Satisfaction: Culture of the Marine Corps (V128)** & 3.14 & 1.04 \\
\hline \multicolumn{3}{|l|}{ Sense of Community } \\
\hline $\begin{array}{l}\text { Agree: What Marine Corps Stands for is important to me } \\
\text { (V100)* }\end{array}$ & 3.88 & 1.09 \\
\hline $\begin{array}{l}\text { Agree: Attachment to Marine Corps is based on similar value } \\
\text { system (V101)* }\end{array}$ & 3.25 & 1.17 \\
\hline Agree: Proud that I joined the Marine Corps (V102)* & 3.92 & 1.17 \\
\hline $\begin{array}{l}\text { Agree: Be happy to spend the rest of career in Marine Corps } \\
\text { (V103)* }\end{array}$ & 2.15 & 1.33 \\
\hline Agree: Do not feel part of Marine Corps Family (V104)* & 2.97 & 1.30 \\
\hline Agree: Do not feel attached to the Marine Corps (V105)* & 3.05 & 1.37 \\
\hline $\begin{array}{l}\text { Agree: Do not feel strong sense of belonging to Marine Corps } \\
\text { (V106)* }\end{array}$ & 2.96 & 1.34 \\
\hline
\end{tabular}

Source: Author, Computed from FY 2001 USMC Retention Survey 


\section{APPENDIX C: BASIC RETENTION MODEL WITH INTERACTIONS}

Table C.1

Basic Retention Model with NO_BELBLACK

( $N=4226$, Male Junior Enlisted Marines)

\begin{tabular}{|l|c|c|c|}
\hline \multicolumn{1}{|c|}{ Variable } & Beta & Standard Error & Pr>Chi Sq \\
\hline NO_BELBLACK & -.0836 & .3904 & .8305 \\
\hline Paygrade (V8) & $.2670^{* * *}$ & .0969 & .0059 \\
\hline QOL_PRGM & $.5386^{* * *}$ & .1058 & $<.0001$ \\
\hline Black & $.5553^{* * *}$ & .1797 & .0020 \\
\hline Married & $.2661^{* *}$ & .1285 & .0383 \\
\hline Children & $.4644^{* * *}$ & .1518 & .0022 \\
\hline NO_BELONG & $-1.0765^{* * *}$ & .1693 & $<.0001$ \\
\hline CIVDIV & $-.6753^{* * *}$ & .1035 & $<.0001$ \\
\hline MILHOUSE & $.5179^{* * *}$ & .1151 & .0001 \\
\hline Leadership (V117) & .0863 & .0544 & .1127 \\
\hline USMC Career (V118) & $.3276^{* * *}$ & .0630 & .0001 \\
\hline Primary MOS (V119) & $.1220^{* * *}$ & .0471 & .0096 \\
\hline Current Duty Station (V120) & $-.1291^{* * *}$ & .0433 & .2111 \\
\hline Working Conditions (V121) & .0733 & .0586 & $<.0001$ \\
\hline Personal Life (V122) & $.2414^{* * *}$ & .0582 & .00398 \\
\hline Family Life (V123) & $.2834^{* * *}$ & .0613 & .1706 \\
\hline Medical Benefits (V126) & $.1199^{* *}$ & .0583 & $<.0001$ \\
\hline Education Benefits (V127) & .0686 & .0501 & .0603 \\
\hline USMC Culture (V128) & $.3184 * * *$ & & \\
\hline * Significant at ten percent level & & \\
** Significant at five percent level & & \\
*** Significant at one percent level & & \\
\hline
\end{tabular}

Table C.2

Basic Retention Model with MARRIED*SATISFACTION WITH EDUCATION ( $N=640$, Female Junior Enlisted Marines)

\begin{tabular}{|l|c|c|c|}
\hline \multicolumn{1}{|c|}{ Variable } & Beta & Standard Error & Pr>Chi Sq \\
\hline MARRIEDED & -.0805 & .3904 & .8305 \\
\hline Paygrade (V8) & .1471 & .1712 & .3902 \\
\hline QOL_PRGM & .2398 & .1876 & .2010 \\
\hline Black & $.5747 * *$ & .2474 & .0202 \\
\hline Married & .2160 & .6830 & .7518 \\
\hline Children & .2722 & .2278 & .2321 \\
\hline NO_BELONG & $-1.068^{* * *}$ & .2167 & $<.0001$ \\
\hline CIVDIV & $-.5011^{* * *}$ & .1762 & .0045 \\
\hline MILHOUSE & $.6934^{* * *}$ & .2250 & .0021 \\
\hline Leadership (V117) & -.1141 & .0941 & .2252 \\
\hline
\end{tabular}




\begin{tabular}{|l|c|c|c|}
\hline USMC Career (V118) & $.3754^{* * *}$ & .1108 & .0007 \\
\hline Primary MOS (V119) & .0497 & .0825 & .5472 \\
\hline Current Duty Station (V120) & $-.1562^{* *}$ & .0762 & .0404 \\
\hline Working Conditions (V121) & $.2916^{* * *}$ & .0979 & .0029 \\
\hline Personal Life (V122) & .0990 & .1005 & .3244 \\
\hline Family Life (V123) & -.0199 & .1048 & .8498 \\
\hline Medical Benefits (V126) & .0820 & .0904 & .3643 \\
\hline Education Benefits (V127) & -.0147 & .1119 & .8954 \\
\hline USMC Culture (V128) & $.3188^{* * *}$ & .1129 & .0047 \\
\hline
\end{tabular}

* Significant at ten percent level

** $\quad$ Significant at five percent level

*** Significant at one percent level

Table C.3

Basic Retention Model with MARRIED*QOL_PRGM

( $N=4226$, Male Junior Enlisted Marines)

\begin{tabular}{|l|c|c|c|}
\hline \multicolumn{1}{|c|}{ Variable } & Beta & Standard Error & Pr>Chi Sq \\
\hline MARRIED*QOL_PRGM & -.1874 & .2033 & .3565 \\
\hline Paygrade (V8) & $.2722^{* * *}$ & .0914 & .0029 \\
\hline QOL_PRGM & $.6049^{* * *}$ & .1175 & $<.0001$ \\
\hline Black & $.5642^{* * *}$ & .1659 & .0007 \\
\hline Married & $.5552^{* * *}$ & .1523 & .0003 \\
\hline NO_BELONG & $-.1 .1749^{* * *}$ & .1592 & $<.0001$ \\
\hline CIVDIV & $-.7044^{* * *}$ & .0973 & $<.0001$ \\
\hline MILHOUSE & $.5758^{* * *}$ & .1086 & $<.0001$ \\
\hline Leadership (V117) & .0580 & .0508 & .2533 \\
\hline USMC Career (V118) & $.3503^{* * *}$ & .0593 & $<.0001$ \\
\hline Primary MOS (V119) & $.1109^{* *}$ & .0442 & .0121 \\
\hline Current Duty Station (V120) & $-.1216^{* * *}$ & .0407 & .0028 \\
\hline Working Conditions (V121) & .0883 & .0547 & .1066 \\
\hline Personal Life (V122) & $.2314^{* * *}$ & .0549 & $<.0001$ \\
\hline Family Life (V123) & $.2201^{* * *}$ & .0575 & .0001 \\
\hline Medical Benefits (V126) & $.1351^{* *}$ & .0545 & .0132 \\
\hline Education Benefits (V127) & .0486 & .0479 & .3098 \\
\hline USMC Culture (V128) & $.3281^{* * *}$ & .0572 & $<.0001$ \\
\hline
\end{tabular}

* Significant at ten percent level

** $\quad$ Significant at five percent level

*** Significant at one percent level 
Table C.4

Basic Retention Model with MARRIED*QOL_PRGM

( $N=640$, Female Junior Enlisted Marines)

\begin{tabular}{|l|c|c|c|}
\hline \multicolumn{1}{|c|}{ Variable } & Beta & Standard Error & Pr>Chi Sq \\
\hline MARRIED*QOL_PRGM & .3565 & .3715 & .3373 \\
\hline Paygrade (V8) & .1624 & .1724 & .3463 \\
\hline QOL_PRGM & .1141 & .2296 & .6190 \\
\hline Black & $.5820^{* *}$ & .2477 & .0188 \\
\hline Married &. .2346 & .2561 & .3596 \\
\hline Children & .2766 & .2284 & .2260 \\
\hline NO_BELONG & $-1.0745^{* * *}$ & .2171 & $<.0001$ \\
\hline CIVDIV & $-.4825^{* * *}$ & .1772 & .0065 \\
\hline MILHOUSE & $.6958^{* * *}$ & .2251 & .0020 \\
\hline Leadership (V117) & -.1096 & .0939 & .2433 \\
\hline USMC Career (V118) & $.3810^{* * *}$ & .1111 & .0006 \\
\hline Primary MOS (V119) & .0386 & .0828 & .6412 \\
\hline Current Duty Station (V120) & $-.1546^{* * *}$ & .0763 & .0427 \\
\hline Working Conditions (V121) & $.2925^{* * *}$ & .0980 & .0028 \\
\hline Personal Life (V122) & .0940 & .1007 & .3507 \\
\hline Family Life (V123) & -.0171 & .1045 & .8697 \\
\hline Medical Benefits (V126) & .0869 & .0903 & .3357 \\
\hline Education Benefits (V127) &. .0387 & .0973 & .6910 \\
\hline USMC Culture (V128) & .3160 & .1127 & .2260 \\
\hline
\end{tabular}

* $\quad$ Significant at ten percent level

** $\quad$ Significant at five percent level

*** Significant at one percent level

Table C.5

Basic Retention Model with MARRIED*FAMSVC ( $N=$ 4226, Male Junior Enlisted Marines)

\begin{tabular}{|l|c|c|c|}
\hline \multicolumn{1}{|c|}{ Variable } & Beta & Standard Error & Pr>Chi Sq \\
\hline MARRIED*FSC & -.00794 & .2001 & .9683 \\
\hline Paygrade (V8) & $.2678^{* * *}$ & .0968 & .0057 \\
\hline QOL_PRGM & $.5395^{* * *}$ & .1150 & $<.0001$ \\
\hline Black & $.5376^{* * *}$ & .1598 & .0008 \\
\hline Married & $.2690^{*}$ & .1556 & .0837 \\
\hline Children & $.4649^{* * *}$ & .1519 & .0022 \\
\hline NO_BELONG & $-1.092^{* * *}$ & .1537 & $<.0001$ \\
\hline CIVDIV & $-.6755^{* * *}$ & .1036 & $<.0001$ \\
\hline MILHOUSE & $.5178^{* * *}$ & .1152 & $<.0001$ \\
\hline Leadership (V117) & .0861 & .0544 & .1136 \\
\hline USMC Career (V118) & $.3272^{* * *}$ & .0630 & $<.0001$ \\
\hline Primary MOS (V119) & $.1218^{* * *}$ & .0471 & .0097 \\
\hline
\end{tabular}




\begin{tabular}{|l|c|c|c|}
\hline Current Duty Station (V120) & $-.1291^{* * *}$ & .0433 & .0029 \\
\hline Working Conditions (V121) & .0737 & .0586 & .2087 \\
\hline Personal Life (V122) & $.2410^{* * *}$ & .0581 & $<.0001$ \\
\hline Family Life (V123) & $.2836^{* * *}$ & .0613 & $<.0001$ \\
\hline Medical Benefits (V126) & $.1195^{* *}$ & .0583 & .0404 \\
\hline Education Benefits (V127) & .0693 & .0500 & .1655 \\
\hline USMC Culture (V128) & $.3185^{* * *}$ & .0603 & $<.0001$ \\
\hline
\end{tabular}

* $\quad$ Significant at ten percent level

** $\quad$ Significant at five percent level

*** Significant at one percent level

Table C.6

Basic Retention Model with MARRIED*FAMSVC

( $N=640$, Female Junior Enlisted Marines)

\begin{tabular}{|l|c|c|c|}
\hline \multicolumn{1}{|c|}{ Variable } & Beta & Standard Error & Pr>Chi Sq \\
\hline MARRIED*FAMSVC & .2819 & .3546 & .4266 \\
\hline Paygrade (V8) & .1526 & .1715 & .3737 \\
\hline QOL_PRGM & .1671 & .2091 & .4243 \\
\hline Black & $.5702^{* *}$ & .2477 & .0213 \\
\hline Married & -.1710 & .2277 & .4528 \\
\hline Children & .2788 & .2284 & .2222 \\
\hline NO_BELONG & $-1.0636^{* * *}$ & .2167 & $<.0001$ \\
\hline CIVDIV & $-.4824 * * *$ & .1775 & .0066 \\
\hline MILHOUSE & $.6960^{* * *}$ & .2250 & .0020 \\
\hline Leadership (V117) & -.1106 & .0939 & .2392 \\
\hline USMC Career (V118) & $.3770^{* * *}$ & .1109 & .0007 \\
\hline Primary MOS (V119) & .0428 & .0825 & .6039 \\
\hline Current Duty Station (V120) & $-.1550^{* *}$ & .0762 & .0420 \\
\hline Working Conditions (V121) & $.2891^{* * *}$ & .0980 & .0032 \\
\hline Personal Life (V122) & .0965 & .1006 & .3372 \\
\hline Family Life (V123) & -.0179 & .1045 & .8642 \\
\hline Medical Benefits (V126) & .0885 & .0904 & .3279 \\
\hline Education Benefits (V127) & -.0385 & .0972 & .6924 \\
\hline USMC Culture (V128) & $.3117^{* * *}$ & .1126 & .0056 \\
\hline
\end{tabular}

* $\quad$ Significant at ten percent level

** Significant at five percent level

*** Significant at one percent level 
Table C.7

Basic Retention Model with MARRIED*MWR ( $N=4226$, Male Junior Enlisted Marines)

\begin{tabular}{|l|c|c|c|}
\hline \multicolumn{1}{|c|}{ Variable } & Beta & Standard Error & Pr>Chi Sq \\
\hline MARRIED*MWR & -.1153 & .1988 & .5618 \\
\hline Paygrade (V8) & $.2689^{* * *}$ & .0968 & .0055 \\
\hline QOL_PRGM & $.5639^{* * *}$ & .1148 & $<.0001$ \\
\hline Black & $.5372^{* * *}$ & .1598 & .0008 \\
\hline Married & $.3167 * *$ & .1553 & .0414 \\
\hline Children & $.4639^{* * *}$ & .1516 & .0022 \\
\hline NO_BELONG & $-1.0930^{* * *}$ & .1537 & $<.0001$ \\
\hline CIVDIV & $-.6760^{* * *}$ & .1035 & $<.0001$ \\
\hline MILHOUSE & $.5197 * * *$ & .1152 & $<.0001$ \\
\hline Leadership (V117) & .0862 & .0544 & .1130 \\
\hline USMC Career (V118) & $.3266^{* * *}$ & .0630 & $<.0001$ \\
\hline Primary MOS (V119) & $.1221 * * *$ & .0471 & .0095 \\
\hline Current Duty Station (V120) & $-.1293 * * *$ & .0433 & .0028 \\
\hline Working Conditions (V121) & .0746 & .0586 & .2031 \\
\hline Personal Life (V122) & $.2402^{* * *}$ & .0582 & $<.0001$ \\
\hline Family Life (V123) & $.2843^{* * *}$ & .0613 & $<.0001$ \\
\hline Medical Benefits (V126) & $.1197 * *$ & .0583 & .0399 \\
\hline Education Benefits (V127) & .0703 & .0500 & .1601 \\
\hline USMC Culture (V128) & $.3182^{* * *}$ & .1516 & $<.0001$ \\
\hline
\end{tabular}

* Significant at ten percent level

** $\quad$ Significant at five percent level

*** Significant at one percent level

Table C.8

Basic Retention Model with MARRIED*MWR ( $N=640$, Female Junior Enlisted Marines)

\begin{tabular}{|l|c|c|c|}
\hline \multicolumn{1}{|c|}{ Variable } & Beta & Standard Error & Pr>Chi Sq \\
\hline MARRIED*MWR & -.0633 & .3548 & .8584 \\
\hline Paygrade (V8) & .1416 & .1716 & .4093 \\
\hline QOL_PRGM & .2544 & .2097 & .2252 \\
\hline Black & $.5724^{* *}$ & .2475 & .0207 \\
\hline Married & -.0569 & .2290 & .8039 \\
\hline Children & .2708 & .2281 & .2352 \\
\hline NO_BELONG & $-1.0629^{* * *}$ & .2168 & $<.0001$ \\
\hline CIVDIV & $-.5011^{* * *}$ & .1764 & .0045 \\
\hline MILHOUSE & $.6947^{* * *}$ & .2253 & .0020 \\
\hline Leadership (V117) & -.1124 & .0939 & .2314 \\
\hline USMC Career (V118) & $.3746^{* * *}$ & .1109 & .0007 \\
\hline Primary MOS (V119) & .0496 & .0827 & .5485 \\
\hline
\end{tabular}




\begin{tabular}{|l|c|c|c|}
\hline Current Duty Station (V120) & $-.1590^{* *}$ & .0763 & .0373 \\
\hline Working Conditions (V121) & $.2930^{* * *}$ & .0980 & .0028 \\
\hline Personal Life (V122) & .0993 & .1006 & .3233 \\
\hline Family Life (V123) & -.0240 & .1045 & .8183 \\
\hline Medical Benefits (V126) & .0848 & .0902 & .3470 \\
\hline Education Benefits (V127) & -.0377 & .0973 & .6980 \\
\hline USMC Culture (V128) & $.3165^{* * *}$ & .1126 & .0049 \\
\hline
\end{tabular}

* $\quad$ Significant at ten percent level

** $\quad$ Significant at five percent level

*** Significant at one percent level

Table C.9

Basic Retention Model with CHILDREN*DAYCARE ( $N=4226$, Male Junior Enlisted Marines)

\begin{tabular}{|l|c|c|c|}
\hline \multicolumn{1}{|c|}{ Variable } & Beta & Standard Error & Pr>Chi Sq \\
\hline CHILDREN*DAYCARE & .0297 & .2690 & .9120 \\
\hline Paygrade (V8) & $.2677^{* * *}$ & .0968 & .0057 \\
\hline QOL_PRGM & $.5358^{* * *}$ & .1071 & $<.0001$ \\
\hline Black & $.5372^{* * *}$ & .1599 & .0008 \\
\hline Married & $.2655^{* *}$ & .1284 & .0387 \\
\hline Children & $.4572^{* * *}$ & .1663 & .0060 \\
\hline NO_BELONG & $-1.0922^{* * *}$ & .1538 & $<.0001$ \\
\hline CIVDIV & $-.6755^{* * *}$ & .1035 & $<.0001$ \\
\hline MILHOUSE & $.5172^{* * *}$ & .1153 & $<.0001$ \\
\hline Leadership (V117) & .0859 & .0544 & .1143 \\
\hline USMC Career (V118) & $.3273^{* * *}$ & .0630 & $<.0001$ \\
\hline Primary MOS (V119) & $.1220 * * *$ & .0471 & .0096 \\
\hline Current Duty Station (V120) & $-.1293^{* * *}$ & .0433 & .0028 \\
\hline Working Conditions (V121) & .0738 & .0586 & .2077 \\
\hline Personal Life (V122) & $.2411^{* * *}$ & .0581 & $<.0001$ \\
\hline Family Life (V123) & $.2832^{* * *}$ & .0613 & $<.0001$ \\
\hline Medical Benefits (V126) & $.1192^{* *}$ & .0583 & .0409 \\
\hline Education Benefits (V127) & .0690 & .0501 & .1684 \\
\hline USMC Culture (V128) & $.3185 * * *$ & .0603 & $<.0001$ \\
\hline
\end{tabular}

* $\quad$ Significant at ten percent level

** $\quad$ Significant at five percent level

*** Significant at one percent level 
Table C.10

Basic Retention Model with CHILDREN*DAYCARE ( $N=640$, Female Junior Enlisted Marines)

\begin{tabular}{|l|c|c|c|}
\hline \multicolumn{1}{|c|}{ Variable } & Beta & Standard Error & Pr>Chi Sq \\
\hline CHILDREN*DAYCARE & .4826 & .4596 & .2937 \\
\hline Paygrade (V8) & .1312 & .1714 & .4440 \\
\hline QOL_PRGM & .1918 & .1930 & .3204 \\
\hline Black & $.5613^{* * *}$ & .2477 & .0235 \\
\hline Married & -.0567 & .1962 & .7724 \\
\hline Children & .1566 & .2567 & .5418 \\
\hline NO_BELONG & $-1.078^{* * *}$ & .2174 & $<.0001$ \\
\hline CIVDIV & $-.5114^{* * *}$ & .1766 & .0038 \\
\hline MILHOUSE & $.6853^{* * *}$ & .2253 & .0024 \\
\hline Leadership (V117) & -.1159 & .0942 & .2186 \\
\hline USMC Career (V118) & $.3767 * * *$ & .1108 & .0007 \\
\hline Primary MOS (V119) & .0523 & .0824 & .5256 \\
\hline Current Duty Station (V120) & $-.1577 * *$ & .0763 & .0387 \\
\hline Working Conditions (V121) & $.2925 * * *$ & .0979 & .0028 \\
\hline Personal Life (V122) & .0947 & .1006 & .3462 \\
\hline Family Life (V123) & -.0224 & .1044 & .8305 \\
\hline Medical Benefits (V126) & .0805 & .0903 & .3725 \\
\hline Education Benefits (V127) & -.0352 & .0973 & .7176 \\
\hline USMC Culture (V128) & .3195 & .1126 & .5418 \\
\hline
\end{tabular}

* $\quad$ Significant at ten percent level

** $\quad$ Significant at five percent level

*** Significant at one percent level

Table C.11

Basic Retention Model with INFANTRY

( $\mathrm{N}=4226$, Male Junior Enlisted Marines)

\begin{tabular}{|l|c|c|c|}
\hline \multicolumn{1}{|c|}{ Variable } & Beta & Standard Error & Pr>Chi Sq \\
\hline INFANTRY & -.0372 & .1332 & .7801 \\
\hline Paygrade (V8) & $.2752^{* * *}$ & .0912 & .0025 \\
\hline QOL_PRGM & $.5458^{* * *}$ & .0991 & $<.0001$ \\
\hline Black & $.5915^{* * *}$ & .1478 & $<.0001$ \\
\hline Married & $.4496^{* * *}$ & .1023 & $<.0001$ \\
\hline NO_BELONG & $-1.1349^{* * *}$ & .1427 & $<.0001$ \\
\hline CIVDIV & $-.6935^{* * *}$ & .0965 & $<.0001$ \\
\hline MILHOUSE & $.5810^{* * *}$ & .1081 & $<.0001$ \\
\hline Leadership (V117) & .0625 & .0506 & .2166 \\
\hline USMC Career (V118) & $.3570^{* * *}$ & .0593 & $<.0001$ \\
\hline Primary MOS (V119) & $.1135^{* * *}$ & .0439 & .0097 \\
\hline Current Duty Station (V120) & $-.1183^{* * *}$ & .0406 & .0035 \\
\hline
\end{tabular}




\begin{tabular}{|l|c|c|c|}
\hline Working Conditions (V121) & .0812 & .0547 & .1377 \\
\hline Personal Life (V122) & $.2308^{* * *}$ & .0546 & $<.0001$ \\
\hline Family Life (V123) & $.2244^{* * *}$ & .0572 & $<.0001$ \\
\hline Medical Benefits (V126) & $.1311^{* *}$ & .0544 & .0159 \\
\hline Education Benefits (V127) & .0477 & .0488 & .3285 \\
\hline USMC Culture (V128) & $.3293^{* * *}$ & .0572 & $<.0001$ \\
\hline
\end{tabular}

* $\quad$ Significant at ten percent level

** $\quad$ Significant at five percent level

*** Significant at one percent level 


\section{LIST OF REFERENCES}

Aizen I., Fishbein, M. (1980) Understanding Attitudes and Predicting Social Behavior, Prentice-Hall, Inc., quoted in Siggerud, Dan, Retention Intention Among U.S. Navy's Enlisted Personnel: An Analysis of Social, Environmental, and Economical Factors, NPS Master's Thesis, (1981).

America, J.F., (2000), FY 01 Marine Corps Exit and Retention Surveys, Marine Administrative Message (MARADMIN) 429/00, September 2000.

America, J.F., (2001), email to Major D.W. Edwards (24 October).

Baker, George and White, Michael (1998). Quality of Life in the United States Marine Corps, Navy Personnel Research and Development Center, Report, September 1998.

Baumgarten, P. (2002) 2002 Quality of Life Survey Support Requirements, MARADMIN 031/02 (10 January).

Babbie, Earl (2001) The Practice of Social Research, Wadsworth, 2001.

Bland, David L., (1990) An Analysis of the effects housing improvements have on the retention of Air Force personnel, Air Force Institute of Technology. Wright-Patterson Air Force Base, Ohio. quoted in Kerce, Elyce, Assessment of USMC Quality of Life (QOL) Program Contributions to Readiness, Performance, and Retention Volume 1: Design and Methodology, TN-98-6, Navy Personnel Research and Development Center (1998), 8

Bicknell, John W. (2001) email to Major Douglas Edwards (November 1).

Birnbaum, Mark, Jennifer Erzring, Brady Howell, Bernard Schulz, Trent Sutton. 2000. Sailing Towards 2020: A Generational Study, The Maxwell School of Citizenship and Public Affairs, Syracuse University, June 2000; quoted in Andrew Wilcox, "Recruiting the Next Generation: A Study of Attitudes, Values, and Beliefs, " 46, Master's Thesis, Naval Postgraduate School, 2001.

Bowen, Gary L., and Orthner, Dennis K. (1989). The Organization Family: Work and Family Linkages in the US Military, Prager, 1989.

Bruce, Deborah Mohr (1990). Evaluating Quality of Life Programs: Summary of a Literature Review, Navy Personnel Research and Development Center, Report TN-90-20, May 1990.

Buddin, Richard J., Gresenz, Carole Roan, Hosek, Susan D., Elliott, Marc N., HawesDawson, Jennifer, (1999). An Evaluation of Housing Options for Military Families, RAND, MR-1020-OSD (1999).

Campbell, A. (1981) The sense of well-being in America: Recent patterns and trends. New York: McGraw-Hill; quoted in Elyse Kerce, (1992), Quality of Life: Meaning, 
Measurement, and Models, Navy Personnel Research and Development Center, TN-9215, May 1992.

Cheng, S (1988). Subjective quality of life in the planning and evaluation of programs. Evaluation and Program Planning, 11, pp. 123-134; quoted in Elyse Kerce, Quality of Life: Meaning, Measurement, and Models, Navy Personnel Research and Development Center, TN-92-15, May 1992.

Converse, J.M., and Presser, S. (1986). Survey questions: Handcrafting the standardized questionnaire, Beverly Hills, CA, Sage Publications (1986); quoted in Jack Edwards, et al., (1997), How to Conduct Organizational Surveys, Sage Publications (1997).

Cronbach, L.J. (1951). Coefficient alpha and the internal structure of tests. Psychometrika, 16, 297-334.

Defense Finance and Accounting Service (2002) web site, available from www.dfas.mil (Basic Pay chart), accessed January 15, 2002.

Department of Defense (2001), Overview of Morale and Quality of Life Study, available from http://www.defenselink.mil/news/Jun2001/d20010621qolo.pdf, accessed October 10, 2001.

Diener, E., Larsen, R.J., Levine, S., \& Emmons, R.A. (1985). Intensity and frequency: The underlying dimensions of positive and negative affect. Journal of Personality and Social Psychology, 48, 1253-1265; quoted in Elyse Kerce, Quality of Life: Meaning, Measurement, and Models, Navy Personnel Research and Development Center, TN-9215, May 1992.

Edwards, Jack, Thomas, Marie, Rosenfeld, Paul, Booth-Kewley, Stephanie, (1997). How to Conduct Organizational Surveys, Sage Publications, 1997.

Ehrenberg, Ronald G, and Smith, Robert S., (2000), Modern Labor Economics, AddisonWesley, 2000.

Fuentes, Gidget (1999). Lee Retires After 31 Years, Marine Corps Times, (June 21).

Fuentes, Gidget (1999). Retired Marine's Chief Goal is Improving Quality of Life, Marine Corps Times, (March 8).

Garcia, J. (1998). Effectiveness of the Voluntary Education Program, Center for Naval Analyses.

Hall, Brinley M. (2001). First-Term Enlisted Male Marines' Satisfaction with Job Characteristics: Evidence from the 1999 USMC Web-Based Retention Survey, NPS Masters Thesis. (March 2001). 
Hatcher, Larry, (1994), A Step by Step Approach to Using the SAS System for Factor Analysis and Structural Equation Modeling, SAS Institute, 1994.

Henry, G.T. (1992). Using graphical displays to empower evaluation audiences. Quoted in Edwards, et al., (1997), How to Conduct Organizational Surveys, Sage, 1997.

Hempel, Kevin R., and Parshall, Ione I., (1989), Time Factors Affecting the Retention Decision of Navy Enlisted Members, NPS Masters Thesis, 1989.

Hobson, Dave (2001), Quality of Life Issues are a Top Priority, available from http://www.house.gov/hobson/milcon1, accessed July 25, 2001

Hosek, James and Totten, Mark (1998). Does Perstempo Hurt Reenlistment? The Effect of Long or Hostile Perstempo on Reenlistment, MR-990-OSD, RAND (1998).

Jones, James L. General, USMC (1999). Commandant's Guidance, All Marine (ALMAR) message 023/99 (July 02).

Jones, J.L. General (2000), testimony to House Armed Services Committee, March 15, 2000, available from www. usmc.mil, accessed September 15, 2001.

Jones, J.L. General (2000), testimony to House Armed Services Committee, September 27, 2000, available from www.usmc.mil, accessed September 15, 2001.

Jowers, Karen (2001). Military to help spouses find portable careers, Marine Corps Times (June 25).

Jowers (2002): Bush Budget boosts Corps' construction, housing repair, Marine Corps Times, (February 25).

Kerce, Elyce W. (1992). Quality of Life: Meaning, Measurement, and Models, Report No. TN92-15, Navy Personnel Research and Development Center.

Kerce, Elyce, W. (1998). Assessment of USMC Quality of Life (QOL) Program Contributions to Readiness, Performance, and Retention, Volume 1: Design and Methodology, Report No. TN98-6, Navy Personnel Research and Development Center.

Kerce, Elyce. W. (1999). Assessment of USMC Quality of Life (QOL) Program Contributions to Readiness, Performance, and Retention, Volume 2: Pilot Test Results Report No. TN-99-5, Navy Personnel Research and Development Center.

Kerr, Sean A. (1997). Retention of First-Term and Second-Term Marine Corps Enlisted Personnel, Naval Postgraduate School Thesis, March 1997.

Kocher, Kathryn and Thomas, George (2000). A Preliminary Analysis of the 1999 USMC Retention Survey, Naval Postgraduate School (May 2000). 
Kocher, Kathryn and Thomas, George (2001). Quadrant Analysis, Course Handout: Manpower Multivariate Analysis Course, Naval Postgraduate School, Spring 2001.

Kocher, Kathryn and Mar, Dennis (2001), Running PROC LOGISTIC for an ordered dependent variable, NPS Class Handout (MN 4111).

Koopman, Martha E. and Goldhaber, Dan D. (1997). Return on Quality of Life Investment, Center for Naval Analyses, CRM 96-147, March 1997.

Kruger, Richard A. (2000). Focus Groups: A Practical Guide for Applied Research, Sage Publications.

Lubold, Gordon (2001). Family Forum Raises Quality of Life Concerns Marine Corps Times (June 18).

Marine Corps Times, (2001). Fewer Married Marines: Downward Trend reflects National Statistics since 1994, Marine Corps Times, (January 21).

Marines Magazine, (2001). Almanac 2001, United States Marine Corps (March).

Maze, Rick (2001). More Housing Money May not help Retention, Marine Corps Times (June 18).

Maze, Rick (2002): Quality of Life: More to be done, spouses, senior enlisted advisors tell lawmakers, Marine Corps Times, (February 18).

Moore, Carol S. and Ann D. Parcell (2001). Navy Surveys on Quality of Life: An Informational Guide Center for Naval Analyses, January 2001.

Nunnally, J. (1978). Psychometric theory. New York: McGraw-Hill; quoted in Edwards, et al., (1997), How to Conduct Organizational Surveys, Jossey-Bass (1997).

White, Michael (2001), Marine Corps Retention Survey, Navy Personnel Research, Studies, and Technology Department (2001).

Rae, L.M, and Parker, R.A., (1992), Designing and conducting survey research: A Comprehensive Guide (Jossey-Bass); quoted in Edwards, et al., (1997), How to Conduct Organizational Surveys, Jossey-Bass (1997).

Rice, R.W. (1984). Work and the Quality of Life. Applied social psychology annual 5: Applications in organizational settings (pp.155-177). Beverly Hills: Sage, quoted in Elyse W. Kerce, (1992) Quality of Life: Meaning, Measurement, and Models, Navy Personnel Research and Development Center, TN-92-15, May 1992. 
Kocher, Kathryn (2000). Selected SAS Documentation for Multivariate Manpower Analysis, SAS Institute, 2000.

Segal, Mady Wechsler (1988). The Military and the Family as Greedy Institutions Edited by Charles C. Moskos and Frank Wood, The Military: More Than Just a Job? (Washington D.C.: Pergamon-Brassy's, 1988), pp. 79-97.

Shanker, Thom, (2001). Army Chief Proposes Changes to Improve Quality of Life, New York Times, (May 29).

Snowden, Alexander (2001), First Term Alignment Plan Progressing at Record Rate, available from http://www.usmc.mil/marinelink, accessed November 28, 2001.

Studenmund, A.H., (2001). Using Econometrics, Harper Collins, New York, NY, 2001.

Van Laar, Colette (1999). Increasing a Sense of Community in the Military RAND Report MR-1071-OSD, RAND Santa Monica, CA.

Wilcox, Andrew G. (2001). Recruiting the Next Generation: A Study of Attitudes, Values, and Beliefs, Naval Postgraduate School Thesis (March).

Wright, Laverne C. (2000). Tabulations of Responses from the 1999 Survey of Active Duty Personnel, DMDC Report No. 2000-006, Defense Manpower Data Center.

Wright, Laverne C (2000). Overview of the 1999 Survey of Active Duty Personnel DMDC Report No. 2000-008, Defense Manpower Data Center. 
THIS PAGE INTENTIONALLY LEFT BLANK 


\section{INITIAL DISTRIBUTION LIST}

1. Defense Technical Information Center

Fort Belvoir, Virginia

2. Dudley Knox Library

Naval Postgraduate School

Monterey, California

3. Marine Corps Representative

Naval Postgraduate School

Monterey, California

4. Director, Training and Education, MCCDC, Code C46

Quantico, Virginia

webmaster@tecom.usmc.mil

5. Director, Marine Corps Research Center, MCCDC, Code C40RC

Quantico, Virginia

6. Marine Corps Tactical Systems Support Activity (Attn: Operations Officer)

Camp Pendleton, California 